\title{
MT-HVdc Systems Fault Classification and Location Methods Based on Traveling and Non-Traveling Waves-A Comprehensive Review
}

\author{
Raheel Muzzammel ${ }^{1, *(\mathbb{D}}$, Ali Raza ${ }^{1}\left(\mathbb{D}\right.$, Mohammad Rashid Hussain ${ }^{2}{ }^{\oplus}$, Ghulam Abbas ${ }^{1}{ }^{\circledR}$, \\ Ishtiaq Ahmed ${ }^{1}$, Mohammed Qayyum ${ }^{2}$, Mohammad Ashiquee Rasool ${ }^{2}$ and \\ Mohammed Abdul Khaleel ${ }^{2}$ \\ 1 Department of Electrical Engineering, The University of Lahore, Lahore 54000, Pakistan; \\ ali.raza@ee.uol.edu.pk (A.R.); ghulam.abbas@ee.uol.edu.pk (G.A.); ishtiaq.ahmad@ee.uol.edu.pk (I.A.) \\ 2 College of Computer Science, King Khalid University, Abha 61421, Saudi Arabia; \\ humohammad@kku.edu.sa (M.R.H.); mgiwm@kku.edu.sa (M.Q.); masheq@kku.edu.sa (M.A.R.); \\ mkhlel@kku.edu.sa (M.A.K.) \\ * Correspondence: raheelmuzzammel@gmail.com or raheel.muzzammel@ee.uol.edu.pk
}

Received: 5 September 2019; Accepted: 31 October 2019; Published: 7 November 2019

\begin{abstract}
Estimation of fault classification and location in a multi-terminal high voltage direct current (MT-HVdc) transmission system is a challenging problem and is considered to be a fundamental maneuver of dc grid protection. This research paper critically reviews traveling and non-travelling wave methods of classification and location of dc faults in multi-terminal HVdc transmission systems. Detailed mathematical analysis of MT-HVdc systems composed of high grounding resistance, cable and overhead line segments, and bipolar coupled transmission network under healthy and faulty conditions, are evaluated. The gravity of this research paper addresses benefits and shortcomings of traveling and non-traveling wave methods and futuristic techniques of fault classification and location.
\end{abstract}

Keywords: DC faults; fault classification and location (FCL); MT-HVdc; non-traveling waves (NTW); traveling waves (TW); transmission system

\section{Introduction}

Recent trends/researches show that a multi-terminal high voltage direct current (MT-HVdc) system is an emerging and encouraging option to meet the growing demands of future transmission networks. MT-HVdc systems not only offer substantial benefits, but have developed some promising applications [1-3]. Integration of offshore wind farms and solar power plants to ac main lands is remarkable feature. This feature leads towards the proposal of European super grid and promising interconnection of North Sea wind farms to Scandinavian hydropower and Mediterranean solar plants [4-6]. Absence of capacitive current in MT-HVdc system makes it the best replacement of long cable ac transmission. In the forthcoming years, robustness and intelligently controlled infrastructures of MT-HVdc grids [7-10] will bring new challenges for power system engineers.

Voltage source converter (VSC) based HVdc is a practical/effective option for multi-terminal HVdc (M-HVdc) as compared to line commutated converter (LCC) based HVdc technology, as VSC offer small filter sizes, black start capability, reactive power support, and soft bidirectional dc power flow [11-15]. An MT-HVdc system is composed of a number of offshore and onshore VSCs. Therefore, operation, control, and protection of MT-HVdc systems are complex and challenging.

VSC based MT-HVdc systems offer benefits like redundancy, flexibility, and reliability for power transmission [2,3]. An appropriate protection scheme ensures the reliability of dc grid and apposite actions are activated in case of abnormalities for averting shutdown of dc grids [7]. However, 
the challenging task is the relatively low impedance of MT-HVdc grid in the event of dc faults. Hence, the dc fault currents build up enormously and rapidly. Thus, reliable and prompt relaying mechanism is required along with HVdc circuit breakers to mitigate the effects of sudden building up of large fault currents and to ensure the continuity of the supply [16]. However, the prototypes of existing dc circuit breakers (DCCB) have limited current interruption capability or are slow in operation [17-20]. A number of relaying algorithms are proposed for prompt response against dc faults [21-24]. These algorithms are based on either selective or non-selective fault clearance strategies.

In the selective fault clearance strategy, HVdc breakers operate exactly at the instant of fault, while HVdc breakers are installed at the ends of the transmission lines (TL) [18]. Non-selective fault clearance strategy is based on the joint action of multiple components, like converters with current limiting or interrupting components [25-29]. Typically, an MT-HVdc grid is divided into various zones of protection to enhance reliability, speed, selectivity, sensitivity, and security [30]. Primary protection (PP) responds to the fault immediately after occurrence. Backup protection (BP) waits unless the primary protection fault clearance time is completed. Backup protection operates after the failure of primary protection. PP may fail due to malfunctioning of DCCB or primary relay. Therefore, it is always necessary to provide BP to enhance security and reliability. A speedy response from backup protection is always expected in case of PP failure [31]. However, a time delay is added between PP and BP operations to avoid incoordination and selectivity issues [32].

Estimation of fault location (FL) is a core constituent of MT-HVdc grid protection. Without it, relaying strategies and circuit breaker technology cannot be developed and there would be a question mark over the reliability of MT-HVdc systems. Different traveling waves (TW) based fault location estimation methods are developed and are available in literature [4,23,33-39]. In this paper, different methods of fault classification and location (FCL) in MT-HVdc systems are critically and mathematically analyzed. Limitations of the traveling wave and non-traveling wave (NTW) based determinations of fault location are identified.

The rest of the paper is organized as follows: a brief explanation of HVdc grid protection is given in Section 2. Section 3 explains TW. Section 4 covers the application of TW for fault estimation in MT-HVdc links having high grounding resistance. Section 5 discusses FCL method for hybrid HVdc systems. Finding of fault location based on natural frequency of TW is provided in Section 6. Variation in voltage signals at pre and post-fault state is used for fault detection and explained in Section 7. Section 8 deals with FCL via symmetrical components of TW. Section 9 contains a morphological gradient based method. Shortcomings of TW based method is covered in Section 10. The dc fault location detection via non-traveling-based methods, i.e., mode extraction, rate of change of voltage and current, voltage level detection, under voltage and over current detection are discussed in Sections 11-15. Transient based fault estimation in MT-HVdc systems is covered in Section 16. Electromagnetic time reversal-based fault classification and location is discussed in Section 17. Short comings of non-traveling wave methods are described in Section 18. Sections 19 and 20 cover the comparison of TW and NTW methods and existing FCL techniques, respectively. Practical realization of TW based relays for FCL is added in Section 21. Section 22 elaborates on future possibilities for efficient FCL in MT-HVdc systems. Finally, conclusions are drawn in Section 23.

\section{High-Voltage Direct Current (HVdc) Grid Protection}

MT-HVdc grid protection is designed in terms of primary and backup protections. Protective devices, relays, and circuit breakers are installed at ends of transmission lines. When a fault occurs in a $\mathrm{dc}$ grid, fault waves travels towards the VSC stations. Timing diagram for MT-HVdc grid protection is proposed and is shown in Figure 1 [2]. Here, $t_{0}$ is the time at which the dc fault occurred. Primary protection relay starts sensing the fault. At time $t_{1}$, PP relay send a trip signal to the breaker associated and at time $t_{2}$, the breaker responds to the trip signal and its contacts are opened to interrupt dc fault current. 


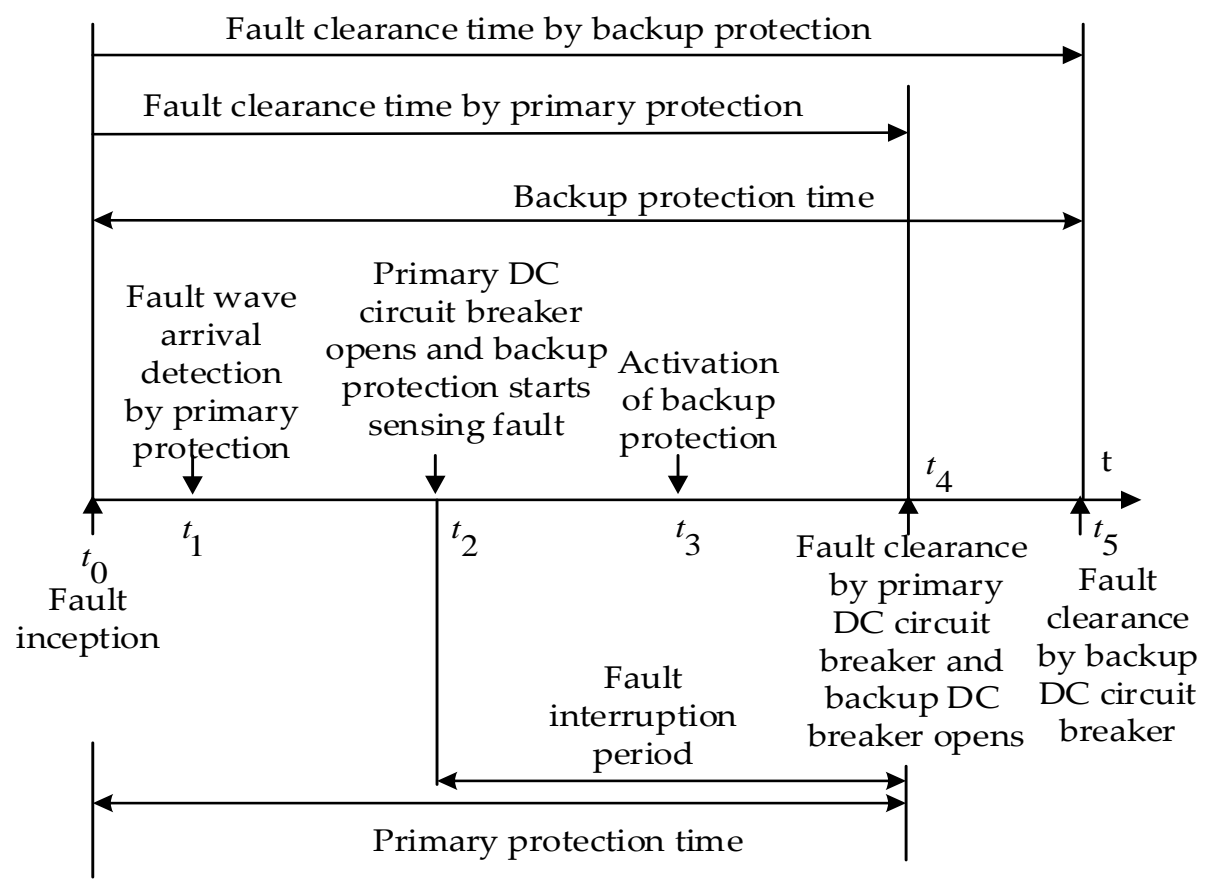

Figure 1. Timing diagram for a direct current (dc) grid protection.

Fault is sensed by backup relay at time $t_{2}$ and a trip signal from backup relay is generated at time $t_{3}$. If primary protection fails to interrupt the current in the interval between $t_{2}$ and $t_{4}$, backup breaker initiates its process of interruption at time $t_{4}$. Fault is completely interrupted by backup protection in the interval between $t_{2}$ and $t_{5}$.

\subsection{Malfunctioning of Direct Current (dc) Breaker}

The operation time of the existing dc breakers affects the protection time frame. Backup protection strategy in event of dc breaker malfunctioning is explained in Figure 2. During the malfunctioning of the dc breaker $B_{1}$, backup protection will trip all the adjacent breakers $\left(B_{2}, B_{3}\right.$ and $\left.B_{4}\right)$ as shown in Figure 2. Hence, the operation time of the backup dc breakers have to be added within the protection time frame.

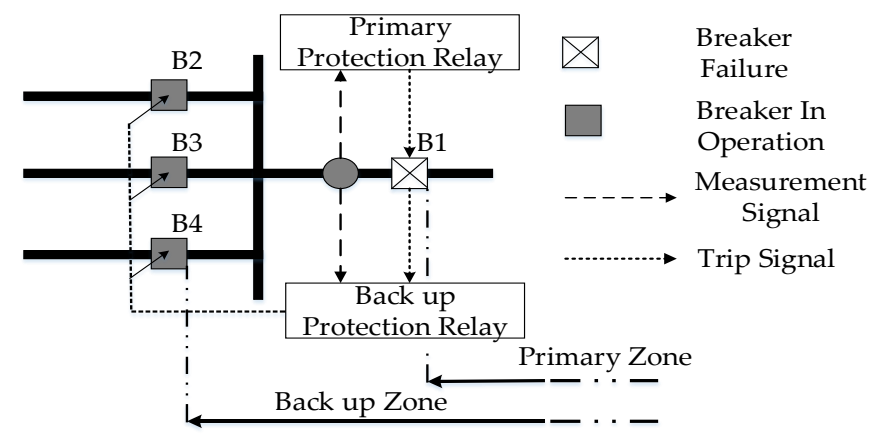

Figure 2. Backup protection strategy in event of direct current $(\mathrm{dc})$ breaker malfunctioning.

Moreover, operation of backup protection can also be explained with the help of voltage current (V-I) plane as shown in Figure 3 [2,3]. 


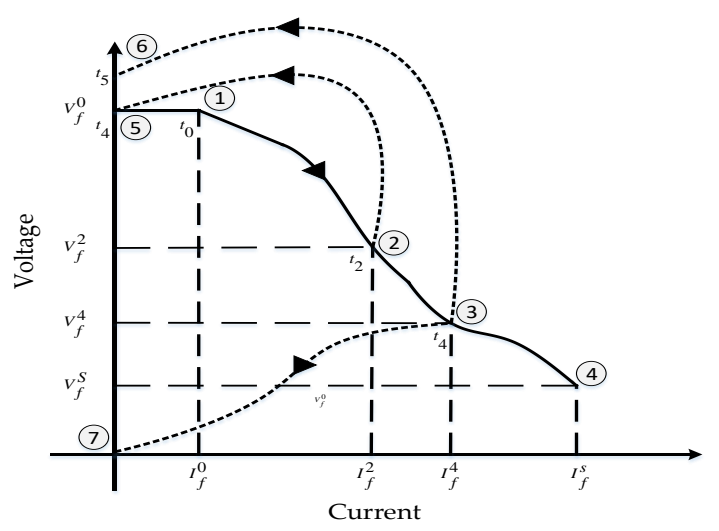

Figure 3. Variations of direct current (dc) voltage and currents in the event of malfunction of breaker.

Points 1 and 2 represent events of fault inception and tripping of dc breaker. Voltage and current variations between fault detection by primary protection (PP) and trip action by breaker $B_{1}$ is represented by a solid line from points 1 to 2 . Faulty line is successfully isolated because of opening of breaker $B_{1}$ under the tripping command of primary protection relay. Under this scenario, loci of voltages and currents are denoted via dashed line from point 2 to 5 . Voltage increases to $V_{f}^{0}$ and fault current decreases from $I_{f}^{2}$ to 0 after clearance of fault.

However, in the case of primary protection failure, loci of voltages and currents are represented by a solid line between points 2 and 4 . Both voltage and current attain steady state values of $U_{f}^{s}$ and $I_{f}^{s}$, respectively. If the backup protection relay clears the fault, current and voltage variations follow the path shown by a combination of solid and dashed lines between points 2 to 3 and then to 6 .

Further, in the event of dc breaker failure, fault is cleared by backup breakers as tripping command is sent to them from backup protection relay as shown in Figure 2. In this event, not only current is reduced to zero, but voltage is also reduced to zero. The loci of dc voltage and current follow the path represented by the line from points 2 to 3 and then 7 . This highlights the effect on protection time frame during malfunctioning of dc breaker $[2,3]$.

\subsection{Overhead Lines and Underground Cables}

Principles of protection for overhead lines (OHL) are similar to underground cables (UGC). However, the behavior of protection methods for overhead lines is different than the underground cables because of the following technical dissimilarities:

- OHL impedance is greater than UGC impedance [40].

- $\mathrm{X} / \mathrm{R}$ ratio of OHL is much higher than UGC [40].

- Series inductance of OHL is 30-50\% higher than UGC [40].

- Shunt capacitance of UGC is 30-40 times higher than OHL [40].

- Steady-state charging current is lower in OHL compared to UGC [40].

- Transient charging and discharging currents caused by the process of energization and de-energization of the grid when faults occur is lower in OHL than UGC [40].

- UGCs are more vulnerable to permanent faults than OHL [41].

- Voltage and current transients due to dc fault are different for the OHL and UGC because of impedance. OHL have large impedance as compared to UGC [42].

\subsection{Protection of Line Commutated Converter (LCC) and Voltage Source Converter (VSC) Based High-Voltage Direct Current (Systems)}

Protection methods for VSC based HVdc systems and LCC based HVdc systems are not the same. Protection methods are entirely different because of the fact that VSC-HVdc systems require rapid interruption and limitation of dc fault current, thereby reducing operating time of protection 
techniques as compared to LCC-based HVdc systems. Moreover, provisions of bidirectional power flow without reversal of polarity and extension to multi-terminal girds in VSC-HVdc systems change the configuration for dc grid protection [43-45].

It is unacceptable for an electric equipment to allow flow of large short circuit currents. High rate of change of current results in failure of IGBTs because of localized heating losses. Therefore, in real life applications, if the technique of fault detection is not quick enough to block the converter switches, these converter switches would be blocked immediately as the dc fault current or rate of change of current surpassing the threshold values of the self-protection of the IGBTs, results in transients. Therefore, technique of fault detection must be fast enough to issue a block command to converter switches before self-protection of IGBTs [46-48].

\section{Traveling Waves (TW)}

In the event of dc fault on transmission line, transients of high frequency voltage and current waves are generated which tend to circulate between TL ends and fault point. These transients are known as traveling waves. Crossley and McLaren presented the phenomenon of traveling waves in 1950 for fault location estimation [49,50]. Practically, TWs based techniques has replaced traditional reactance and impedance-based methods for fault location estimation because of its accuracy and high efficiency. However, TW based methods could not be applied on large scale due to shortcomings such as difficulty in detection of first TW wavefront (containing maximum information), measurement error in speed of propagated TW wavefront, inaccuracy in detection if dc faults appear near VSCs/terminals, or amplitude of dc fault TW is close to zero crossings.

Traveling waves are mainly caused by the events of switching, faults, and lightning. Traveling wave technique is not effective for ac transmission networks due to small amplitude of the TWs [51].

TWs generated by the fault in a dc transmission line are different from the TWs in ac transmission line due to the dispersion and the attenuation occurring in AC TLs. Attenuation at rising edge results in reduced amplitude, while dispersion at falling edge makes TW difficult to be detected [52]. Fault location estimation with respect to voltage phase angle is not acceptable because of small fault angle $[33,53,54]$. Traveling wave-based protection system was first introduced in 1978, based on discrimination between forward and reverse waves [55]. Pick-up sequences of discriminant functions are used to find the direction of fault [56]. Correlation is used to determine the similarity between traveling waves generated from healthy and faulty locations within dc grid, helps in fault discrimination and identification [57]. Digital signal processing approaches are used to design a protection based on direction of propagation of traveling waves [58]. Surges due to faults are distinguished from others by correlation function-based traveling wave protection algorithm [59].

Precise detection and identification of wavefront arrival time at relays is the key in the assessment of fault location. High frequency components of terminal voltages are extracted by band-pass filter or by evaluation of current through the surge capacitors $[34,60,61]$. These high frequency components are employed to detect the arrival time of TWs of transients and faults. Required accuracy of results for detection of arrival time of wavefront is obtained by a high signal sampling rate, achieved through methods of digital signal processing and this is limitation of traveling wave method. However, this issue can be addressed through the latest transducer technology $[53,62]$. Conventional time and frequency domain methods are not useful for detection of arrival time of wavefronts. However, wavelet transform is highly applicable for the analysis of wavefronts because of simultaneous localization capabilities of time and frequency, particularly for multi-terminal dc systems [63-65].

Discrete wavelet transform (DWT) is mostly applied to solve the research problems of dc line fault location Because of its speed, resolution, accuracy, and selectivity, [65,66]. However, it is noted that continuous wavelet transform (CWT) is more efficient in generating detailed and continuous analysis for transients. In CWT, wavelet which is required to be analyzed is shifted precisely over the input signal domain, whereas in DWT, wavelet which is required to be analyzed is shifted in the dyadic 
grid (grid consisting of tiles of different width and length depending on actual time and frequency resolution of each partial DWT spectra component in the time scale plane [66-68].

Different dc fault location estimation methods in MT-HVdc systems are discussed in the subsequent sections, for different configurations, based on the parameters of traveling waves.

\section{Fault Location in Multi-Terminal High-Voltage Direct Current (MT-HVdc) Grid Having High Grounding Resistance}

Typically, the traveling wave-based fault location identification technique is affected by the high grounding resistance of transmission lines because of abrupt and evolutionary changes in the voltage samples [50]. Therefore, a dc fault detection algorithm is required that can read the short window voltage samples and take appropriate actions according to the sampling information. For this, time frequency domain analysis of short window voltage samples obtained via $S$ transform is carried out, which would help in determining the accurate location of wave front of traveling wave. Further, wave front position is used to detect dc fault location. As the characteristics of traveling waves are different for different faults, therefore, separate principles for faults are required for implementation. An $S$ transform is generalization of short-term Fourier Transform, an extension of wavelet transform. It has the advantage of fixing modulation sinusoid with respect to time axis. Thus, localization of scalable Gaussian Window dilation and translation is done [69]. Consequently, a transformation matrix having complex elements is obtained as follows:

$$
S(t, f)=A(t, f) e^{j \varnothing(t, f)}
$$

where $A(t, f)$ is amplitude and $\varphi(t, f)$ is the phase function of the matrix. Every moment is acquired from the integration or by calculation of area under the curve of frequency spectrum at a specific instant. Therefore:

$$
I[t]=\int_{m}^{n} A(t, f) d f
$$

Samples of voltage signals at instant of fault are analyzed into the instantaneous frequency spectrum matrix. Integration of every moment is calculated by instantaneous frequency spectrum matrix. Accuracy of fault location is found by maximum value of the wave front calculated by $S$ transform.

Location finding devices need to be deployed at both ends of the transmission line so that time and voltage signals could be analyzed and saved in a real time buffer memory for a time length $t_{1}$. Another voltage signal is analyzed for time $t_{2}$ with consideration that absolute value of voltage signal is less than the threshold value. Sum of these two samples of different time lengths forms a long sample of $t=t_{1}+t_{2}$. An $S$ transform is applied to analyze time frequency domain of long sample to achieve $A(t, f)$.

\subsection{Fault Location Criteria}

Typically, fault criterion is different for various faults. Thus, dc fault location criterion for common kind of faults is defined in following section:

\subsubsection{Type Faults}

Synchronized timers are employed to detect arrival of first wave front at relay [70]. Abrupt changes in electrical characteristics are recorded at time $t_{s}$. This is the time at which $I[t]$ has maximum value i.e., $I\left[t_{s}\right]$. Mathematically, it is expressed as:

$$
\max \left\{i[t], t \in\left[t_{o}-t_{1}^{\prime}, t_{0}-t_{2}^{\prime}\right]\right\}=i\left[t_{s}\right]
$$


Time is recorded at both ends of the TL via synchronized timers i.e., $t_{s m}$ and $t_{s n}$ and distance is calculated from one/single end of TL and given by:

$$
l=\frac{L+v\left(t_{s m}-t_{s n}\right)}{2}
$$

where $l$ is the distance of fault from relaying point. $v$ is the velocity of the traveling wave and $L$ is the length of TL.

\subsubsection{A Type Faults}

The concept of time lag is employed here. Typically, dc fault generate two traveling waves which travels toward both ends of the dc-link. The first traveling wave reaches straight at primary protection relay while the second traveling wave reaches at PP relay after reflection from second end of the dc-link. As it is difficult to make a difference between two wave fronts, the local maximum value of integration is used for identification and mathematically given as;

$$
\text { local } \max \left\{i[t], t \in\left[t_{o}-t_{1}^{\prime}, t_{o}-t_{2}^{\prime}\right]\right\}=I\left[t_{d i}\right]
$$

where $i=1,2,3, \ldots$ and $t_{d i}$ are the points of time of reflected and refracted wave fronts.

Magnitude of first transient traveling wave is important because of the attenuation phenomenon in transmission lines. Thus, the location of fault can be detected easily via the first traveling wave reaching at relaying point from fault position with time $t_{s 1}$ and traveling wave reflected from the second end of dc-link with time $t_{s 2}$. The intensity of TW reflected from fault position is higher than the intensity of wave reflected from second end when fault position is near to the ends containing detectors or when the resistance is very small [60]. Mathematically, it can be expressed as:

$$
\begin{gathered}
\left\{\begin{array}{c}
I\left[t_{s 1}\right]>\forall \text { local max }\{i[t]\} \\
t \in\left[t_{o}-t_{1}^{\prime}, t_{s 2}\right) \cup\left(t_{s 2}, t_{o}+t_{2}^{\prime}\right]
\end{array}\right. \\
I\left[t_{s 2}\right]>\forall \text { local max }\{i[t]\} \\
t \in\left[t_{o}-t_{1}^{\prime}, t_{s 1}\right) \cup\left(t_{s 1}, t_{o}+t_{2}^{\prime}\right]
\end{gathered}
$$

and

$$
t_{s 2}>t_{s 1}
$$

The distance of VSC station containing detector from fault point is calculated by:

$$
l=L-\frac{v\left(t_{s 2}-t_{s 1}\right)}{2}
$$

Thus, dc fault location for type A faults in MT-HVdc systems having high grounding resistances can be found from Equation (8).

\section{Fault Location in Direct Current (DC) Grid Having Cable and Overhead Line Segments}

Accurate relay measurement is key factor in the fault location estimation. Normally, inverters are not installed close to the shore; therefore, it is always required to employ a combination of overhead transmission lines and submarine cables for offshore wind farms integration with onshore grids. Kii Channel HVdc system [71], Anan Kihoku HVdc system [72], Hokkaido Hanshu HVdc link, Japan [73] and Basslink HVdc inter-connecter system, Australia [74] are possible examples of power transmission over hybrid medium. Three-line segment model of dc-link is considered to elaborate the behavior of cables and $\mathrm{OH}$ line for dc fault location estimation with respect to TWs in the following section. Here, faults are classified as dc cable and dc overhead line faults. 


\subsection{Three-Line Segment Model}

It is important to measure the traveling wave arrival time precisely because of the involvement of difference of arrival time of traveling waves at converter stations at two ends.

A three-line segments model of HVdc system is shown in Figure 4.

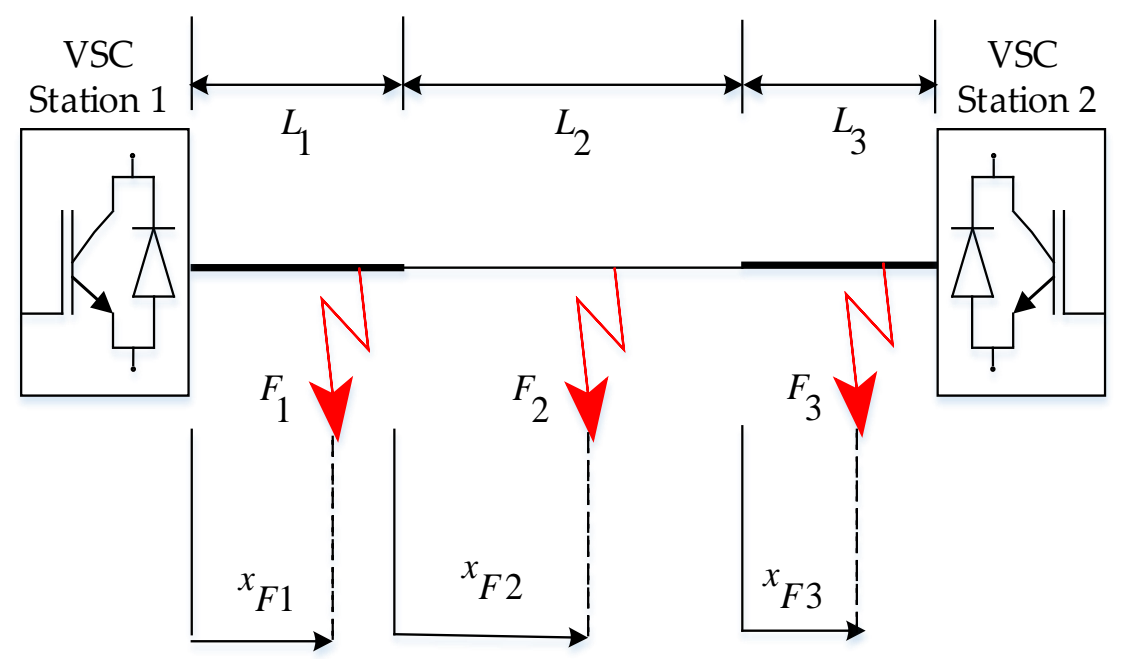

Figure 4. The direct current (dc)-link model with two overhead lines and one cable segment.

$L_{1}, L_{2}$, and $L_{3}$ are lengths of the segments of a line. $F_{1}$ is a fault located in segment (overhead line) $L_{1}$. Similarly, $F_{2}$ and $F_{3}$ are the faults located within segments $L_{2}$ (cable) and $L_{3}(\mathrm{OH})$, respectively. $x_{F 1}$, $x_{F 2}, x_{F 3}$ are the distances of faults from the start of each segment $L_{1}, L_{2}$, and $L_{3}$, respectively.

Mathematical formulation involved in finding distance of fault from the VSC station in three-line segment model under different positions of fault is discussed through case- 1 to case- 3 .

\subsubsection{Case 1}

If the fault $F_{1}$ occurs at $t=0$ in the first section (overhead segment) of dc-link as shown in Figure 4 , then the arrival time of TW at terminal $T_{1}$ is given by:

$$
t_{1-F 1}=\frac{x_{F 1}}{v_{1}}
$$

where $v_{1}$ is the propagation velocity of traveling wave. The arrival time of traveling wave at terminal $T_{2}$ is given by:

$$
t_{2-F 1}=\frac{L_{1}-x_{F 1}}{v_{1}}+\frac{L_{2}}{v_{2}}+\frac{L_{3}}{v_{3}}
$$

where $v_{2}$ and $v_{3}$ are the propagation velocities of traveling wave in segments $L_{2}$ and $L_{3}$, respectively. And the difference between arrival times at terminal $T_{1}$ and $T_{2}$ is given by:

$$
\begin{gathered}
\Delta t_{12-F 1}=t_{1-F 1}-t_{2-F 1} \\
\Delta t_{12-F 1}=\frac{2 \cdot x_{F 1}}{v_{1}}-\frac{L_{1}}{v_{1}}-\frac{L_{2}}{v_{2}}-\frac{L_{3}}{v_{3}}
\end{gathered}
$$

The distance from the fault point to the start of segment $L_{1}$ is given by:

$$
x_{F 1}=\left(\Delta t_{12-F 1}+\frac{L_{1}}{v_{1}}+\frac{L_{2}}{v_{2}}+\frac{L_{3}}{v_{3}}\right) \times \frac{v_{1}}{2}
$$




\subsubsection{Case 2}

Let us consider fault $F_{2}$. It occurs in the middle segment, $L_{2}$ as shown in Figure 4 . If this fault occurs at $t=0$, then arrival times of traveling waves at terminals $T_{1}$ and $T_{2}$ are:

$$
\begin{gathered}
t_{1-F 2}=\frac{x_{F 2}}{v_{2}}+\frac{L_{1}}{v_{1}} \\
t_{2-F 2}=\frac{L_{2}-x_{F 2}}{v_{2}}+\frac{L_{3}}{v_{3}}
\end{gathered}
$$

The difference between arrival times is given by:

$$
\Delta t_{12-F 2}=\frac{2 \cdot x_{F 2}}{v_{2}}+\frac{L_{1}}{v_{1}}-\frac{L_{2}}{v_{2}}-\frac{L_{3}}{v_{3}}
$$

The distance of the fault location from the start of $L_{2}$ segment is given by:

$$
x_{F 2}=\left(\Delta t_{12-F 2}-\frac{L_{1}}{v_{1}}+\frac{L_{2}}{v_{2}}+\frac{L_{3}}{v_{3}}\right) \times \frac{v_{2}}{2}
$$

\subsubsection{Case 3}

Suppose that a fault $F_{3}$ occurs in the third $\mathrm{OH}$ line segment of length $L_{3}$ as shown in Figure 4. If this fault occurs at $t=0$, then the arrival times of the traveling waves at terminal $T_{1}$ and $T_{2}$ are:

$$
\begin{gathered}
t_{1-F 3}=\frac{x_{F 3}}{v_{3}}+\frac{L_{2}}{v_{2}}+\frac{L_{1}}{v_{1}} \\
t_{2-F 3}=\frac{L_{3}-x_{F 3}}{v_{3}}
\end{gathered}
$$

The difference between arrival times is given by:

$$
\Delta t_{12-F 3}=\frac{2 \cdot x_{F 3}}{v_{3}}+\frac{L_{1}}{v_{1}}+\frac{L_{2}}{v_{2}}-\frac{L_{3}}{v_{3}}
$$

The distance of the FL from start of segment $L_{3}$ is given by:

$$
x_{F 3}=\left(\Delta t_{12-F 3}-\frac{L_{1}}{v_{1}}-\frac{L_{2}}{v_{2}}+\frac{L_{3}}{v_{3}}\right) \times \frac{v_{3}}{2}
$$

Based on the distance of fault location from the beginning/start of respective segment, particular faulty segment is identified via algorithm given in subsequent section.

\subsection{Identification of Faulty Line Segment}

Ideally, the fault location is supposed to be known. However, practically, this is not known. An arrival time of the TW is measured at two ends of TL. Therefore, an arrival time difference is calculated. Hence, it is always important to identify the faulty segment to make it possible to find the location of fault. This is achieved by following the steps as explained in the Figure 5. For instance, consider an event in which dc fault occurs in the middle segment $\left(L_{2}\right)$. The actual difference between the arrival time of traveling waves at two ends of TL is given by Equation (15). Now the estimated value of $x_{F 1}$ Is calculated by the substitution of $\Delta t_{12}$ From Equation (15) into (12) and the result is:

$$
x_{F 1}=L_{1}+x_{F 2} \times \frac{v_{1}}{v_{2}}
$$




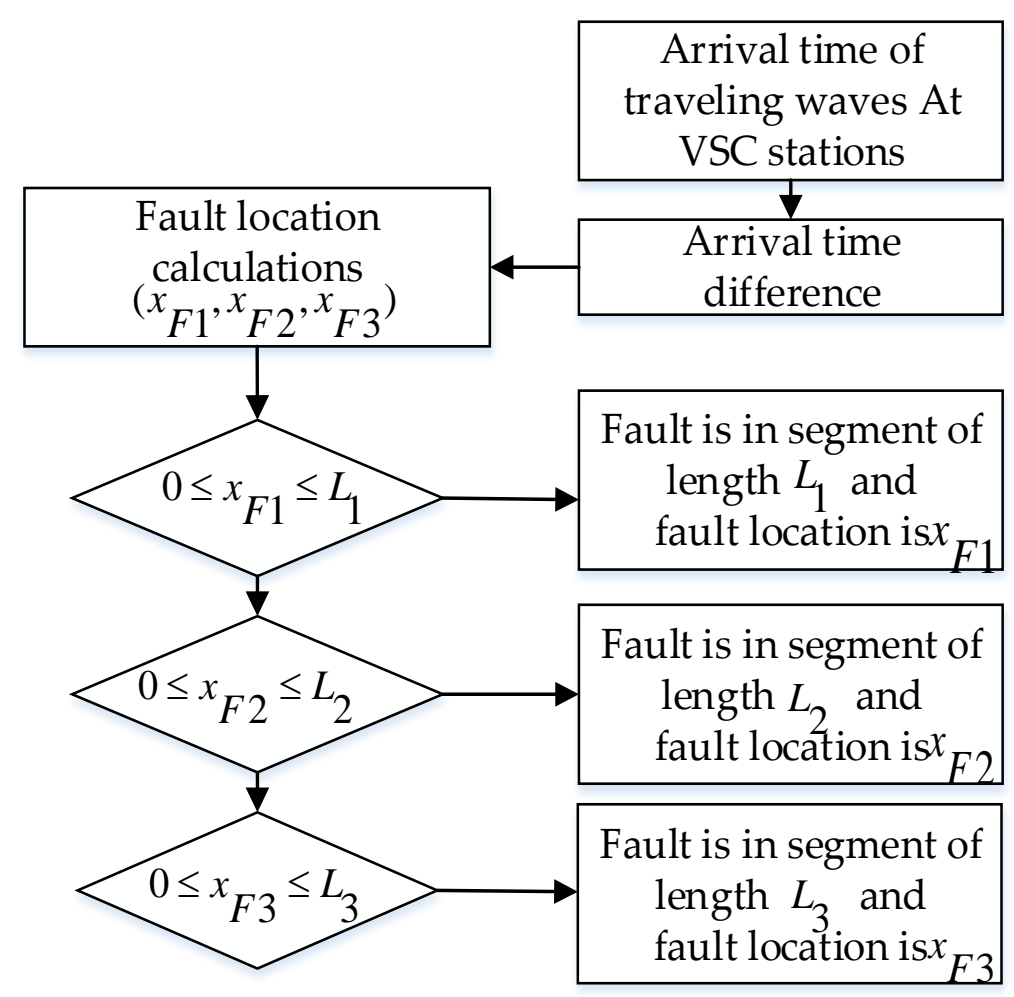

Figure 5. Faulty segment identification algorithm.

Since $\left(\frac{v_{1}}{v_{2}}\right)>0$, therefore $x_{F 1}>L_{1}$. Hence, fault is not present in segment $L_{1}$. Similarly, putting the estimated value of $\Delta t_{12}$ From Equation (15) into (20) results:

$$
x_{F 3}=\left(x_{F 2}-L_{2}\right) \times \frac{v_{3}}{v_{2}}
$$

Since $\left(\frac{v_{3}}{V_{2}}\right)>0$, therefore, $x_{f 2}>L_{2}$. Hence, the estimated value of $x_{f 3}$ would be negative which is a clear indication that fault is not present in $l_{3}$. In this way, faulty segment is identified and voltage samples measured at VSCs are used to trace the fault location in the faulty segment. This method can be extended to $n$ number of heterogeneous segments and generalized fault location equation for a fault segment identification is:

$$
x_{F i}=\Delta t_{12-F i}-\frac{L_{1}}{v_{1}}-\frac{L_{2}}{v_{2}}-\ldots-\frac{L_{i-1}}{v_{i-1}}+\frac{L_{i+1}}{v_{i+1}}+\ldots+\frac{L_{n-1}}{v_{n-1}}+\frac{L_{n}}{v_{n}}
$$

\subsection{Fault Arrival Time Identification}

Precision of traveling wave-based dc fault location highly depends upon the accuracy of detection of faulty surge arrival time. Traveling wave front may present in the terminal voltages or it may flow through the surge capacitors, deployed at the converter stations for VSC protection [61]. For a permanent fault on dc-link, steepness of voltage profile decreases when a fault propagates along the length of the line as increase in TW wavelength results in attenuation. Here, if a level detection method is employed for determining arrival time of surge, then an error may occur due to change in shape of wave front for a fault location closer to the VSC station. This effect is not considerable in the event of occurrence of fault in middle of the TL.

In case of high impedance fault, magnitude and steepness of the TW would be small, making it difficult for classical methods to proceed for analysis. Therefore, time frequency analysis, i.e., wavelet transform is employed because of its high efficiency and performance for high impedance 
faults $[61,64,66]$. Normally continuous wavelet transform is used for transient identification within dc faults. Continuous wavelet transform of a signal $f(t)$ is given by:

$$
\begin{gathered}
\operatorname{CWT}(f(t)): a, b)=\int_{-\infty}^{\infty} f(t) \varphi_{a, b}^{*}(t) d t \\
\varphi_{a, b}^{*}(t)=\frac{1}{\sqrt{a}} \varphi\left(\frac{t-b}{a}\right)
\end{gathered}
$$

where $\psi_{a, b}^{*}(t)$ is complex continuous function in time and frequency domains and is known as mother wavelet. $a$ is a scaling (dilation) factor and $b$ is the shifting (translation) factor. For discrete wavelet transform, mother wavelet may be dilated and translated in a dyadic block.

\section{Wavelet Based Surge Detection}

Transients in the fault can be identified by analyzing the coefficients of CWT of the measured terminal voltages or coefficients of current signals from surge capacitor [61]. Magnitude of CWT coefficients are evaluated on different scales: $a=16,32,64$, and 128 at each terminal (station). These magnitudes are then compared against pre-determined thresholds to detect the arrival of initial surge. The instant at which the magnitude of CWT is lying above the threshold is known as arrival time of the traveling wave.

\section{Natural Frequency Based Fault Location Finding in Multi-Terminal High-Voltage Direct Current (MT-HVdc) Systems}

Traveling wave methods for fault locations are based on the time utilized by the generated traveling wave to reach the converter stations. These methods are highly efficient and are independent of the effects of parameters of transmission lines [34,62,75,76]. But the velocity of the propagation of TW and the wave front of the TW are key parameters for traveling wave-based algorithms. However, it is difficult to detect these parameters for high resistance faults and for gradual change in resistance. Fault location calculation is dependent on the velocity and traveling time of TW from fault point to VSC station. However, the velocity of traveling wave is highly influenced by the electrical parameters of the transmission lines and thus raise concerns on the precision of the result of fault location calculated by TW based algorithms [77-79]. Therefore, in order to overcome aforementioned shortcomings, natural frequency of traveling wave is measured to predict and estimate fault location and distance from VSC station [35]. Traveling wave's spectrum of faulty voltage signals can be employed for calculation of fault distance from VSC stations. When system's impedance is zero or infinite, dc fault distance and natural frequencies of TW are defined by $L=c / 4 f$ and $f=1 / 4 \tau$, respectively [80-82].

\subsection{Natural Frequency of a Traveling Wave}

Typically, traveling waves originate from dc fault point and inter-reflect between fault point and VSCs. Frequency spectrum of traveling waves of the fault is created by the series of fundamental (dominant) and harmonic components of the frequency. The lowest harmonic order frequency is characterized by its high amplitude and is designated as dominant frequency while amplitude decreases as the harmonic order of frequency increases. Surge reflection routes in faulted line and spectrum of traveling wave at converter stations are shown in Figure 6. Total reflection would be positive when traveling wave reaches at end of TL and total reflection would be negative when TW strikes the fault point. This process continues till the time period $T_{1}=4 d / v$, where $v$ is the velocity of the propagation of traveling wave. When the system impedance is zero, the total reflection will be positive on the first reach of traveling wave at VSC station and total reflection will be negative on the reach of traveling wave at fault point. The terminal voltage changes with time period $T_{2}=2 d / v$. 


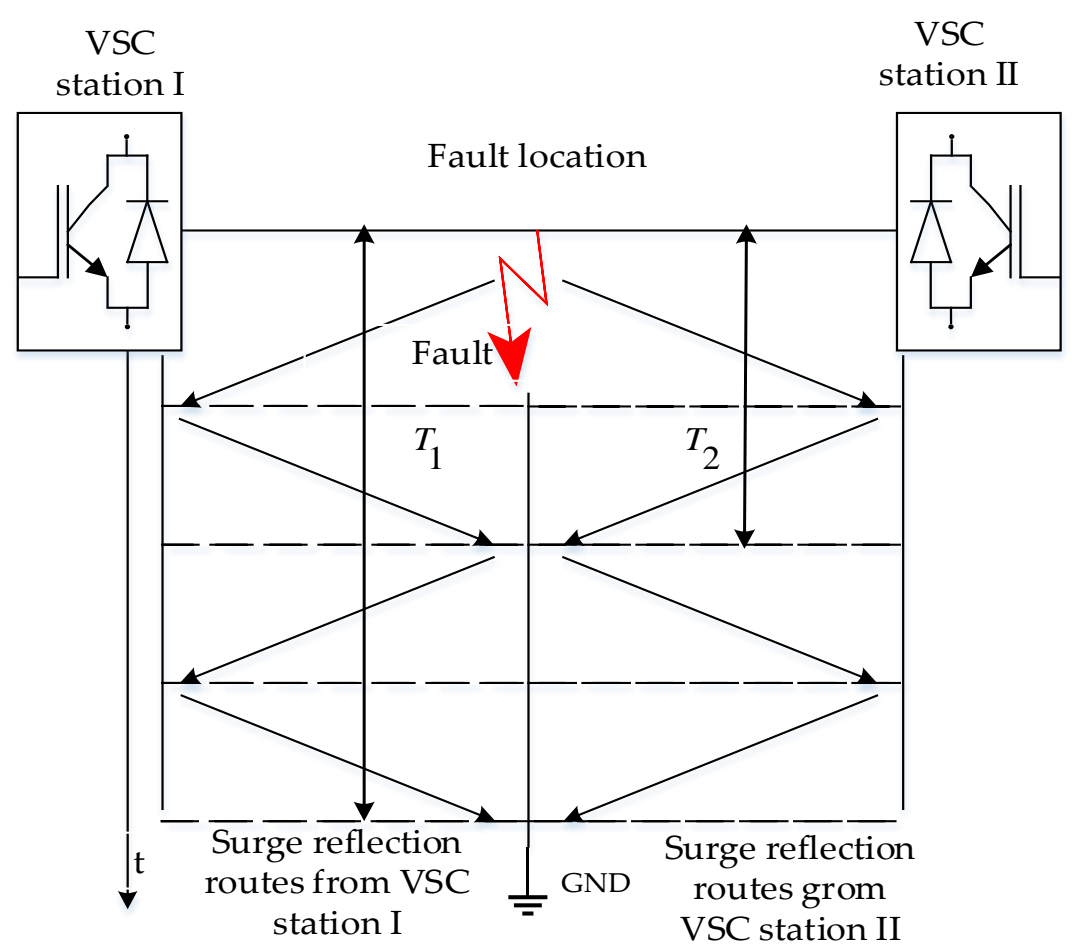

Figure 6. Surge reflection routes in a faulted line.

This phenomenon of natural frequency is employed for finding the FL in MT-HVdc systems. For this, a relationship is derived between dominant component of natural frequency and distance of fault from the converter station.

\subsection{Relationship between Distance and Dominant Component of Natural Frequency}

Thevenin's equivalent of two conductor transmission line circuit is shown in Figure 7.

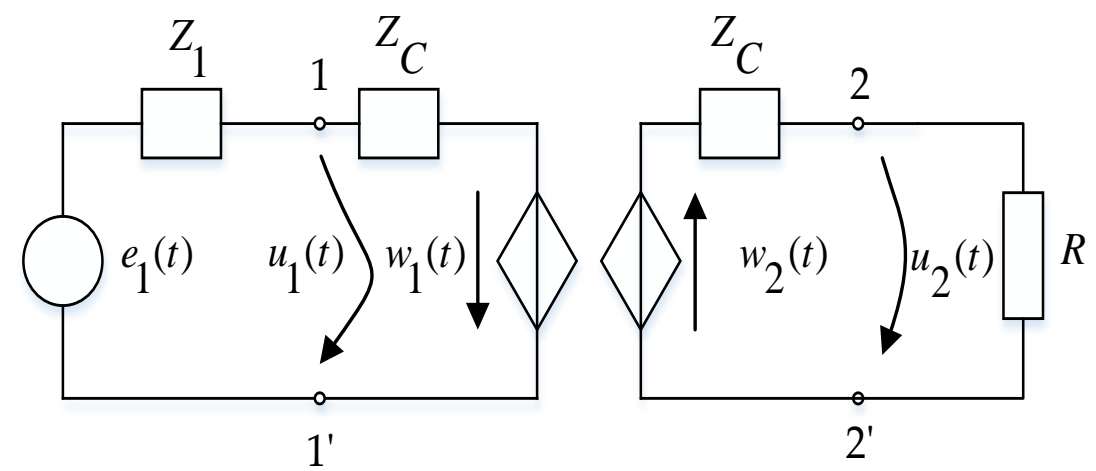

Figure 7. Equivalent circuit of bipolar transmission line.

The terminal voltages are expressed in Laplace Transform as:

$$
\begin{aligned}
& V_{1}(s)=\frac{Z_{1}(s)}{Z_{1}(s)+Z_{c}(s)} W_{1}(s)+\frac{Z_{c}(s)}{Z_{1}(s)+Z_{c}(s)} E_{1}(s) \\
& V_{2}(s)=\frac{Z_{2}(s)}{Z_{2}(s)+Z_{c}(s)} W_{2}(s)+\frac{Z_{c}(s)}{Z_{2}(s)+Z_{\mathcal{c}}(s)} E_{2}(s)
\end{aligned}
$$

where $V_{1}(s)$ and $V_{2}(s)$ are the terminal voltages, respectively. $E_{1}(s)$ and $E_{2}(s)$ are Thevenin's voltage sources of systems 1 and 2 , respectively. $Z_{1}(s)$ and $Z_{2}(s)$ are the equivalent impedance of system 1 and 
2 , respectively. $Z_{c}(s)$ is the characteristic impedance of TL. The state variables $W_{1}(s)$ and $W_{2}(s)$ are given by following expressions:

$$
\begin{aligned}
& W_{1}(s)=\frac{P(s)}{1-\tau_{1}(s) \tau_{2}(s) P^{2}(s)}\left[\frac{2 Z_{c}(s)}{Z_{2}(s)+Z_{c}(s)} E_{2}(s)+\tau_{2}(s) P(s) \frac{2 Z_{c}(s)}{Z_{1}(s)+Z_{2}(s)} E_{1}(s)\right] \\
& W_{1}(s)=\frac{P(s)}{1-\tau_{1}(s) \tau_{2}(s) P^{2}(s)}\left[\frac{2 Z_{c}(s)}{Z_{1}(s)+Z_{2}(s)} E_{1}(s)+\tau_{1}(s) P(s) \frac{2 Z_{c}(s)}{Z_{2}(s)+Z_{\mathcal{c}}(s)} E_{2}(s)\right]
\end{aligned}
$$

where $\tau_{1}(s)$ and $\tau_{2}(s)$ are reflection coefficients of TL ends:

$$
\begin{aligned}
& \tau_{1}(s)=\left|\tau_{1}\right| e^{j \theta_{1}}=\frac{Z_{1}(s)-Z_{2}(s)}{Z_{1}(s)+Z_{c}(s)} \\
& \tau_{2}(s)=\left|\tau_{2}\right| e^{j \theta_{2}}=\frac{Z_{2}(s)-Z_{2}(s)}{Z_{2}(s)+Z_{c}(s)}
\end{aligned}
$$

and $P(s)$ is the delay operator of the line:

$$
P(s)=e^{-s T}
$$

where $T$ is the time required by the TW to reach at second end from first end of the line. The roots of the natural frequencies of the line is given by:

$$
H(s)=\frac{1}{1-P(s) \tau_{1}(s) \tau_{2}(s)}
$$

Equation (33) can produce infinite roots, which is an indication that traveling wave is composed of infinite number of oscillatory components. Thus, frequencies of these oscillatory components are determined by Equation (30). Equating denominator of Equation (33) to zero provides the information about all natural frequencies induced by the dc fault:

$$
1-P(s) \tau_{1}(s) \tau_{2}(s)=0
$$

Using $s=\sigma+j \omega$ in (32) for $n^{\text {th }}$ component of natural frequency:

$$
P(s)=e^{-\left(\sigma_{n}+j \omega_{n}\right) T}
$$

where $\sigma_{n}$ and $\omega_{n}$ are the damping constant and angular frequency of the $n^{\text {th }}$ component of the natural frequency, respectively. Substituting the delay operator in Equation (34) results in:

$$
e^{2\left(\sigma_{n}+j \omega_{n}\right) T}=\tau_{1} \tau_{2} e^{j 2 k \pi} \quad(k=0,1,2, \ldots)
$$

The dominant component of natural frequency possesses largest amplitude among all the components and therefore, it is used for the evaluation of fault distance. When a fault occurs in an HVdc transmission line, the reflection coefficient at the point of fault is given by:

$$
\tau_{f}(s)=\left|\tau_{f}\right| e^{j \theta_{f}}=-\left[2 Z_{c}(s)^{-1}+Y_{f}(s)\right]^{-1} Y_{f}(s)
$$

or

$$
\tau_{f}(s)=\left|\tau_{f}\right| e^{j \theta_{f}}=\frac{-Z_{c}(s)}{2 Z_{f}(s)+Z_{c}(s)}
$$

where $Y_{f}(s)$ is an admittance of the fault. Thus, Equation (36) implies:

$$
e^{2\left(\sigma_{n}+j \omega_{n}\right) T}=\left|T_{1}\right| e^{j \theta_{1}}\left|T_{f}\right| e^{j \theta_{f}} e^{j 2 k \pi}
$$


Since $T=d v$, using this substitution in Equation (39):

$$
d=\frac{\left(\theta_{1}+\theta_{f}+2 k \pi\right) \times v}{4 \pi f_{n}}
$$

where $f_{n}$ is component of natural frequency and $n=1,2,3, \ldots$. For dominant component of natural frequency $f_{1}$, Equation (40) becomes:

$$
d=\frac{\left(\theta_{1}+\theta_{f}\right) \times v}{4 \pi f_{1}}
$$

Since the reflection angle $\theta_{f}$ due to fault is approximately equal to $\pi$, thus Equation (41) becomes:

$$
d=\frac{\left(\theta_{1}+\pi\right) \times v}{4 \pi f_{1}}
$$

Propagation velocity $v$ in $\mathrm{m} / \mathrm{s}$ at certain frequency $\omega(\mathrm{rad})$ is given by:

$$
v=\frac{\omega}{\beta}=\frac{\omega}{\operatorname{imag}(\sqrt{Z(j \omega) Y(j \omega)})}
$$

Hence, identification of natural frequency is required for estimation of fault location from converter station.

\subsection{Identification of Dominant Natural Frequency}

Identification of dominant component of natural frequency involves the mode extraction and signal classification.

\subsubsection{Mode Extraction}

Bipolar HVdc system is considered as in [83]. One transmission tower is erected for two lines of bipolar HVdc system in order to make it economical. Thus, current coupling exists. There is a need to decouple the current into an independent modulus by mode transformation matrix [83]. The telegraph equation of transmission line is:

$$
\left\{\begin{array}{l}
\frac{\partial u}{\partial x}=-L \frac{\partial i}{\partial t}-R i \\
\frac{\partial i}{\partial x}=-C \frac{\partial u}{\partial t}-G i
\end{array}\right.
$$

where $u=\left[\begin{array}{c}u_{R+} \\ u_{R-}\end{array}\right], i=\left[\begin{array}{c}i_{R+} \\ i_{R-}\end{array}\right], L=\left[\begin{array}{cc}L_{s} & L_{m} \\ L_{m} & L_{s}\end{array}\right], R=\left[\begin{array}{cc}R_{s} & R_{m} \\ R_{m} & R_{s}\end{array}\right], C=\left[\begin{array}{cc}C_{s} & -C_{m} \\ -C_{m} & C_{s}\end{array}\right], C_{s}=C_{o}+$ $C_{m}, G_{s}=G_{0}+G_{m}$.

$L_{s}$ and $L_{m}$ are self and mutual inductances of line, respectively. $R_{S}$ and $R_{m}$ are self and mutual resistances, respectively. $G_{o}$ and $G_{m}$ are line to earth and line-line conductances, respectively. $C_{o}$ and $C_{m}$ are line to earth and line-line capacitance of the TL, respectively. By applying Karenbauer phase mode transformation matrix, mode form of voltage and current are:

$$
\begin{aligned}
& \frac{\partial u_{m}}{\partial x}=-S^{-1} L S \frac{\partial i_{m}}{\partial t}-S^{-1} R S i_{m} \\
& \frac{\partial i_{m}}{\partial x}=-S^{-1} C S \frac{\partial u_{m}}{\partial t}-S^{-1} G S u_{m}
\end{aligned}
$$

where $i_{m}=\left[\begin{array}{l}i_{0} \\ i_{1}\end{array}\right]=S^{-1}\left[\begin{array}{c}i_{R+} \\ i_{R-}\end{array}\right]=\frac{\sqrt{2}}{2}\left[\begin{array}{cc}1 & 1 \\ 1 & -1\end{array}\right]\left[\begin{array}{c}i_{R+} \\ i_{R-}\end{array}\right] i_{0}$ and $i_{1}$ are zero mode and one mode currents of dc transmission line, respectively. $i_{R+}$ and $i_{R-}$ are the positive and negative line currents, respectively. Since the transient energy of one mode current is higher than the transient energy of zero mode current, therefore, information of one mode current is utilized for the extraction of dominant component of natural frequency. Algorithm of protection based on natural frequency is presented in Figure 8. 


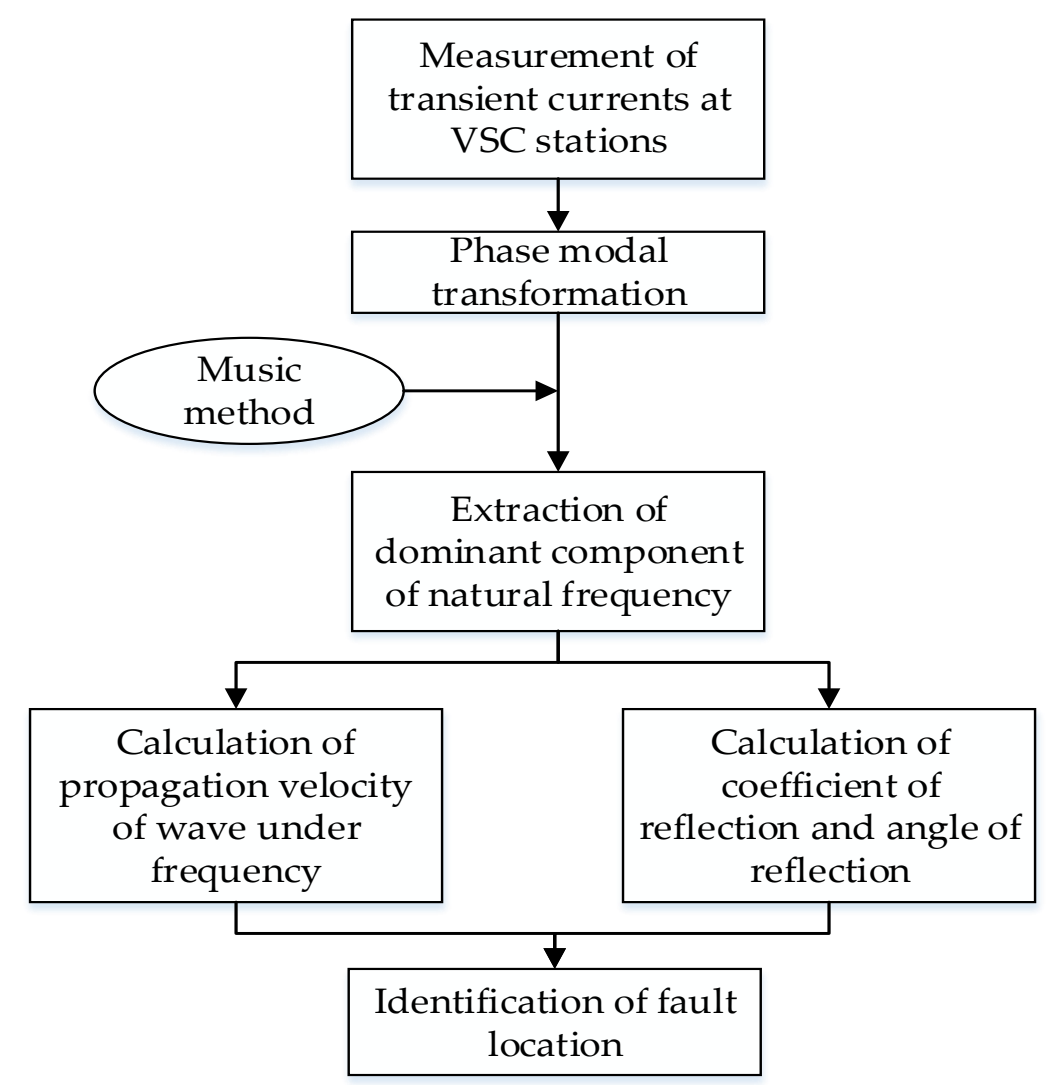

Figure 8. Flowchart of natural frequency-based protection for high-voltage direct current (HVdc) transmission lines.

\subsubsection{Multiple Signal Classification}

Natural frequencies are extracted from complex traveling waves by the application of higher resolution spectra estimation tool. A parameter-based method known as multiple signal classification is employed for extraction of higher frequency components of natural frequency. In this method, data is considered as a sinusoidal component of noise. Higher resolution spectrum is achieved by dividing the signal eigen vector into signal and noise subspaces. A sampled signal is expressed as:

$$
x(n)=\sum_{i=1}^{P} \begin{array}{r}
A_{i} e^{j\left(2 \pi f_{i} n+\varphi_{i}\right)}+\omega(n) \\
n=1,2, \ldots, N
\end{array}
$$

where $p$ is the number of harmonics. $A_{i}, f_{i}, \phi_{i}$ are the amplitude, frequency, and inception angle of the $i^{\text {th }}$ harmonic component. $w(n)$ is noise. Auto-correlation of matrix of $X(n)$ is given as:

$$
R_{x x}=E\left\{X(n) X^{T}(n)\right\}
$$

where $X(n)$ is a $m \times N$ matrix and given by:

$$
X(n)=[x(n) x(n+1) \ldots x(n+m-1)]^{T}
$$

The weight of each component of frequency is given by power spectrum and mathematically as:

$$
P\left(f_{i}\right)=\frac{1}{\sum_{k=p+1}^{m}\left|s\left(f_{i}\right)^{T} v_{k}\right|^{2}}
$$


where $s\left(f_{i}\right)=\left[1 e^{j 2 \pi f i} \ldots e^{j 2 \pi(N-1) f i}\right]^{T}$.

Peaks of the frequency spectrum is obtained by the expression of power spectrum $P\left(f_{i}\right)$. These peaks help in determination of dominant component of natural frequency. This dominant component of natural frequency is then employed for determination of distance of fault from converter station in MT-HVdc systems.

\section{Fault Location Method Based on Similarity of Voltage Signals}

Several researches are conducted for enhancing the traveling wave methods performance by considering different topologies and configurations $[7,33,34,36,37,84-87]$. Some intrinsic problems like wave front identification and precision are associated with TW method. Machine learning and pattern recognition approaches played a key role in reducing the inherent problems associated with TW methods [38].

In this section, learning based method for identification of fault location in HVdc transmission line is discussed. In this method, samples from a time window of a post fault voltage is referred as input feature. Pearson correlation coefficient is calculated to find similarity between samples of the input feature and existing feature. Then this similarity is used to estimate the fault location [88]. The sampling frequency is $80 \mathrm{kHz}$. Post fault voltage signal depends on the oscillations of the energy stored in the capacitors and the transients generated by the fault because of the reflection of traveling waves $[80,89,90]$. Post fault voltage signal would have considerable correlation with the distance from fault point. Therefore, Pearson correlation coefficient is employed to measure the similarity of the voltage signals and expressed as:

$$
r(x, y)=\frac{\sum_{i=1}^{n}\left(x_{i}-\frac{1}{n} \sum_{j=1}^{n} x_{j}\right)}{\sqrt{\sum_{i=1}^{n}\left(x_{i}-\frac{1}{n} \sum_{j=1}^{n} x_{j}\right)^{2}}} \times \frac{\left(y_{i}-\frac{1}{n} \sum_{j=1}^{n} y_{j}\right)}{\sqrt{\sum_{i=1}^{n}\left(y_{i}-\frac{1}{n} \sum_{j=1}^{n} y_{j}\right)^{2}}}
$$

where $r(x, y)$ is the Pearson correlation coefficient of signals $x$ and $y$ and $r(x, y) \in[-1,+1]$. Correlation coefficient +1 illustrates positive linear correlation. Correlation coefficient -1 represents negative linear correlation. No linear correlation present at all correlation coefficient 0 .

The voltage signals for fault location are measured at one terminal of the HVdc system. In this method, whence a dc fault is occurred, one pole (either positive or negative) is selected for voltage (signal) measurements for determination of fault location. Appropriate voltage samples are collected, when an absolute value of voltage is less than the threshold value of the voltage. These samples are employed as feature of the pattern. Similarity of the new pattern extracted from voltage samples is measured by comparing with the existing patterns available in the database. Fault location is estimated by the weighted average of the pointed values obtained from the $k$ most similar patterns, which is called $k$ nearest neighbor principle. Therefore, correlation is converted to positive value distance matrix and expressed as [75]:

$$
d_{r}(x, y)=1-r(x, y)
$$

where $d_{r}(x, y)$ is Pearson distance of signal $x$ and $y$ and, $d_{r}(x, y) \in[0,2]$. Equation (52) is employed to estimate the fault location obtained via new pattern [75].

$$
F F_{L}\left(x^{\prime}\right)=\frac{\sum_{x \in S\left(x^{\prime}\right)} F_{L}(x) \times e^{\left(-d_{r}\left(x, x^{\prime}\right)\right)^{2}}}{\sum_{x \in S\left(x^{\prime}\right)} e^{\left(-d_{r}\left(x, x^{\prime}\right)\right)^{2}}}
$$

where $F_{L}(x)$ is corresponding fault location of the existing pattern $x$ and $b . F_{L}\left(x_{0}\right)$ is the estimated fault location corresponding to new pattern $x_{0}$. $S\left(x_{0}\right)$ is set of $k$ patterns similar to new pattern $x_{0} . d_{r}\left(x, x_{0}\right)$ is Pearson distance of existing pattern $\mathrm{x}$ and the new pattern $x_{0}$. Voltage samples are collected for a time window of length of $10 \mathrm{~ms}$ if voltage values are less than the threshold values of voltage in the case of fault. Features are extracted from these voltage samples and are compared with the samples available 
in data base for the fault. $k$ most similar patterns are determined and weighted average of patterns are employed to evaluate location of fault. Fault location algorithm is given in Figure 9.

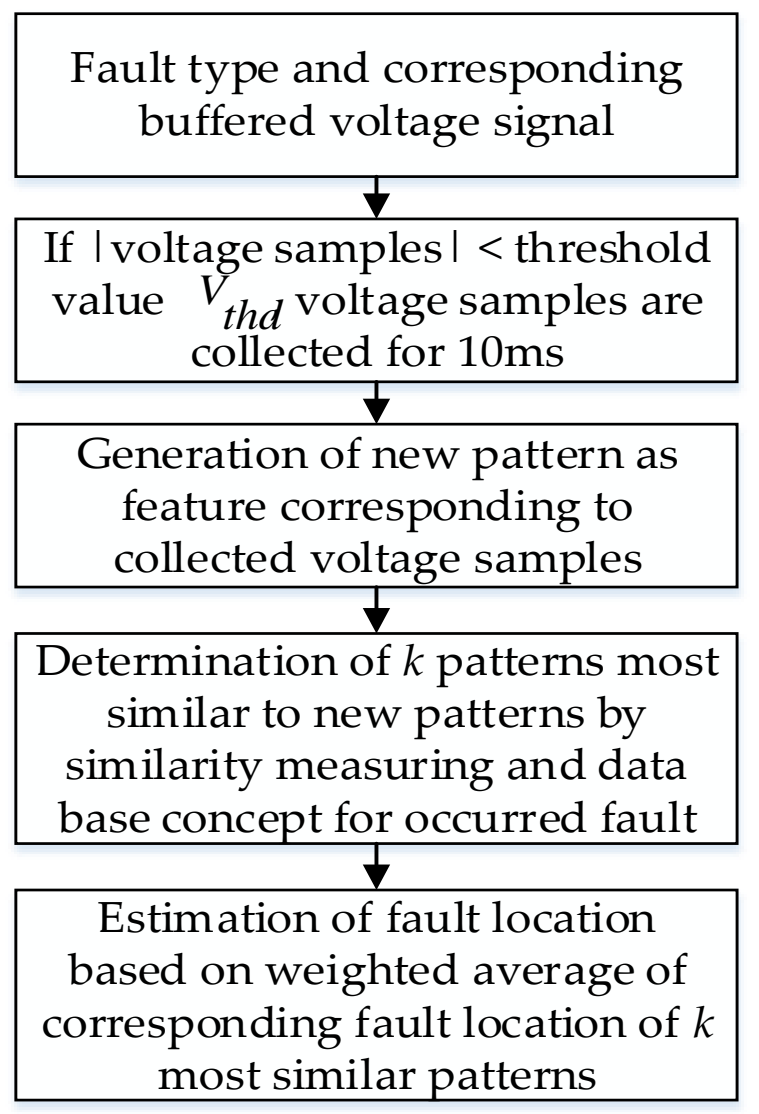

Figure 9. Fault location algorithm based on voltage similarity signals.

\section{Symmetrical Component Analysis for Fault Classification in Multi-Terminal High-Voltage Direct Current (MT-HVdc) Systems}

Faults in HVdc circuits generate traveling waves and these waves are compared and computed with different analytical methods [80]. However, there is a lot of space for researchers to carry out investigations upon the characteristics of fault for bipolar $\mathrm{HVdc}$ lines for efficient designing of protection. Because of unsymmetrical nature of travelling waves originated from fault location in MT-HVdc systems, symmetrical component analysis is employed for fault detection in MT-HVdc systems.

\subsection{Fault Analysis Based on Symmetrical Components}

Voltage vectors $u_{a}$ and $u_{b}$ and, current vectors $i_{a}$ and $i_{b}$ are shown in Figure 10. These vectors are resolved into their components i.e., zero sequence and positive sequence components and are represented:

$$
\begin{gathered}
\left\{\begin{array}{c}
u_{a}=u_{a 0}+u_{a 1} \\
u_{b}=u_{b 0}+u_{b 1}
\end{array}\right. \\
\left\{\begin{array}{l}
u_{b 0}=u_{a 0} \\
u_{b 1}=u_{a 1}
\end{array}\right.
\end{gathered}
$$




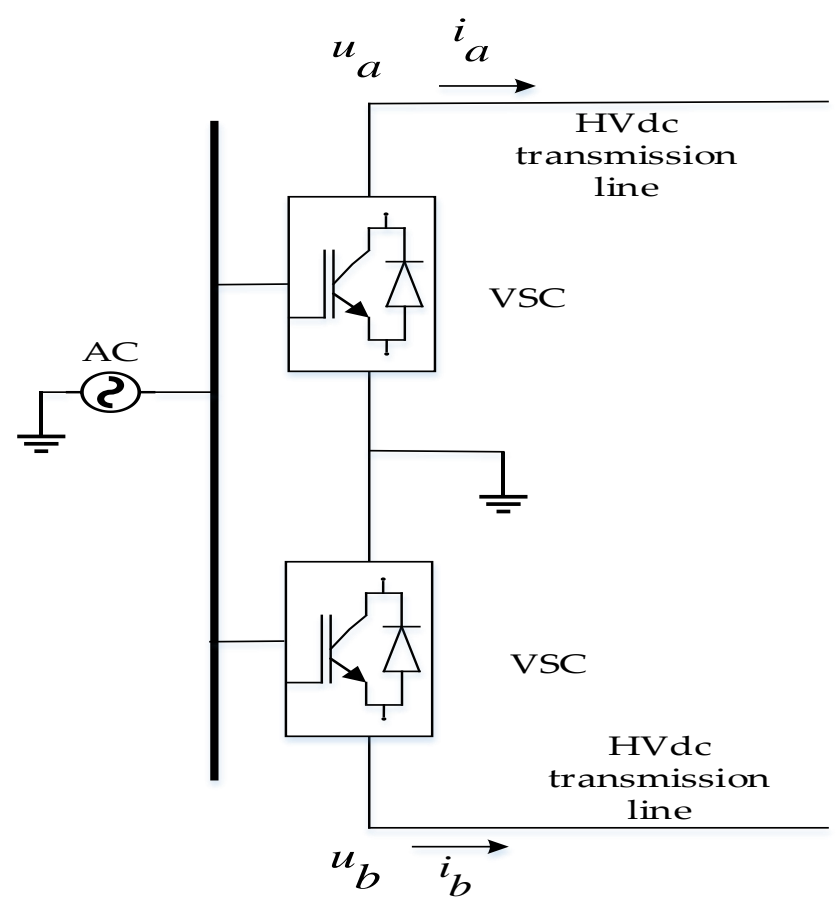

Figure 10. Bipolar voltage source converter (VSC) high-voltage direct current (HVdc) station with specified voltage and current.

Using Equations (53) and (54), following expression is achieved:

$$
\left[\begin{array}{l}
u_{a} \\
u_{b}
\end{array}\right]=\left[\begin{array}{cc}
1 & 1 \\
1 & -1
\end{array}\right]\left[\begin{array}{l}
u_{a 0} \\
u_{a 1}
\end{array}\right]
$$

and symmetrical components are expressed as:

$$
\left[\begin{array}{l}
u_{a 0} \\
u_{a 1}
\end{array}\right]=\frac{1}{\sqrt{2}}\left[\begin{array}{cc}
1 & 1 \\
1 & -1
\end{array}\right]\left[\begin{array}{l}
u_{a} \\
u_{b}
\end{array}\right]
$$

Because of bipolar HVdc systems and its working under normal conditions, nominal rated value of voltage is given by:

$$
\left\{\begin{array}{l}
u_{a}=U_{d c-} \\
u_{b}=U_{d c+}
\end{array}\right.
$$

Voltages are assumed to be constant for steady state operation unless rectifier is at constant $\alpha$ (firing angle) mode and inverter is at constant $\gamma$ (extinction angle) mode. However, pre-fault condition at fault location is given by:

$$
\left\{\begin{array}{c}
u_{a 1}=\sqrt{2} U_{d c-} \\
u_{b 1}=\sqrt{2} U_{d c+} \\
u_{a 0}=0 \\
u_{b 0}=0
\end{array}\right.
$$

When a fault occurs in a dc grid, fault network is converted into symmetrical two-phase system according to the superposition theorem as shown in Figure 9.

$$
\left\{\begin{array}{c}
\sqrt{2} u_{d c-}-i_{f a 1} Z_{1 \Sigma}=u_{f a 1} \\
0-i_{f a 0} Z_{0 \Sigma}=u_{f a 0}
\end{array}\right.
$$


where $Z_{0 \Sigma}$ and $Z_{1 \Sigma}$ are zero and positive sequence Thevenin's impedance at the fault point. Faults are classified as pole to ground fault, pole to pole fault, and double pole to ground fault in HVdc systems. These fault scenarios are analyzed based on zero and positive sequence components of TWs.

\subsubsection{Pre-Pole to Ground Fault}

Instantaneous boundary conditions for grounding resistance $R_{g}$ as shown in Figure 11, is given by:

$$
i_{f a}=0 u_{f a}=i_{f a} R_{g}
$$

and its sequence components are:

$$
\left\{\begin{array}{c}
i_{f a 0}-i_{f a 1}=0 \\
u_{f a 0}+u_{f a 1}=\left(i_{f a 0}+i_{f a 1}\right) R_{g}
\end{array}\right.
$$

where voltage sequence components are:

$$
\left\{\begin{array}{c}
u_{f a 0}=\frac{\sqrt{2} u_{d c} Z_{0 \Sigma}}{Z_{1 \Sigma}+Z_{0 \Sigma}+2 R_{g}} \\
u_{f a 1}=\frac{\sqrt{2} U_{d c}\left(Z_{1 \Sigma}+2 R_{g}\right)}{Z_{1 \Sigma}+Z_{0 \Sigma}+2 R_{g}}
\end{array}\right.
$$

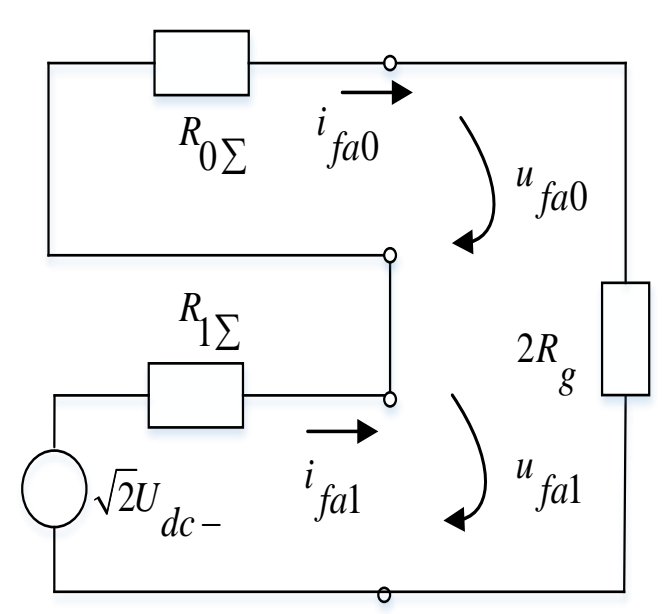

Figure 11. Sequence network connections for pole to ground fault.

\subsubsection{Pre-Double Pole to Ground Fault}

Let us consider the grounding resistances $R_{g a}$ and $R_{g b}$ for pole $a$ to ground and pole $b$ to ground, respectively. Figure 12 shows circuit for pole $a$ to ground and its respective instantaneous boundary conditions are:

$$
u_{f a}=i_{f a} R_{g a} u_{f b}=i_{f b} R_{g b}
$$

and sequence components are:

$$
\left\{\begin{array}{c}
u_{f a 0}+u_{f a 1}=\left(i_{f a 0}+i_{f a 1}\right) R_{g a} \\
u_{f a 0}+u_{f a 1}=\left(i_{f a 0}-i_{f a 1}\right) R_{g b}
\end{array}\right.
$$




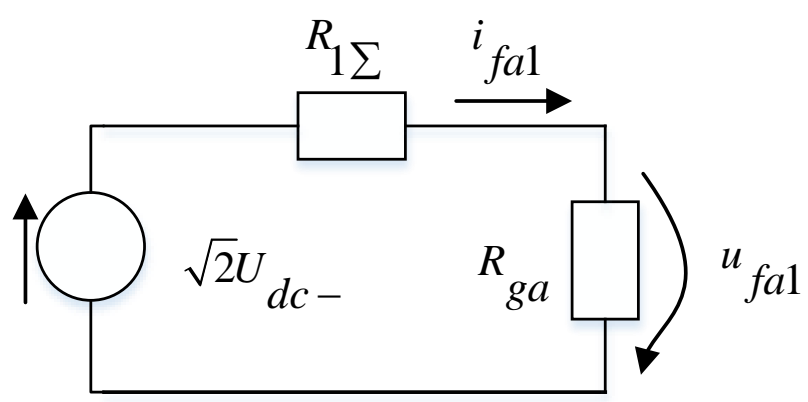

Figure 12. Sequence network connections for pole-pole to ground fault.

Similarly, one can write for pole $b$ to ground. However, if $R_{g a} \neq R_{g b}$, then:

$$
\left\{\begin{array}{c}
u_{f a 0}=\frac{\sqrt{2} U_{d c+}\left(R_{g b}-R_{g a}\right) Z_{0 \Sigma}}{Z_{\Sigma}} \\
u_{f a 1}=\frac{\sqrt{2} U_{d c-}\left[\left(R_{g a}+R_{g b}\right) Z_{0 \Sigma}+2 R_{g a} R_{g b}\right.}{Z_{\Sigma}}
\end{array}\right.
$$

where

$$
Z_{\Sigma}=2\left(R_{g a} R_{g b}+Z_{0 \Sigma} Z_{1 \Sigma}\right)+\left(R_{g a}+R_{g b}\right)\left(Z_{1 \Sigma}+Z_{0 \Sigma}\right)
$$

8.1.3. Pre-Pole to Pole Fault

Suppose that the fault resistance is $R_{g a}$ as shown in Figure 13 and boundary conditions are:

$$
\left\{\begin{array}{c}
i_{f a}=-i_{f b} \\
u_{f a}-u_{f b}=i_{f a} R_{g}
\end{array}\right.
$$

Instantaneous current sequenced components are:

$$
\left\{\begin{array}{c}
i_{f a 0}=0 \\
2 u_{f a 1}=i_{f a 1} R_{g}
\end{array}\right.
$$

and voltage sequence components are:

$$
\left\{\begin{array}{c}
u_{f a 0}=0 \\
u_{f a 1}=\frac{\sqrt{2} U_{d c-} R_{g}}{R_{g}+2 Z_{1 \Sigma}}
\end{array}\right.
$$

Post fault traveling waves are analyzed for the detection and classification of accurate characteristics of the dc fault. Zero and positive sequence components of TWs are observed at post fault state in MT-HVdc systems.

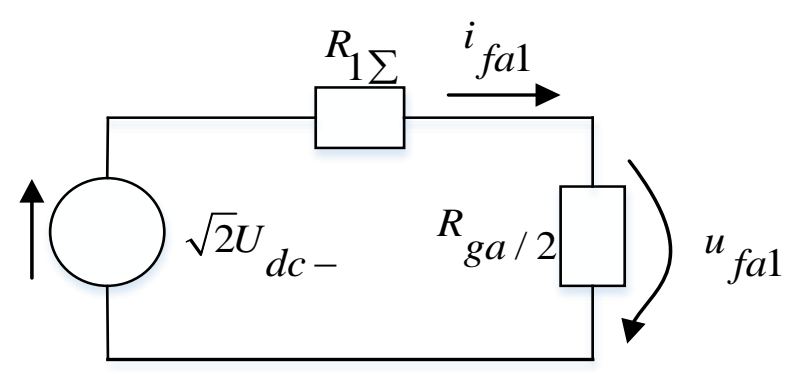

Figure 13. Sequence network connection for pole-pole fault. 


\subsection{Post Fault Traveling Waves}

Traveling waves travel towards the both ends of TL from fault point. Superposition of transient sequence components and pre-fault steady state conditions are used to analyze the behavior of the fault:

\subsubsection{Post Pole to Ground Fault}

Pre and post fault voltage values of zero and positive sequence components of pole to ground faults are observed. Difference between pre and post fault voltage values are evaluated to determine the effect of grounding resistance on fault.

$$
\left\{\begin{array}{c}
\Delta u_{f a 0}=u_{f a 0}=\frac{\sqrt{2} u_{d c} Z_{0 \Sigma}}{Z_{1 \Sigma}+Z_{0 \Sigma}+2 R_{g}} \\
\Delta u_{f a 1}=u_{f a 1}-u_{a 1}=\frac{\sqrt{2} U_{d c} Z_{1 \Sigma}}{Z_{1 \Sigma}+Z_{0 \Sigma}+2 R_{g}}
\end{array}\right.
$$

and

$$
\frac{\Delta u_{f a 0}}{\Delta u_{f a 1}}=\frac{Z_{0 \Sigma}}{Z_{1 \Sigma}}
$$

where $Z_{0 \Sigma}=Z_{s}+Z_{m}, Z_{1 \Sigma}=Z_{s}-Z_{m} . Z_{s}$ and $Z_{m}$ are the self-inductance and mutual inductance, respectively, of the dc-link and;

$$
\begin{gathered}
Z_{0 \Sigma}>Z_{1 \Sigma} \\
\frac{\Delta u_{f a 0}}{\Delta u_{f a 1}}>1
\end{gathered}
$$

Hence, it is concluded that single pole to ground fault analysis is independent of grounding resistance.

\subsubsection{Post Double Pole to Ground Fault}

Positive and zero sequence components of voltage are observed before and after the faults. Difference between sequence components are used to find out the impact of fault resistance on system under fault condition.

$$
\left\{\begin{array}{c}
\Delta u_{f a 0}=u_{f a 0}=\frac{\sqrt{2} u_{d c+}\left(R_{g b}-R_{g a}\right) Z_{0 \Sigma}}{Z_{\Sigma}} \\
\Delta u_{f a 1}=u_{f a 1}-u_{a 1}=\frac{\sqrt{2} u_{d c-}\left[\left(R_{g a}+R_{g b}+2 Z_{0 \Sigma}\right) Z_{1 \Sigma}\right.}{Z_{\Sigma}}
\end{array}\right.
$$

and

$$
\frac{\Delta u_{f a 0}}{\Delta u_{f a 1}}<\frac{Z_{0 \Sigma}}{Z_{1 \Sigma}}
$$

\subsubsection{Post Pole to Pole Fault}

In pole to pole fault, sequence components are observed before and after faults to examine the change in voltage values. This change is used to evaluate the behavior of fault resistance under fault conditions. This study is used to determine the variations of traveling waves.

$$
\left\{\begin{array}{c}
\Delta u_{f a 0}=u_{f a 0}=0 \\
\Delta u_{f a 1}=u_{f a 1}-u_{a 1}=\frac{2 \sqrt{2} U_{d c+} Z_{1 \Sigma}}{R_{g}+2 Z_{1 \Sigma}}
\end{array}\right.
$$

and

$$
\left\{\frac{\Delta u_{f a 0}}{\Delta u_{f a 1}}=0\right.
$$


From Equation (77), it is concluded that initial value of positive to zero sequence voltage for double pole is smaller than that of line to ground fault.

Maximum possible variations in the amplitude of voltage wave is observed at the instant of origination of first traveling wave due to fault. Therefore, it is essential to observe first travelling wave because maximum information of fault can be extracted from it.

\subsection{Obsevance of the First Traveling Wave}

First zero and positive sequence components of traveling waves are observed at converter station and are:

$$
\left\{\begin{array}{l}
b_{0}(t)=\Delta u_{0}-Z_{0 c} \Delta i_{0}=2 \Delta u_{f 0} e^{-\alpha_{0} t} \epsilon\left(t-\tau_{0}\right) \\
b_{1}(t)=\Delta u_{1}-Z_{1 c} \Delta i_{1}=2 \Delta u_{f 1} e^{-\alpha_{1} t} \epsilon\left(t-\tau_{1}\right)
\end{array}\right.
$$

and

$$
\frac{b_{0}}{b_{1}}=\frac{\Delta u_{f 0}}{\Delta u_{f 1}}=\frac{e^{-\alpha_{0} t} \epsilon\left(t-\tau_{0}\right)}{e^{-\alpha_{1} t} \epsilon\left(t-\tau_{1}\right)}
$$

where $\Delta u_{0}, \Delta u_{1}, \Delta i_{0}$, and $\Delta i_{1}$ are the superimposed zero and positive sequence voltage and currents at relay location. $Z_{0 c}$ and $Z_{1 c}$ are zero and positive sequence surge impedances. $\alpha_{0}$ and $\alpha_{1}$ are attenuated coefficients of zero and positive sequence and $\tau_{0}$ and $\tau_{1}$ are traveling times of TWs from fault to the VSCs. $\varepsilon(\mathrm{t})$ is a step input. When time period equals twice the traveling time of TW, $b_{0}$ and $b_{1}$ will remain constant at $2 \Delta u_{f 0}$ and $2 \Delta u_{f 1}$, respectively. It is clear from Equation (79) that ratio of positive and negative sequence waves not only depends on the initial values of the traveling waves but also depends on the attenuation and the velocity. The polarities of zero and positive sequence TWs for pole to ground fault are the same at faulty pole and are different at healthy pole, as expressed in Equations (70) and (78). It is obvious from the Equations (71), (75), (77), and (79) that the ratio of positive and zero sequence traveling waves is greater for single pole fault than double pole fault after the fault initiation. This is an important result in designing the identification of fault.

\subsection{Protection Scheme for High-Voltage Direct Current (HVdc) Transmission Line Using Symmetrical Components Method}

Ideally, relaying signal $x_{1}$ as shown in Figure 14, is zero under steady state conditions. When a dc fault occurs, fault current starts building up immediately. A data window is then achieved which must obey the criterion given in Equation (80) to select the first sample for integration:

$$
\left|x_{1}\right|>M_{1}
$$

where $M_{1}$ is preset data window of fault current signal. Smoothing reactors or in some cases harmonic filters or surge capacitors, are present in HVdc systems and are connected pole to ground. Current cannot change abruptly because of smoothing reactors and dc filters. This results in the decaying of traveling waves. Gradient of traveling wave is lower for external fault than for internal faults [91]. Thus, criterion for internal fault detection is described as:

$$
\left|\Delta x_{1}\right|>M_{2}
$$

where $M_{2}$ is minimum value of gradient required for internal fault detection. The ratio of positive to zero sequence components is greater for single pole fault than double pole fault for a small moment of time after fault initiation. Because of short duration, it is difficult to detect the type of fault in a classical way. Therefore, integration of sub-durations of the short duration of time is done to set up a criterion for detection of fault type and to classify faulty pole [92].

$$
k=\frac{\int_{\tau_{0}}^{\tau+\tau_{0}}\left|x_{0}\right|}{\int_{\tau_{1}}^{\tau+\tau_{1}}\left|x_{1}\right|}
$$


where $\tau_{1}$ is the time of protection startup and $\tau$ is the data window of fault which is chosen to be nearly equal to $1 \mathrm{~ms} . \tau_{0}$ is the arrival time of the first zero sequence traveling wave and the criterion for detection of zero sequence traveling wave is given by:

$$
\left|x_{0}\right|>M_{0}
$$

and from Figure 15, if $k>k_{0}$, fault is single pole to ground, otherwise it would be double pole fault. Faulty pole can be detected by viewing the polarity of positive and zero sequence backward traveling waves. If polarity is same in case of single pole to ground fault then it is faulty pole and if the polarity is different, then it is healthy pole.

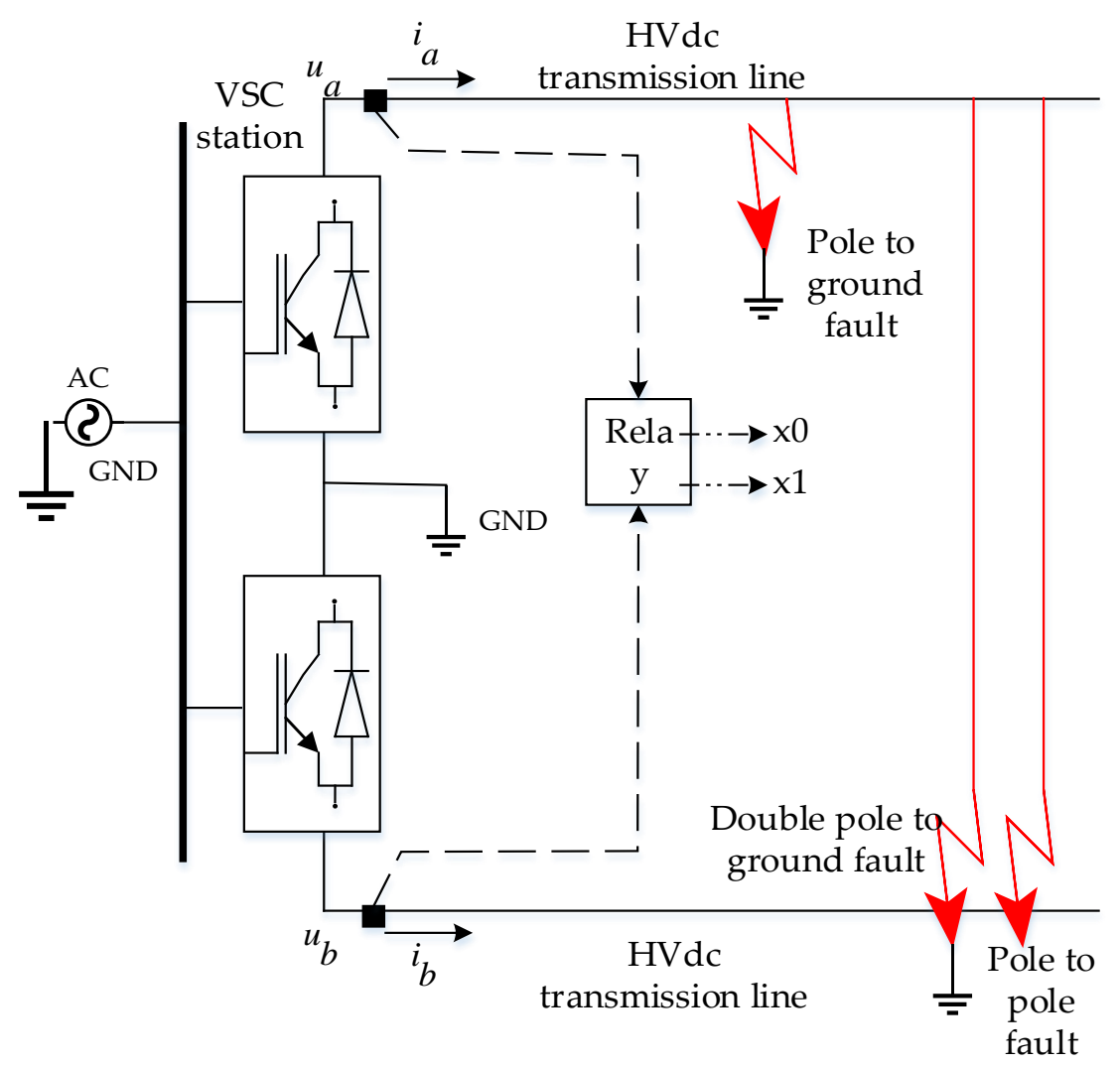

Figure 14. Protective relaying signal for high-voltage direct current (HVdc) link under faulty conditions. 


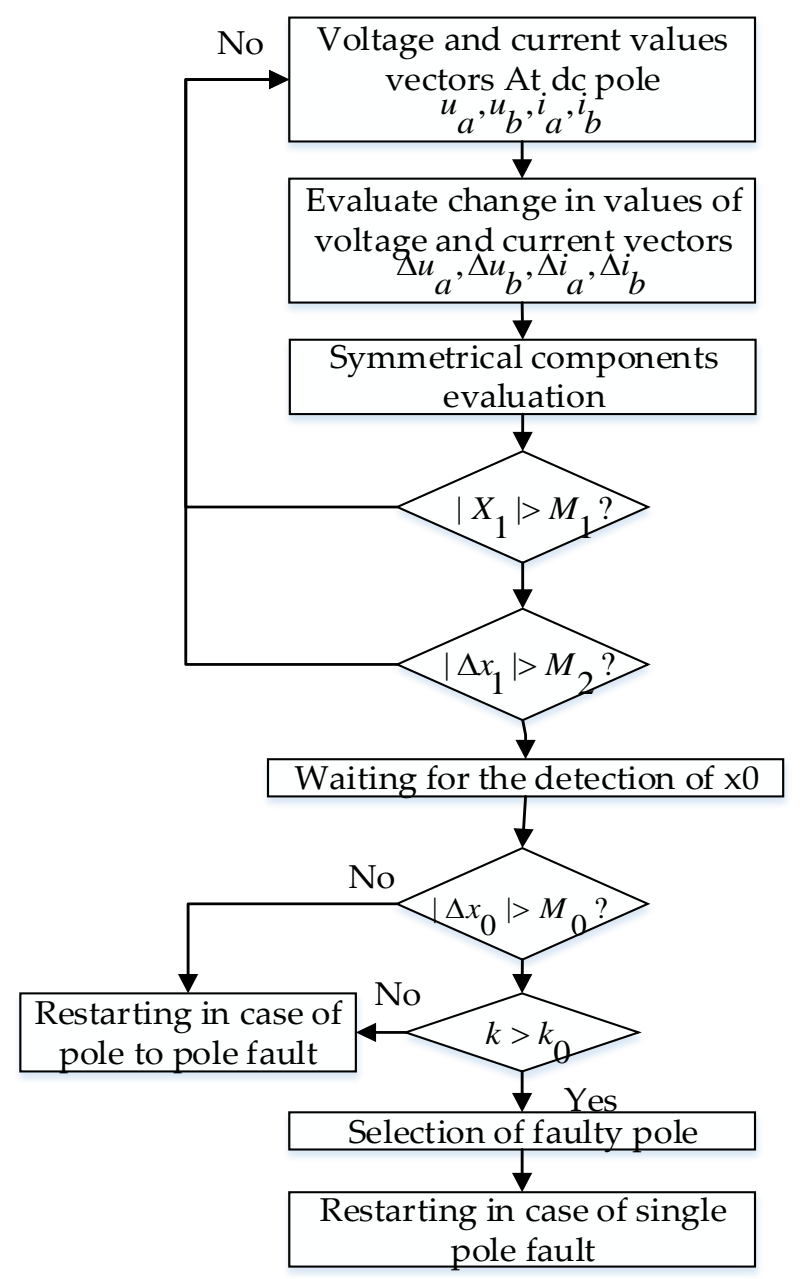

Figure 15. Protection scheme for bipolar high-voltage direct current (HVdc) transmission system.

\section{Morphological Gradient Based Fault Estimation in Multi-Terminal High-Voltage Direct Current (MT-HVdc) Systems}

Mathematical morphology is a promising approach to highlight the features of the wavefronts involved in the estimation of fault location and classification. Mathematical morphology involves little computational efforts and smaller data windows compared to wavelet transform [93-96].

Spatial structures analyzed with theoretical and technical knowledge of mathematical morphology [83]. It is based on set theory, integral geometry, and lattice algebra. It is a non-linear technique in contrast to linear Fourier and wavelet transforms. It deals with the waveforms in time domain rather than in the frequency or time frequency domain. Mathematical morphology is a highly effective tool for fault identification and classification because of its robustness features involved in the preservation of waveforms or shapes suppressed by noise [97,98].

Appropriate structure of a set is extracted from the main function of mathematical morphological operators. Interaction between the set and another set, known as structuring element (SE), is used for extraction. An a-priori knowledge about the shape of signal is employed to predefine the shape of structuring element. A pair of dual transformation is formed based on dilation and erosion [96].

Arithmetical difference between dilation and erosion of a signal of structuring element is known as morphological gradient (MG). It is an effective technique for edge detection. So, it can be employed to extract features of transient behavior (composed of sharp peaks and valleys) of MT-HVdc system under faulty conditions $[98,99]$. 
Suppose that signal and structuring element are denoted by $x$ and $y$, respectively. Length of structuring element is assumed to be considerably shorter than the length of signal. Dilation, erosion and morphological gradient are defined as, respectively:

$$
\begin{gathered}
f \oplus g=\max _{s}\left\{f(x+s)+g(s) \mid(x+s) \in D_{f}, s \in D_{g}\right\} \\
f \ominus g=\max _{s}\left\{f(x+s)-g(s) \mid(x+s) \in D_{f}, s \in D_{g}\right\} \\
M G(f)=(f \oplus g)-(f \ominus g)
\end{gathered}
$$

where $\oplus$ is dilation operator and $\ominus$ is erosion operator. $f(n)$ is assumed as processing signal whose domain is $D_{f}=1,2, \ldots, M-1 . g(n)$ is assumed to be a one-dimensional structuring element whose domain is $D_{g}=1,2, \ldots, M-1 . M G(f)$ is morphological gradient of signal $f(n)$.

In case of fault in any line of MT-HVdc system, travelling waves are generated which start propagating towards the converter stations in both directions where fault sensing equipment is deployed. Voltage and current at converter stations are the summation of backward and forward travelling waves $[97,100]$. In a lossless transmission line, voltage and current values are:

$$
\begin{gathered}
u(x, t)=f_{1}\left(t-\frac{x}{v}\right)+f_{2}\left(t+\frac{x}{v}\right) \\
i(x, t)=\frac{1}{z}\left[f_{1}\left(t-\frac{x}{v}\right)+f_{2}\left(t+\frac{x}{v}\right)\right]
\end{gathered}
$$

where $z=\sqrt{\frac{L}{C}}$ and $v=1 / \sqrt{L C} . f_{1}$ and $f_{2}$ are forward and backward projected travelling waves respectively. $x$ is the distance from the fault location. $z$ is the characteristics impedance of transmission line and $v$ is the propagation velocity. $f_{1}$ and $f_{2}$ are evaluated by the values of voltage and current at starting instant of fault. Values of voltage and current at the instant of initiation of fault are dependent on fault location, fault resistance and other line parameters. Traveling waves are partly transmitted and reflected back towards the fault point until they are attenuated to a negligible value.

\subsection{Multi-Terminal High-Voltage Direct Current (MT-HVdc) Test System}

When a dc fault $F$ occurs on transmission line $L_{1}$ connected to converter station, traveling wave of voltage at fault instant starts propagating towards the series inductor deployed at both ends of transmission line. At the converter station, traveling waves are reflected back and transmitted to other transmission lines connected to this converter station. Therefore, ratio of transmitted wave at line side of series inductor of a normal line to transmitted wave at line side of series inductor of faulted line helps to determine the faulted line in MT-HVdc transmission system. For this, equivalent impedance $z_{t}$ of lines connected to converter station with the exclusion of line $L_{1}$ is given by:

$$
z_{t}=\left(s L_{2}+z_{2}\right)\|\ldots\|\left(s L_{n}+z_{n}\right) \| z_{\text {conv }}
$$

where $z_{c o n v}=R_{c o n v}+s L_{c o n v}+\frac{1}{s C_{c o n v}}$ and $R_{c o n v}, L_{c o n v}$ and $C_{c o n v}$ are the equivalent resistance, inductance and capacitance of converter, respectively. $s$ is the Laplace operator. Capacitive discharge stage of MT-HVdc system during dc faults is modelled by RLC circuit. Converter topology helps to determine the parameters of this circuit.

Figure 16 shows the network of $n$ HVdc transmission lines connected to MT-HVdc converter station. $z_{k}$ and $L_{k}$ represent characteristics impedance and series inductor of $k$ transmission lines. $F$ is dc fault on line $L_{1} \cdot u_{i k}, u_{r k}$, and $u_{t k}$ denote incident, reflected, and transmitted traveling waves of voltage, respectively, at the converter station connected to $k$ lines. The ratios of transmitted traveling 
waves of voltage and transmitted traveling wave of current to incident traveling waves of voltage at $L_{1}$ are given by:

$$
\begin{aligned}
\frac{u_{t 1}}{u_{i 1}} & =\frac{2\left(s L_{1}+z_{t}\right)}{s L_{1}+z_{t}+z_{1}} \\
\frac{i_{t 1}}{u_{i 1}} & =\frac{2}{s L_{1}+z_{t}+z_{1}}
\end{aligned}
$$

The ratio of transmitted traveling waves of voltage to $k$ lines and incident traveling waves of voltage at $L_{1}$ is:

$$
\frac{u_{t k}}{u_{i 1}}=\frac{2}{s L_{1}+z_{t}+z_{1}} \times z_{t} \times \frac{z_{k}}{s L_{k}+z_{k}}
$$

The ratio of transmitted traveling waves of voltage to $k$ lines to transmitted traveling waves of voltage at line $L_{1}$ is represented by $k_{t k t 1}$ and given by:

$$
k_{t k t 1}=\frac{u_{t k}}{u_{t 1}}=\frac{z_{t} z_{k}}{\left(s L_{1}+z_{t}\right)\left(s L_{k}+z_{k}\right)}
$$

By considering the basic values of characteristics impedance and series inductor, the ratio $k_{t k t 1}$ works as a low pass filter. This low pass filter is used to attenuate high frequencies. Figure 17 shows the behavior of $k_{t k t 1}$. It is observed that traveling waves originated due to fault contain higher frequency components as compared to traveling waves transmitted on normal lines. Therefore, faulted line is identified with the help of this characteristic behavior and MG. Proposed flow chart of MG algorithm is shown in Figure 18.

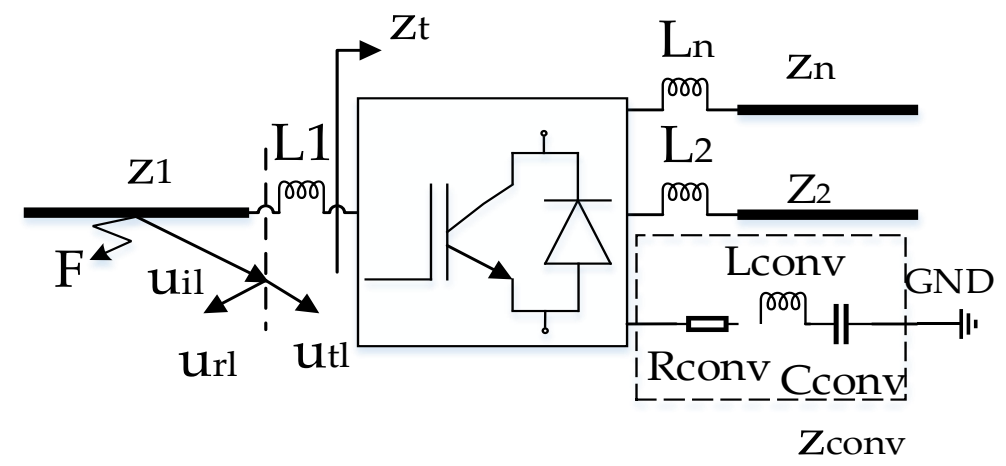

Figure 16. Multi-terminal high-voltage direct current (MT-HVdc) converter station under fault condition.

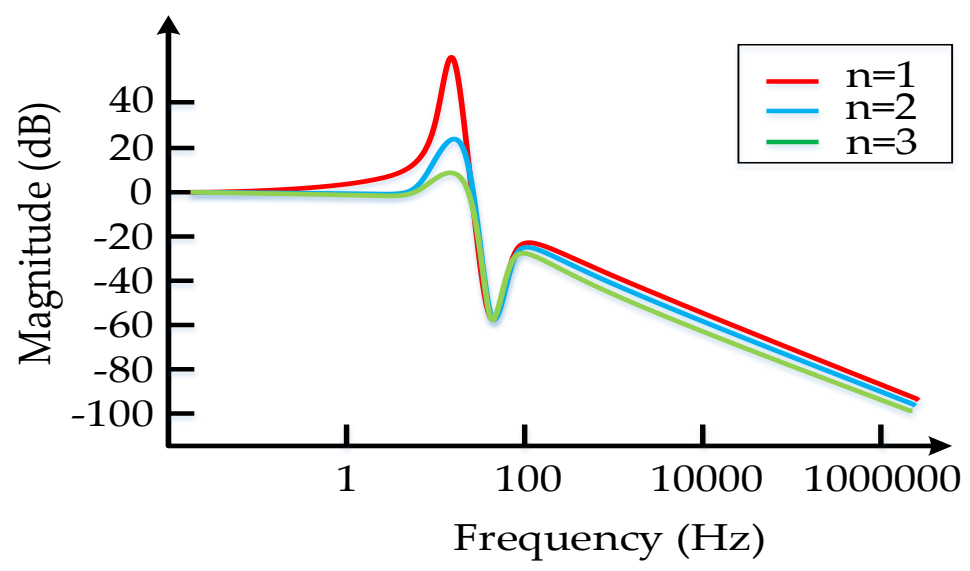

Figure 17. Characteristics curve of ratio of transmitted traveling wave to k non faulted high-voltage direct current $(\mathrm{HVdc})$ lines and transmitted traveling wave to faulted $\mathrm{HVdc}$ line. 


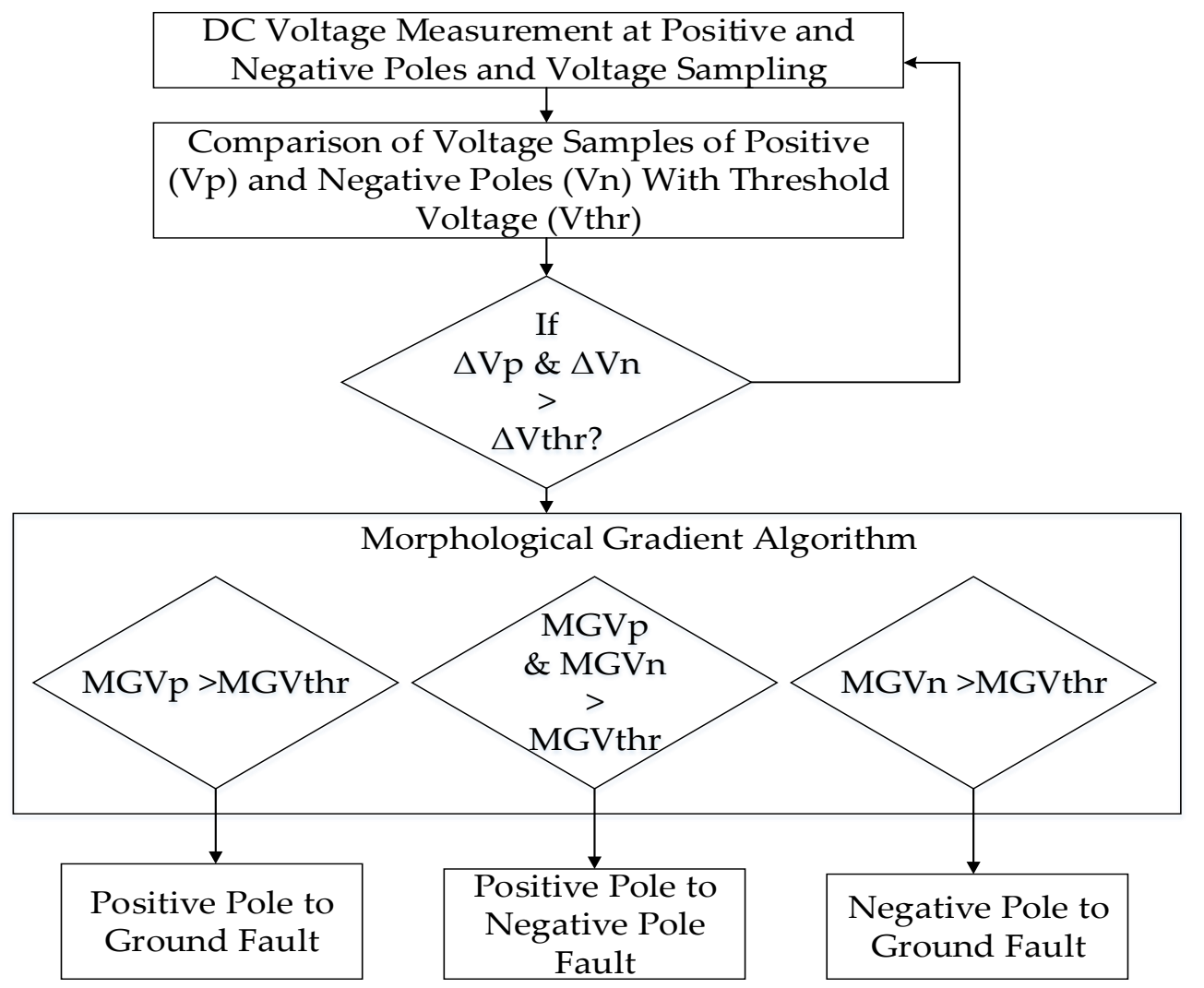

Figure 18. Proposed flow chart of Morphological gradient algorithm for fault classification in multi-terminal high-voltage direct current (MT-HVdc) transmission system.

\subsection{Discrimination between Different Cases of Direct Current (DC) Fault Current Rise}

Maximum fault resistance is characterized by minimum rate of change of current values, minimum voltage values and lowest peak values of MGV in the case of an internal fault. Morphological gradient voltage (MGV) value is an arithmetic difference of dilation and erosion of a signal obtained from the interaction of voltage sample and threshold value. Table 1 presents cases of rise of dc fault current in terms of MGV values.

Table 1. Cases of rise of dc fault current in terms of morphological gradient voltage (MGV) values.

\begin{tabular}{ccl}
\hline Serial Number & Fault Type & Discrimination/Classification of Fault \\
\hline 1 & $\begin{array}{c}\text { Internal fault } \\
\text { and external fault }\end{array}$ & $\begin{array}{l}\text { Maximum value of peaks of MGV in } \\
\text { external fault is smaller than minimum } \\
\text { value of peaks of MGV in internal fault }\end{array}$ \\
\hline 2 & $\begin{array}{c}\text { Positive pole to ground fault and } \\
\text { Negative pole to ground fault }\end{array}$ & $\begin{array}{l}\text { MGV values are similar because of } \\
\text { symmetrical nature }\end{array}$ \\
\hline 3 & Healthy Pole and Faulted Pole & $\begin{array}{l}\text { Rise in MGV values is more noticeable } \\
\text { at faulted pole }\end{array}$ \\
\hline 4 & Opening of dc circuit breaker and \\
internal fault & $\begin{array}{l}\text { MGV values in opening of dc circuit } \\
\text { breakers are smaller than minimum } \\
\text { peaks values in internal fault }\end{array}$ \\
\hline
\end{tabular}

Reliability of protection algorithm is, therefore, dependent on correct evaluation of margin between minimum MGV peak value for internal fault and maximum MGV peak value for external fault. This nullifies inevitable measurement errors and probable signal distortion. 


\subsection{Noise Reduction Filter}

Robustness and accuracy of MMG are affected by the presence of noise in the signal. Therefore, noise reduction filters (NRF) should be incorporated into MMG technique to address robustness and accuracy [101].

MMG term $\rho_{g}^{a}$ is employed in power system protection of MT-HVdc system to identify the arrival time of wave head of traveling wave generated at sensing terminal of converter station. MMG is basically an advancement in MG. It employs a series of scalable flat SEs with inverter origins $g^{+}$and $g^{-}$for each level of decomposition a as shown in following equations:

$$
\begin{gathered}
p_{g^{+}}^{a}=\left(\rho^{a-1} \oplus g^{+}\right)(x)-\left(\rho^{a-1} \ominus g^{+}\right)(x) \\
p_{g^{-}}^{a}=\left(\rho^{a-1} \ominus g^{-}\right)(x)-\left(\rho^{a-1} \oplus g^{-}\right)(x) \\
\rho_{g}^{a}=p_{g^{+}}^{a}+p_{g^{-}}^{a}
\end{gathered}
$$

The SEs $g^{+}$and $g^{-}$are defined as:

$$
\begin{aligned}
& g^{+}=\left[g_{1}, g_{2}, \ldots, g_{l-1}, g_{l}\right] \\
& g^{-}=\left[g_{l}, g_{l-1}, \ldots, g_{2}, g_{1}\right]
\end{aligned}
$$

where $g_{l}$ is the origin of the SE with length $l=2^{l-a} l_{g} . l_{g}$ is the length of SE of first decomposition level. When $a=1, \rho^{o}=f$.

Noise reduction filters (NRFs) are Morphological Median Filter [94-96], Multi resolution Morphological Opening-Closing Filter [96,102], Opening-Closing/Closing-Opening [103] and Opening_Closing maximal/Closing_Opening minimal [103]. In NRFs, signals are countered between upper and lower edge and average between them is evaluated. Flat line SE is employed to maintain the feature of original signal. Moreover, length of SE is calculated for each level of NRF as given by:

$$
l=\lambda^{1-b} l_{1}
$$

where $\lambda$ is the dilating factor, $\mathrm{b}$ is the level filter and $l_{1}$ is the length of $\mathrm{g}$ at level 1 . For $b=1, g^{0}$ is the SE with length $l_{1}$ and $f^{1}$ is the initial signal. In the level 1 , the initial signal is filtered by an NRF with SE length $l_{1}$. In the next level, $b$ is updated with $b=b+1$. Filtered signal is employed as an input of NRF. SE length used for filtering is updated by Equation (99). This process is repeated with the intention of requirement of level of filtration.

\subsection{Morphological Median Filter (MMF)}

MMF represented by $\mu$, is basically a mean value of dilated and eroded signal as described below when $b=1, \mu^{o}=f$ :

$$
\mu^{b}=\frac{\left(\mu^{b-1} \oplus g^{b}\right)(x)+\left(\mu^{b-1} \ominus g^{b}\right)(x)}{2}
$$

\subsubsection{Multi Resolution Morphological Opening Closing Filter (MMOCF)}

MMOCF represented by $\theta$ is the mean value of opening and closing filters as given below when $b=1, \theta^{o}=f$.

$$
\theta^{b}=\frac{\left(\theta^{b-1} \circ g^{b}\right)(x)+\left(\theta^{b-1} \cdot g^{b}\right)(x)}{2}
$$




\subsubsection{Opening-Closing/Closing-Opening (OCCU)}

OCCU represented by $\chi$ is a combination of opening—closing (OC) and closing—opening (CO) filters. Positive and negative impulse noises are filtered out simultaneously and given as when $b=1, O C^{o}=f, C O^{o}=f:$

$$
\begin{gathered}
O C^{b}=\left(\left(O C^{b-1} \circ g^{b}\right) \cdot g^{b}\right)(x) \\
C O^{b}=\left(\left(C O^{b-1} \cdot g^{b}\right) \circ g^{b}\right)(x) \\
\chi=\frac{O C^{b}+C O^{b}}{2}
\end{gathered}
$$

\subsubsection{Maximal Opening—Closing/Minimal Closing—Opening}

Maximal Opening Closing/minimal Closing Opening filter represented by $\Lambda$ is obtained by parallel combination of opening-closing and closing—opening filters [101-103]. OC filter is calculated at different SEs and maximal value is given by:

$$
O C_{\max }=\max \left(O C_{S E_{1}}, O C_{S E_{2}}, \ldots, O C_{S E_{b}}\right)
$$

9.4.4. Closing-Opening Minimal

Minimum value is obtained among filters to calculate $\mathrm{CO}_{\min }$ given by:

$$
C O_{\min }=\min \left(C O_{S E_{1}}, C O, \ldots, C O_{S E_{b}}\right)
$$

$O C_{\max } C O_{\min }$ filter $(\Lambda)$ is the mean between $O C_{\max }$ and $C O_{\min }$.

$$
\Lambda=\frac{O C_{\max }+C O_{\min }}{2}
$$

Figure 19 explains the flow process of $O C_{\max }-\mathrm{CO}_{\min }$ filter. 


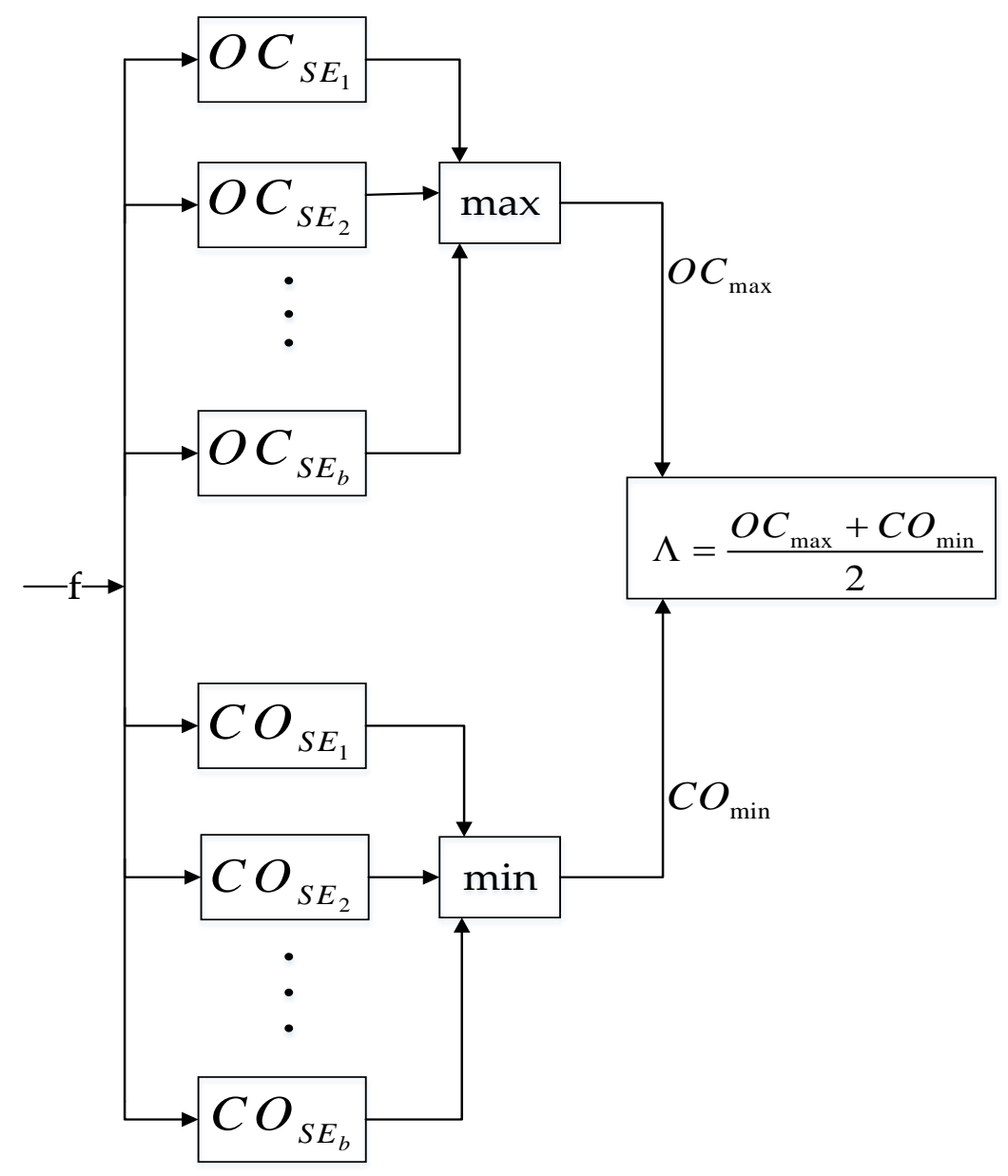

Figure 19. Process flow of opening closing (OC) max-closing opening (CO) min filter.

\section{Shortcomings of Traveling Waves (TW) Based Methods}

As discussed, detection of the wavefront is the key to finding the location of fault. However, if the wave front does not exist at instant of $\mathrm{dc}$ fault occurrence, fault detection and identification is not possible. For instance, in a high resistive grounded TL, magnitude of the transient TW is too small to detect the fault location. Similarly, in the event of variations in transition resistance; traveling transients are too small to be utilized for fault detection $[104,105]$.

In traveling wave method, arrival time of wavefront at the VSC station and speed of the wave front is used to calculate distance of fault from substation. Therefore, speed and time measurement is directly related to the accuracy of detection of fault location. These measurements are highly dependent on the electrical parameters of the faulted line. A very high sampling frequency is required for accurate finding of fault location as speed of the wavefront is almost equivalent to the speed of light. Interference signal is another parameter that badly effects the traveling wave. Thus, non-traveling-based fault detection, location and estimation methods are referred to overcome above aforementioned shortcomings [86,104-106].

\section{Non-traveling Wave (NTW) Based Fault Location Estimation in Multi-Terminal High-Voltage Direct Current (MT-HVdc) Systems}

In non-travelling wave-based technique, fault location is identified and detected by evaluating voltage and current values after dc fault in any section of the line. This method is based on distributed parameters of the transmission line model. Current and voltage measurements at both ends are calculated and voltage distribution over the TL is obtained. Fault is detected with the help of this voltage distribution but non-traveling-based techniques are slow [39]. Although TW techniques are 
rapid $[33,59,63,66,77,78]$ yet offer aforementioned shortcomings. Non-traveling wave-based method can be made rapid if fault location algorithm is based on time domain. Short window of the data is sufficient to achieve satisfactory accuracy and detection $[39,91,107]$. Data window for non-traveling wave-based method can be acquired precisely from distributed parameter model of dc transmission lines.

Non-traveling wave-based method is applied on bipolar HVdc transmission line systems. Schematic diagram of bipolar HVdc transmission line is shown in Figure 20 [39].

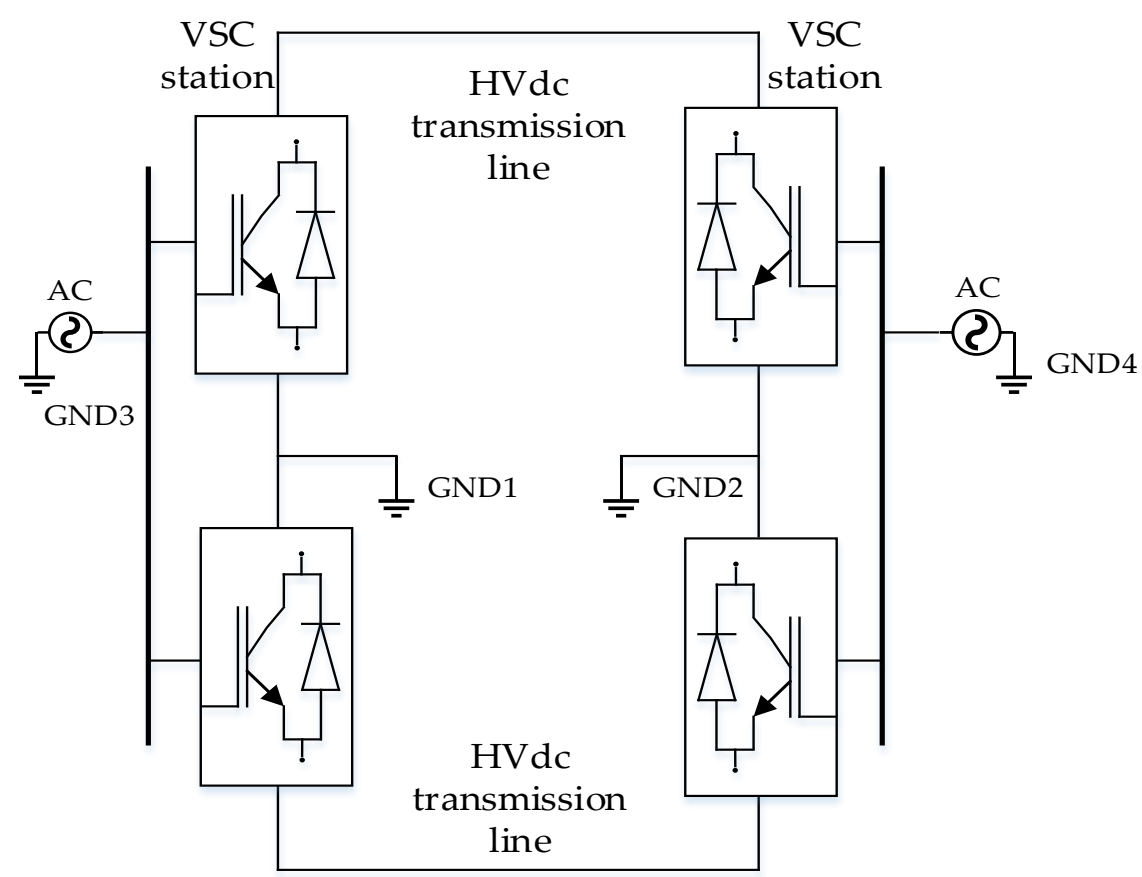

Figure 20. Bipolar high-voltage direct current (HVdc) transmission line model.

\subsection{Mode Extraction}

Mode Extraction is required for decoupling of HVdc lines as both positive and negative lines are insttalled on single transmission tower. Telegraph equations with mutual inductance effects are written as:

$$
\left\{\begin{array}{l}
\frac{\partial u}{\partial x}=-L \frac{\partial i}{\partial t}-R i \\
\frac{\partial i}{\partial x}=-C \frac{\partial u}{\partial t}-G i
\end{array}\right.
$$

where $u=\left[\begin{array}{l}u_{J p} \\ u_{J n}\end{array}\right], i=\left[\begin{array}{c}i_{J p} \\ i_{J n}\end{array}\right], L=\left[\begin{array}{cc}L_{s} & L_{m} \\ L_{m} & L_{s}\end{array}\right], R=\left[\begin{array}{cc}R_{s} & R_{m} \\ R_{m} & R_{s}\end{array}\right], C=\left[\begin{array}{cc}C_{s} & -C_{m} \\ -C_{m} & C_{s}\end{array}\right], C_{s}=C_{o}+C_{m}$, $G_{s}=G_{0}+G_{m}$.

$R_{s}$ and $R_{m}$ are self and mutual resistances of the line, respectively. $L_{s}$ and $L_{m}$ are self and mutual inductances of the line, respectively. $C_{o}$ and $C_{m}$ are pole to earth and pole to pole capacitances of the line, respectively. $G_{o}$ and $G_{m}$ are pole to earth and pole to pole conductances of the line, respectively. $u_{J p}$ and $u_{J n}$ are positive and negative poles voltage at terminal $J$, respectively. $i_{J p}$ and $i_{J n}$ are positive and negative pole currents at terminal $J$, respectively. By using decoupling matrix:

$$
\left\{\begin{array}{l}
\frac{\partial u_{m}}{\partial x}=-S^{-1} L S \frac{\partial i_{m}}{\partial t}-S^{-1} R S i_{m} \\
\frac{\partial i_{m}}{\partial x}=-S^{-1} C S \frac{\partial u_{m}}{\partial t}-S^{-1} G S u_{m}
\end{array}\right.
$$


where $u_{m}=S^{-1} \times u, i_{m}=S^{-1} \times i$,

$$
\begin{gathered}
S^{-1} R S=\left[\begin{array}{cc}
R_{S}-R_{m} & 0 \\
0 & R_{S}+R_{m}
\end{array}\right], S^{-1} L S=\left[\begin{array}{cc}
L_{S}-L_{m} & 0 \\
0 & L_{S}+L_{m}
\end{array}\right], \\
S^{-1} C S=\left[\begin{array}{cc}
C_{0}+2 C_{m} & 0 \\
0 & C_{0}
\end{array}\right], S^{-1} G S=\left[\begin{array}{cc}
G_{0}+2 G_{m} & 0 \\
0 & G_{0}
\end{array}\right]
\end{gathered}
$$

And $u_{m}=\left[\begin{array}{l}u_{1} \\ u_{0}\end{array}\right], i_{m}=\left[\begin{array}{l}i_{1} \\ i_{0}\end{array}\right], u_{1}$ and $i_{1}$ are 1-mode voltage and current while $u_{0}$ and $i_{0}$ are 0-mode voltage and current, respectively. Because of stability, 1-mode parameters are used for analysis and parameters of TL are derived as:

$$
\left\{\begin{array}{c}
R_{1}=R_{s}-R_{m} \\
L_{1}=L_{s}-L_{m} \\
C_{1}=C_{0}+2 C_{m} \\
G_{1}=G_{0}+2 G_{m}
\end{array}\right.
$$

And 0-mode parameters are derived as follow:

$$
\left\{\begin{array}{c}
R_{0}=R_{s}+R_{m} \\
L_{0}=L_{s}+L_{m} \\
C_{0}=C_{0} \\
G_{0}=G_{0}
\end{array}\right.
$$

Therefore, voltage values are required for mode extraction.

\subsection{Bergeron Transmission Line Model and Voltage Distribution}

When a fault occurs on a TL, current and voltage are measured at both ends of transmission line. Voltage at the fault point are matched with voltage distribution curves time to time. Voltage distribution curves are shown in Figure 21 [39,91,107,108]. Generalized voltage distribution curve equation of mode $i$ at time $t$ and at distance $x$ from terminal $J$ and $K$ is:

$$
\begin{aligned}
u_{i J}(x, t) & =\frac{1}{2}\left(\frac{Z_{c i}+\frac{r_{i} x}{4}}{Z_{c i}}\right)^{2} \times\left[u_{J i}\left(t+\frac{x}{v_{i}}\right)-i_{J i}\left(t+\frac{x}{v_{i}}\right) \times\left(Z_{c i}+\frac{r_{i} x}{4}\right)\right] \\
+ & \frac{1}{2}\left(\frac{Z_{c i}-\frac{r_{i} x}{4}}{Z_{c i}}\right)^{2} \times\left[u_{J i}\left(t-\frac{x}{v_{i}}\right)+i_{J i}\left(t-\frac{x}{v_{i}}\right) \times\left(Z_{c i}-\frac{r_{i} x}{4}\right)\right] \\
& -\left(\frac{\frac{r_{i} x}{4}}{Z_{c i}}\right)^{2} \times u_{J i}(t)-\frac{r_{i} x}{4} \times\left(\frac{Z_{c i}+\frac{r_{i} x}{4}}{Z_{c i}}\right)\left(\frac{Z_{c i}-\frac{r_{i} x}{4}}{Z_{c i}}\right) \times i_{J i}(t) \\
u_{i K}(x, t)= & \frac{1}{2}\left(\frac{Z_{c i}+\frac{r_{i} x}{4}}{Z_{c i}}\right)^{2} \times\left[u_{K i}\left(t+\frac{x}{v_{i}}\right)-i_{K i}\left(t+\frac{x}{v_{i}}\right) \times\left(Z_{c i}+\frac{r_{i} x}{4}\right)\right] \\
+ & \frac{1}{2}\left(\frac{Z_{c i}-\frac{r_{i} x}{4}}{Z_{c i}}\right)^{2} \times\left[u_{K i}\left(t-\frac{x}{v_{i}}\right)+i_{K i}\left(t-\frac{x}{v_{i}}\right) \times\left(Z_{c i}-\frac{r_{i} x}{4}\right)\right] \\
& -\left(\frac{r_{i} x}{4} Z_{c i}^{2} \times u_{K i}(t)-\frac{r_{i} x}{4} \times\left(\frac{Z_{c i}+\frac{r_{i} x}{4}}{Z_{c i}}\right)\left(\frac{Z_{c i}-\frac{r_{i} x}{4}}{Z_{c i}}\right) \times i_{K i}(t)\right.
\end{aligned}
$$

where $i=1$ or $i=0$ is the index of the mode, $r_{1}$ is resistance per kilometer, $Z_{c i}$ is characteristic impedance and $v_{i}$ is wave speed of $i$-mode, respectively. $i_{j i}(t)$ and $i_{K i}(t)$ are the $i$-mode currents at terminals J and $\mathrm{K}$ at time $\mathrm{t}$, respectively. $u_{J i}(t)$ and $u_{K i}(t)$ are the $i$ - mode voltages at terminals $J$ and $K$ at time $t$, respectively. $u_{J i}(x, t)$ and $u_{K i}(x, t)$ are the voltage distributions of $i$ - mode at time $t$ and at point $x$ from terminals $J$ and $K$, respectively. Hence, voltage values determined at the converter stations are employed for detection of fault location in MT-HVdc systems. 


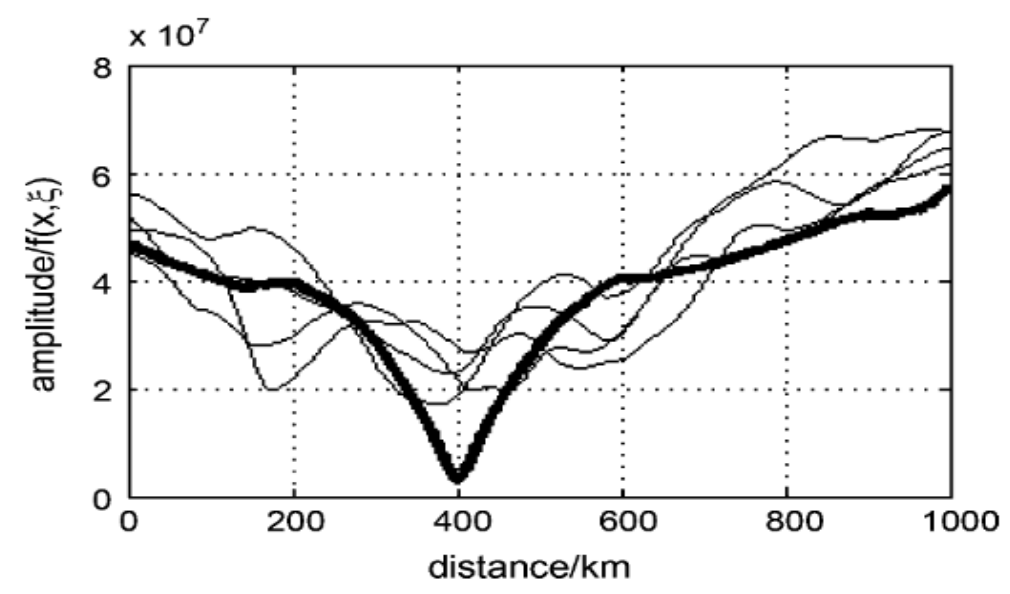

Figure 21. Voltage distribution curves at different fault locations.

\subsection{Fault Location Algorithm}

Because of the transition resistance, voltage distribution obtained from the evaluation of fault point and substation is held true only for the section existing between fault point and substation. Voltage distribution obtained for second end/terminal is held true only for the section between first end/terminal and faulted point. However, on healthy section of a line, it is not necessary that voltage distribution should be same $[39,91,107,108]$. Therefore, fault location criterion can be established as:

$$
\begin{gathered}
f(x)=\sum_{t=t_{1}}^{t_{2}}\left|u_{i J}(x, t)-u_{i K}(l-x, t)\right| \\
x \in[0,1]
\end{gathered}
$$

where $l$ is the total length of the line. $x$ is the distance/length from fault point $x$ to terminal $J$ and $\left(t_{2}-t_{1}\right)$ is the time of the redundant or no longer needed data window. In the case of fault, Equation (114) would be equal to zero and for no fault, it would be always greater than zero. For approximation, minima of the function $f(x)$ is calculated:

$$
f\left(x_{f}\right)=\min \{f(x): x \in(0,1)\}
$$

where $x_{f}$ is the distance between fault point and the substation. For redundancy, no longer or redundant data window is added to calculate the total length of data window as double propagation time is required to calculate the single voltage distribution curve over the entire line.

$$
t_{\omega}=\frac{2 x}{v}+\left(t_{2}-t_{1}\right)
$$

\section{Non-Traveling Wave (NTW) Method Based on Rate of Change of Voltage and Current}

When a dc fault occurs in MT-HVdc system, voltage and current undergo a decrease and an increase at a certain rate, respectively [109]. This change is basically a difference between voltage and current values measured at pre-fault and post-fault conditions of HVdc grid. This difference is then compared with the threshold or reference value to estimate the health of MT-HVdc system. If the voltage value is less than the reference value, fault is diagnosed in HVdc system via algorithm presented in Figure 22. In the similar fashion, if the current sample is greater than the reference value, fault is detected in the dc system as shown in Figure 23.

Criteria for fault location and detection is given by:

$$
\Delta V=\text { Vpost }- \text { Vpre }
$$




$$
\begin{gathered}
\Delta V \leq \text { Vref } \\
\Delta I=I_{\text {post }}-I_{\text {pre }} \\
\Delta I \leq I_{\text {ref }}
\end{gathered}
$$

Information about fault is processed with in milliseconds but is affected by the noise which raise questions over accuracy of detection [110]. Normally, it is used for primary protection [109]. In a bipolar topology of HVdc system, this method is applied on each pole as its stable under any kind of disturbances.

Rate of change of voltage and current methods depend upon the fault loop impedance. Therefore, in a fault where impedance is high or closer to terminals of converter station, this method does not provide satisfactory results because of minute rate of changes [110].

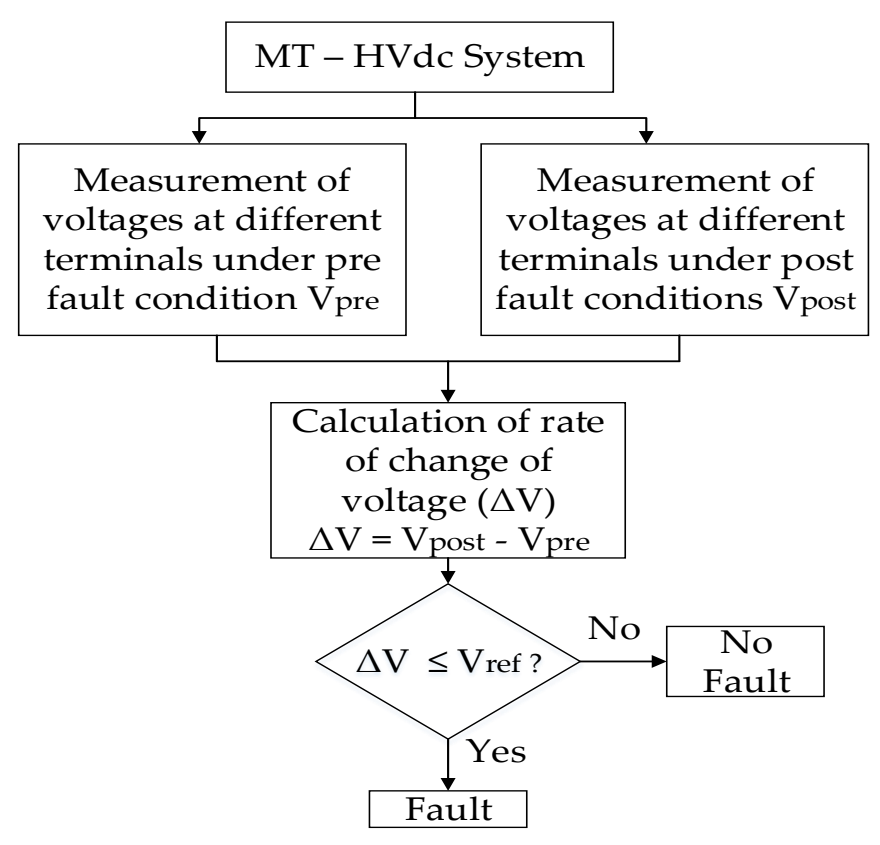

Figure 22. NTW method based on rate of change of voltage.

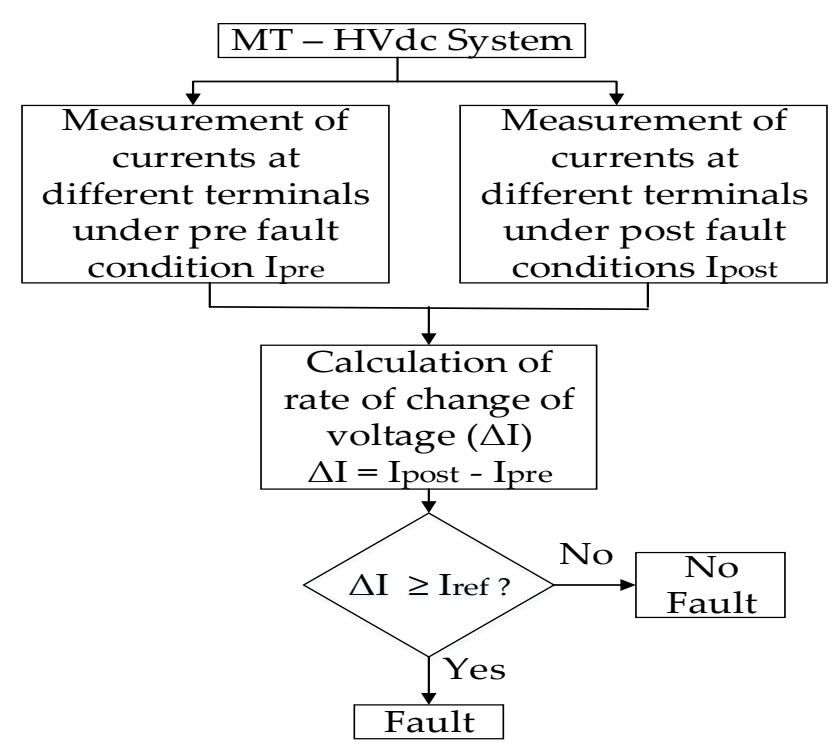

Figure 23. Non-traveling wave (NTW) method based on rate of change of current. 


\section{Non-Traveling Wave (NTW) Method Based on Voltage Levels}

This method is particularly applicable to high impedance faults or the faults closer to converter stations. In this method, decrease in the voltage is observed over a long interval of time. The algorithm is explained in Figure 24. Because of longer intervals of time, this method is referred for backup protection of non-traveling wave method based on rate of change of voltage or current. Selection of time delays and longer time intervals are made carefully in order to avoid operation of protection scheme during abnormal transients or load switching [110].

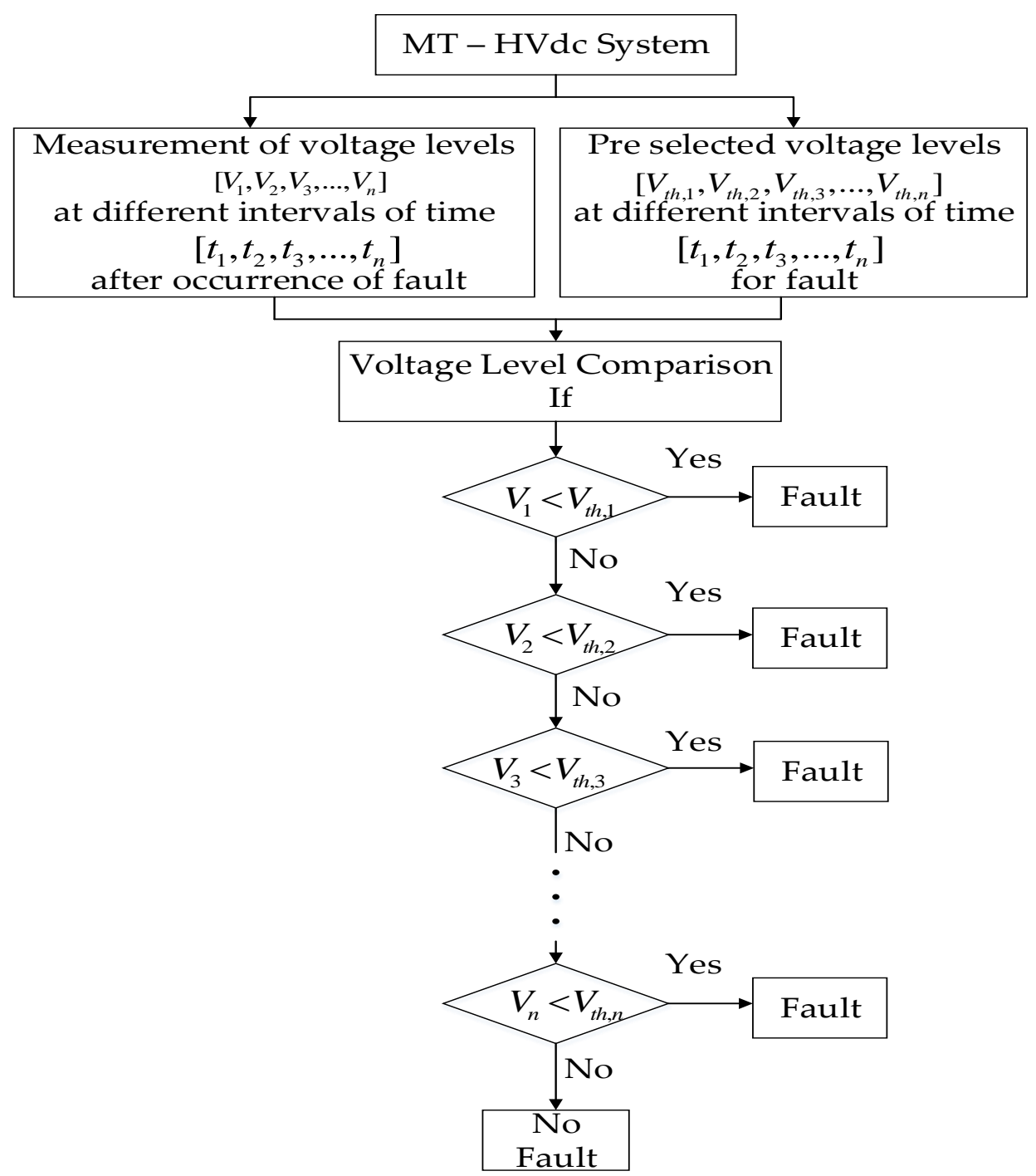

Figure 24. Non-traveling wave (NTW) method based on level of dc voltage detection.

In this method, setup for fault identification is made with multiple levels and deeper voltage depressions with shorter response time [110]. Otherwise, this method may fail with the failure of primary protection.

Accuracy of this method is not questioned because of non-engagement of telecom infrastructure and multiple voltage depression levels. Therefore, it is suitable for backup protections. 


\section{Non-Traveling Wave (NTW) Method Based on Under Voltage}

In the event of the dc fault, under voltages are observed [111,112] and if voltage drop below the threshold value, then fault is detected as shown in Figure 25. Tripping criterion is given as:

$$
V_{\text {postfault }}<V_{\text {threshold }}
$$

This method has a drawback that drop in the voltage is observed on all terminals associated with MT-HVdc link. Therefore, it is not possible to discriminate between the healthy and faulty part of the grid. Additional work is required to carry out proper discrimination and distinction [111,112].

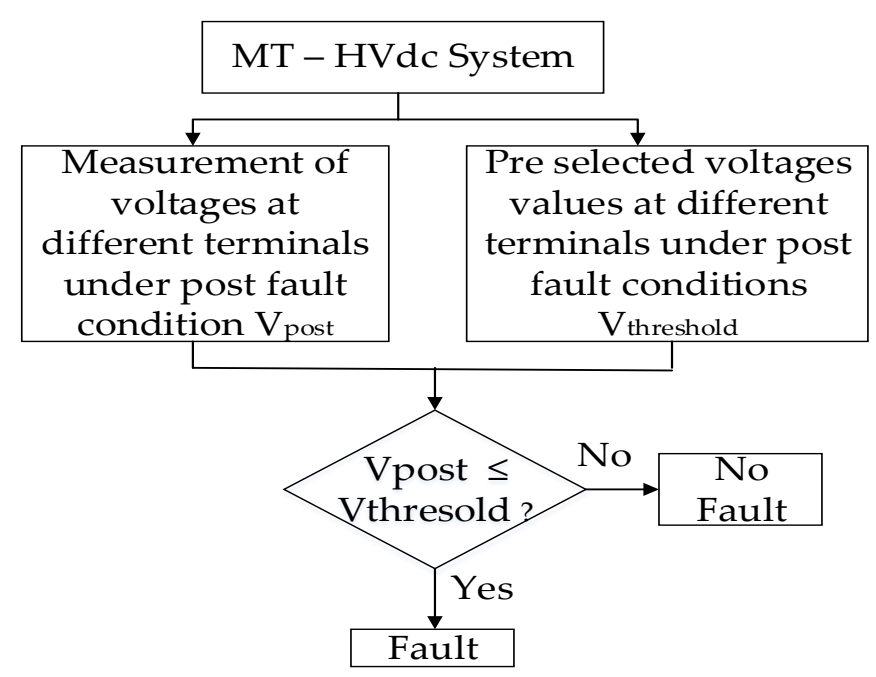

Figure 25. Non-traveling wave (NTW) method based on under voltage values.

\section{Non-Traveling Wave (NTW) Method Based on Over Current}

Over current protection is also being used for fault estimation in MT-HVdc systems [112,113]. In this technique, value of the current is measured and observed. If it is found that value of current is higher than the threshold, fault signal is generated to the HVdc breakers to interrupt the dc fault current, following the algorithm described in Figure 26.

$$
I_{\text {postfault }}>I_{\text {threshold }}
$$

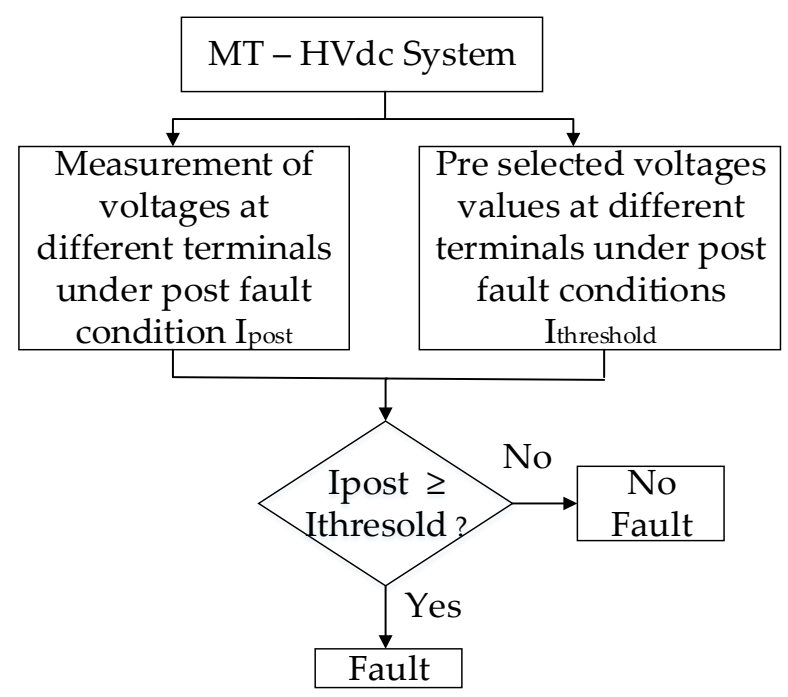

Figure 26. Non-traveling wave (NTW) method based on over current values. 
In order to attain proper discrimination and tripping, threshold value must be set high. This technique is relatively slower as threshold value is dependent on the speed of isolation of dc breaker. Therefore, it results in building of large fault currents which may damage the VSC stations and dc filters.

\section{Non-Traveling Wave (NTW) Method Based on Transient}

Measurement of transients at the VSC-HVdc stations is another promising approach for fault estimation. Transient is calculated in terms of rate of change of power. Therefore, both voltage and current values are observed at the converter stations before and after the occurrence of fault [98]. Rate of change of voltage and current are calculated to find out the change in power or transient magnitude. If this rate of change of power is less than the threshold or reference value set for transient, fault is identified via flow chart shown in Figure 27.

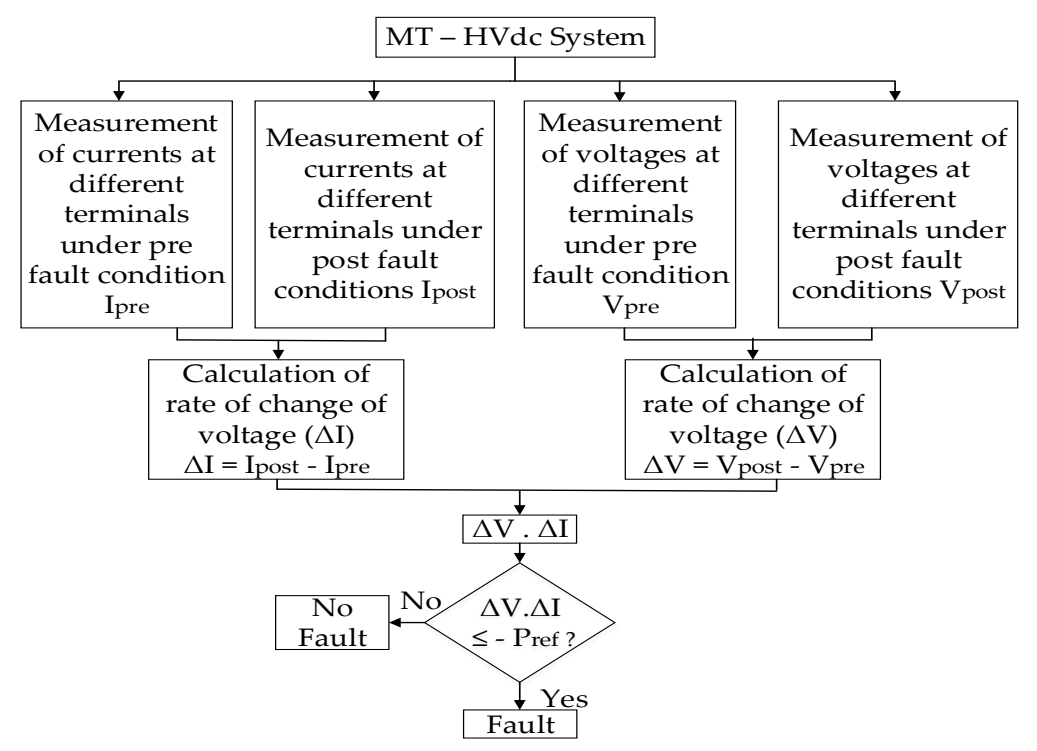

Figure 27. Non-traveling wave (NTW) method based on transient values in multi-terminal high-voltage direct current (MT-HVdc) system.

This method is more sensitive and accurate than non-traveling wave methods based on voltage or current values, only. Tripping criteria is given as:

$$
\begin{gathered}
\Delta V=V_{\text {post }}-V_{\text {pre }} \\
\Delta I=I_{\text {post }}-I_{\text {pre }} \\
\Delta P=\Delta V \Delta I \\
\Delta P \leq-P_{r e f}
\end{gathered}
$$

\section{Non-Traveling Wave (NTW Method Based on Electromagnetic Time Reversal (EMTR):}

Electromagnetic time reversal (EMTR) method for fault estimation in MT-HVdc offers significant advantages, such as tolerance of low sampling rate, non-requirement of accurate fault arrival time, and superiority compared to transient method for high resistance faults [114-121]. This method is based on reversing the direction of time $(t)$, given as:

$$
t \rightarrow T-t, t \in[0, T]
$$

where $T$ is time delay. 
In this method, electric fields are recorded at terminals (VSCs). Recorded electric fields are flipped over time and re-transmission of electric fields is achieved from sensing terminals and reflected back to the sensing terminals are observed [114,117]. Mathematically, electric field $E(t)$ is given as:

$$
\begin{aligned}
& E_{V S C 1}\left(L_{V S C 1}, t\right)=\frac{\varnothing\left(t-\left(\frac{\left\|L_{V S C 1}-L_{F}\right\|}{v}\right)\right)}{\left\|L_{V S C 1}-L_{F}\right\|} \\
& E_{V S C 2}\left(L_{V S C 2}, t\right)=\frac{\varnothing\left(t-\left(\frac{\left\|L_{V S C 2}-L_{F}\right\|}{v}\right)\right)}{\left\|L_{V S C 2}-L_{F}\right\|}
\end{aligned}
$$

where $\varnothing(\mathrm{t})$ is the electric potential depending on the temporal-spatial behavior of the fault current, $v$ is the propagation speed of the electromagnetic field, $L$ is the length of $\mathrm{HVdc}$ line between two VSC stations i.e., $L_{v s c 1}=0, L_{v s c 2}=L$ as shown in Figure 28 [114-116].

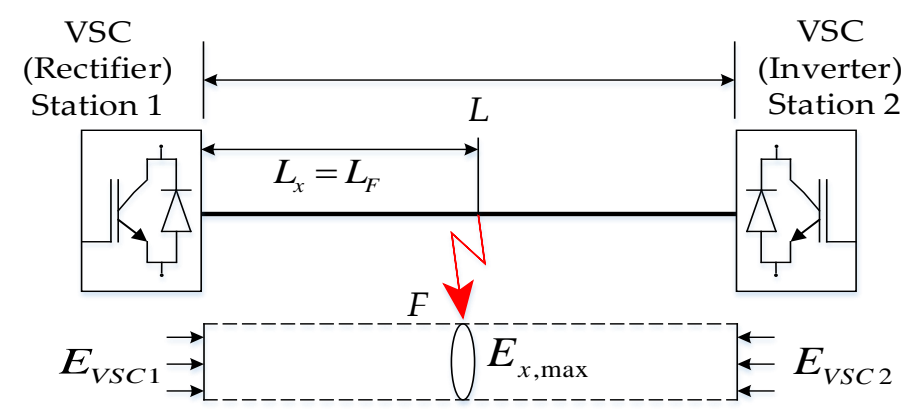

Figure 28. Electromagnetic time reversal (EMTR) based model of high-voltage direct current (HVdc) transmission system.

Thus, time reversed electric fields are:

$$
\begin{aligned}
& E_{V S C 1}\left(L_{V S C 1}, T-t\right)=\frac{\varnothing\left(T-\left(t-\left(\frac{\left\|L_{V S C 1}-L_{F}\right\|}{v}\right)\right)\right)}{\left\|L_{V S C 1}-L_{F}\right\|} \\
& E_{V S C 2}\left(L_{V S C 2}, T-t\right)=\frac{\varnothing\left(T-\left(t-\left(\frac{\left\|L_{V S C 2}-L_{F}\right\|}{v}\right)\right)\right)}{\left\|L_{V S C 2}-L_{F}\right\|}
\end{aligned}
$$

Re-transmission of electric fields is accomplished and total reflected field is [117]:

$$
\begin{aligned}
& E_{X}=\frac{\varnothing\left(T-\left(t-\left(\frac{\left\|L_{V S C 1}-L_{F}\right\|}{v}\right)\right)-\left(\frac{\left\|L_{X}-L_{F}\right\|}{v}\right)\right)}{\left\|L_{V S C 1}-L_{F}\right\|\left\|L_{X}-L_{F}\right\|} \\
&+ \varnothing\left(T-\left(t-\left(\frac{\left\|L_{V S C}-L_{F}\right\|}{v}\right)\right)-\left(\frac{\left\|L_{X}-L_{F}\right\|}{v}\right)\right) \\
&\left\|L_{V S C 2}-L_{F}\right\|\left\|L_{X}-L_{F}\right\|
\end{aligned}
$$

If a fault is set at the point where total electric field is calculated then, $L_{x}=L_{F}$, given as:

$$
E_{X, \max }=\varnothing(T-t)\left(\frac{1}{\left\|L_{F}-L_{V S C}\right\|^{2}}+\frac{1}{\left\|L_{F}-L_{V S C 2}\right\|^{2}}\right)
$$

There exists a positive correlation between electric field and currents given by:

$$
|I|=\oint \sigma E d s
$$


Therefore, currents of HVdc systems are measured and converted into 1 -mode and 0 -mode components. For bipolar HVdc system, modal components are given by:

$$
\begin{aligned}
& i_{V S C 1,0}(t)=\frac{i_{V S C 1 P}(t)+i_{V S C 1 N}(t)}{\sqrt{2}} \\
& i_{V S C 1,0}(t)=\frac{i_{V S C 2 P}(t)+i_{V S C 2 N}(t)}{\sqrt{2}} \\
& i_{V S C 1,1}(t)=\frac{i_{V S C 1 P}(t)-i_{V S C 1 N}(t)}{\sqrt{2}} \\
& i_{V S C 2,1}(t)=\frac{i_{V S C 2 P}(t)-i_{V S C 2 N}(t)}{\sqrt{2}}
\end{aligned}
$$

Effects of nonlinear voltage source are eliminated by 0 -mode components of current because of opposite direction. As a result, fault current is:

$$
i_{x 0}=i_{M 0}\left(t-\frac{x}{v}\right)+i_{N 0}\left(t-\frac{x}{v}\right)
$$

where

$$
v=\frac{w}{\left\{1 / 2\left[w^{2} L_{0}^{2} C_{0}^{2}-R_{0} G_{0}+\sqrt{\left(R_{0}^{2}+w^{2} L_{0}^{2}\right)\left(G_{0}^{2}+w^{2} C_{0}^{2}\right)}\right]\right\}}
$$

where $R_{0}, L_{0}, C_{0}$ and $G_{0}$ are 0 -mode resistance, inductance, capacitance, and conductance, respectively. These modal components of current are employed to classify the fault in terms of pole-ground fault and pole-pole fault. Digital filtering is applied to choose current at specific frequency. With the assumption of fault happening for every $\Delta x$, fault current energy along the TL is calculated as:

$$
\tau_{i_{F}}=\sqrt{\sum_{j=1}^{N} i_{F}(j)^{2}}, N=\frac{T}{\Delta t}
$$

where $N$ is the number of samples and $\Delta t$ is the sampling time. Afterwards, relative maxima of the fault current energy is calculated to locate the fault in HVdc system as:

$$
\tau\left(\mathrm{i}_{\mathrm{F}, \text { real }}\right)=\max \left\{\tau\left(\mathrm{i}_{\mathrm{F}}\right)\right\}
$$

Fault classification and location algorithm based on EMTR is presented in Figure 29.

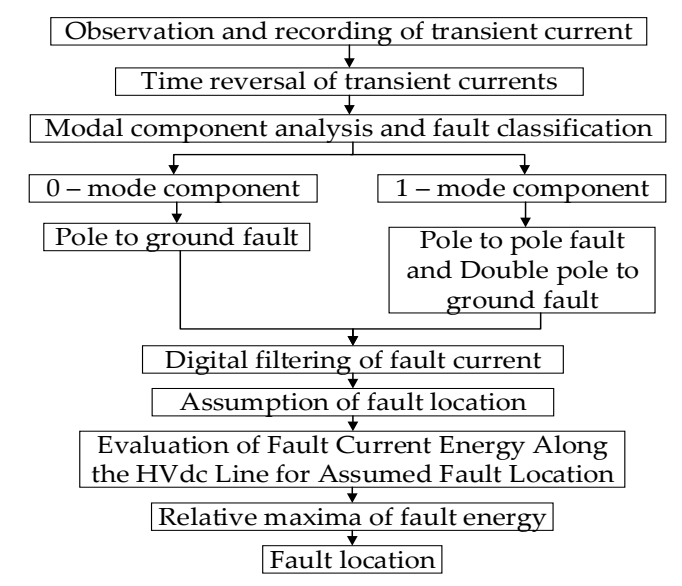

Figure 29. Fault classification and location algorithm based electromagnetic time reversal (EMTR). 
In case of mono-polar faults in MT-HVdc system, harmonics are eliminated by 0-mode currents. 1 mode components are used for bipolar faults. High frequency $0 / 1-$ m-ode components of current ae not affected by measurement error [120]. This results in increased accuracy of estimation of fault [121].

\section{Shortcomings of Non-Traveling Wave (NTW) Based Method}

Following are the shortcomings associated with NTW based fault location methods:

Sampling frequency and interpolation of voltage and current values in non-traveling wave-based method play a significant role in creating an impact on results of fault estimation through non traveling wave based method. Accuracy of fault location is improved as sampling frequency increases. Further interpolation of original samples and values of the fault location function can improve the accuracy of finding fault location. Bias and difficulty in handling high sampling rate are the drawbacks linked to these ways of improvement of NTW results.

NTW method requires little modification and sensitivity to attain accurate results of fault location. Practically, it is not possible that voltage and current values are measured at high synchronism. Therefore, aligning and matching are required. Thus, fault location function is modified as:

$$
f(x, \xi)=\sum_{t=t_{1}}^{t_{2}}\left|u_{i J}(x, t)-u_{i K}(l-x, t+\xi)\right|: x \in[0,1], \xi \in[0, T]
$$

where $\xi$ is the time difference between non-synchronized data. $T$ is the maximum time lag between data at two ends of TL. Minimum function is modified as:

$$
f\left(x_{f}, \xi\right)=\min \{f(x, \xi): x \in[0,1] ; \xi \in[0, T]\}
$$

where $f\left(x_{f}, \xi\right)$ is a function of the fault distance and time difference between non-synchronized data. There is a possibility that aligning and matching may result in the change of characteristic curve of fault. Convergence issues are also raised with alignment.

\section{Comparison of Traveling Wave and Non-Traveling Wave Based Methods}

There is no doubt that traveling wave methods for fault location and classification are found accurate and rapid as compared to non-traveling wave methods. However, detection of first traveling wavefront and handling large length of data window are the challenging tasks associated with the traveling wave methods. Table 2 summarizes the comparison of traveling and non-traveling wave-based methods for fault location estimation in MT-HVdc transmission system.

Table 2. Comparison of traveling and non-traveling wave-based methods for multi-terminal high-voltage direct current (MT-HVdc) transmission systems.

\begin{tabular}{clll}
\hline Serial Number & \multicolumn{1}{c}{ Parameters } & \multicolumn{1}{c}{$\begin{array}{c}\text { Traveling Wave Based } \\
\text { Method }\end{array}$} & $\begin{array}{c}\text { Non-Traveling Wave Based } \\
\text { Method }\end{array}$ \\
\hline 1 & $\begin{array}{l}\text { Wavehead/wavefront } \\
\text { detection }\end{array}$ & $\begin{array}{l}\text { First traveling wavefront is } \\
\text { required } \\
\text { Difficult to detect }\end{array}$ & Not Required \\
\hline 2 & $\begin{array}{l}\text { Post and pre fault } \\
\text { voltage values }\end{array}$ & $\begin{array}{l}\text { Post and pre fault voltage } \\
\text { values are required. }\end{array}$ & $\begin{array}{l}\text { Only post fault voltage values } \\
\text { are required. }\end{array}$ \\
\hline 3 & $\begin{array}{l}\text { Post and pre fault } \\
\text { current values }\end{array}$ & $\begin{array}{l}\text { Post and pre fault voltage } \\
\text { values are required. }\end{array}$ & $\begin{array}{l}\text { Only post fault current values } \\
\text { are required. }\end{array}$ \\
\hline 4 & $\begin{array}{l}\text { Length of data window } \\
\text { for fault estimation }\end{array}$ & $\begin{array}{l}\text { Large length of data window } \\
\text { is employed for an accurate } \\
\text { fault estimation }\end{array}$ & $\begin{array}{l}\text { Smaller data window is } \\
\text { sufficient for an accurate fault } \\
\text { estimation. }\end{array}$ \\
\hline
\end{tabular}


Table 2. Cont.

\begin{tabular}{|c|c|c|c|}
\hline Serial Number & Parameters & $\begin{array}{c}\text { Traveling Wave Based } \\
\text { Method }\end{array}$ & $\begin{array}{c}\text { Non-Traveling Wave Based } \\
\text { Method }\end{array}$ \\
\hline 5 & $\begin{array}{l}\text { Transmission line } \\
\text { parameters }\end{array}$ & $\begin{array}{l}\text { Arrival time of traveling wave } \\
\text { is greatly influenced by } \\
\text { transmission lines. }\end{array}$ & $\begin{array}{l}\text { Transmission line resistance } \\
\text { influence the post voltage and } \\
\text { current values. }\end{array}$ \\
\hline 6 & Information of fault & $\begin{array}{l}\text { First traveling wave wavefront } \\
\text { contains maximum } \\
\text { information of fault }\end{array}$ & $\begin{array}{l}\text { Only a section of line's data } \\
\text { from fault transient to steady } \\
\text { state is sufficient to estimate } \\
\text { fault over the entire dc } \\
\text { transmission line. }\end{array}$ \\
\hline 7 & $\begin{array}{l}\text { DC faults near converter } \\
\text { stations }\end{array}$ & $\begin{array}{l}\text { Difficult to identify or locate. } \\
\text { This is because of small } \\
\text { variation in amplitude of } \\
\text { traveling wave wavefront. }\end{array}$ & $\begin{array}{l}\text { Significant change in post fault } \\
\text { dc current value enables } \\
\text { identification and location of } \\
\text { fault. }\end{array}$ \\
\hline 8 & $\begin{array}{l}\text { DC faults characteristics } \\
\text { closed to zero crossings }\end{array}$ & $\begin{array}{l}\text { Inaccurate detection. } \\
\text { Transformations are required }\end{array}$ & $\begin{array}{l}\text { Post dc fault current increases } \\
\text { rapidly to steady state value. } \\
\text { No such issue exists in this } \\
\text { method. }\end{array}$ \\
\hline 9 & $\begin{array}{l}\text { Accuracy in fault } \\
\text { estimation }\end{array}$ & High & $\begin{array}{l}\text { Low as compared to traveling } \\
\text { wave method }\end{array}$ \\
\hline 10 & $\begin{array}{l}\text { Speed of detection with } \\
\text { same data length }\end{array}$ & High & Low \\
\hline 11 & $\begin{array}{l}\text { Time and frequency } \\
\text { domain analysis }\end{array}$ & $\begin{array}{l}\text { Accuracy is increased by time } \\
\text { and frequency domain } \\
\text { analysis for fault estimation } \\
\text { Wavelet transform and DSP } \\
\text { techniques increase accuracy } \\
\text { and speed }\end{array}$ & $\begin{array}{l}\text { Time domain increases } \\
\text { accuracy and speed of fault } \\
\text { estimation }\end{array}$ \\
\hline 12 & $\begin{array}{l}\text { Knowledge based } \\
\text { methods }\end{array}$ & $\begin{array}{l}\text { Applicable with both pre and } \\
\text { post fault voltage and current } \\
\text { values }\end{array}$ & $\begin{array}{l}\text { Applicable with only post fault } \\
\text { voltage and current values }\end{array}$ \\
\hline 13 & $\begin{array}{l}\text { DC transmission line } \\
\text { model }\end{array}$ & $\begin{array}{l}\text { It works well for both lumped } \\
\text { and distributed parameter line } \\
\text { model }\end{array}$ & $\begin{array}{l}\text { It works well with distributed } \\
\text { parameter line model. }\end{array}$ \\
\hline
\end{tabular}

\subsection{Traveling Wave (TW) Based Methods for Internal and External Faults}

When an internal fault $F_{1}$ occurs, the process of propagation of TW is shown in Figure 30. According to the fault superposition principle, a voltage source $U_{F 1}$ is superimposed at $F_{1}$ from where TWs spread towards the end terminals of TL. Initial TWs detected by the protection equipment installed at end terminals are backward TWs i.e., $U_{R b}$ and $U_{I b}$. Later on, these backward TWs are reflected as forward TWs i.e., $U_{R f}$ and $U_{I f}[109-112,122]$.

However, when an external fault $F_{2}$ occurs, the corresponding process of propagation of TWs is presented by solid line in Figure 31. Forward TW $U_{R f}$ is detected at the rectifier station which further propagates towards the inverter station and is detected as backward TW $U_{I b}$ while at the inverter station, backward TW $U_{I b}$ is reflected as forward TW $U_{I f}$. Further, $U_{I f}$ is detected as backward TW $U_{R b}$ at the rectifier station. Hence, first TW is detected as forward TW at rectifier station while first TW detected as backward TW at inverter station in case of external fault at ac side of rectifier station. 


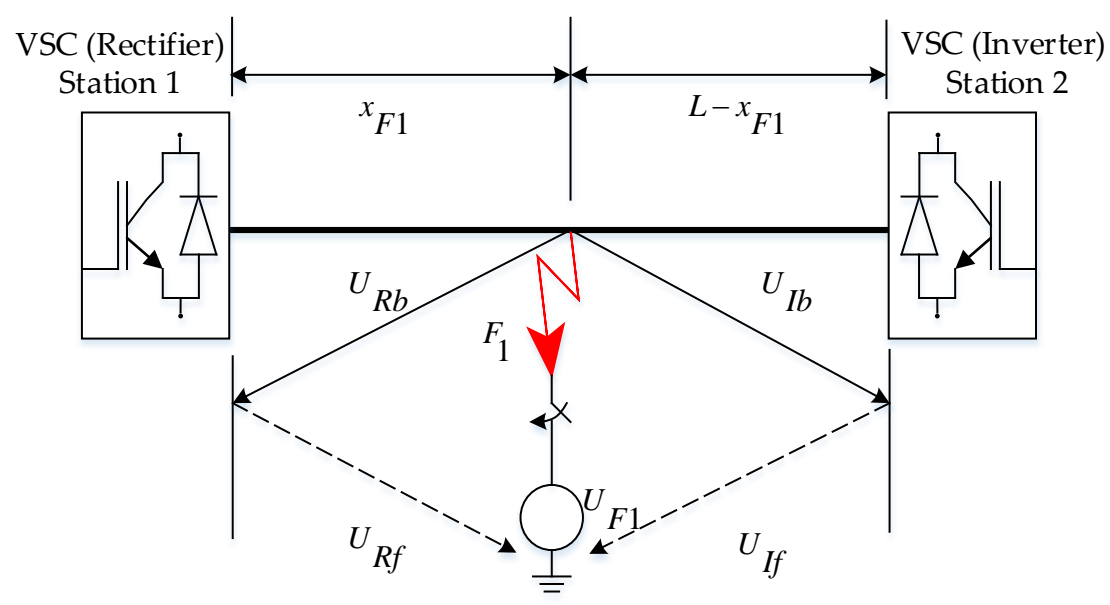

Figure 30. Propagation of traveling waves in case of internal fault.

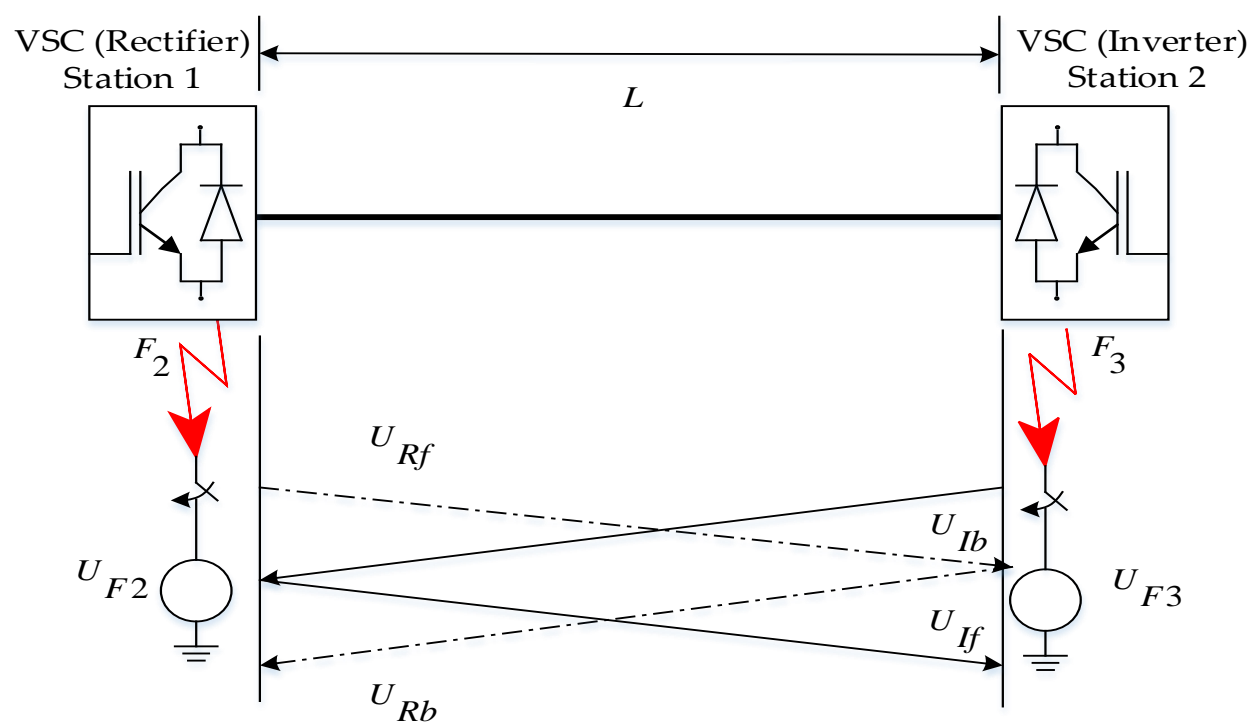

Figure 31. Propagation of traveling wave in case of external fault.

Similarly, when an external fault occurs at $F_{3}$, the corresponding process of propagation of TWs is presented by dotted line in Figure 31. Forward TW $U_{I f}$ is detected by inverter station which propagates towards the rectifier and is detected as backward TW $U_{R b}$. At rectifier station, backward TW $U_{R b}$ is reflected as forward TW $U_{R f}$ which is then detected as backward TW $U_{I b}$ at the inverter station. Hence, first TW is detected as forward TW at inverter station while first TW detected as backward TW at rectifier station in case of external fault at ac side of inverter station.

\subsection{Non-Traveling Wave (NTW) for External and Internal Faults}

It is difficult to differentiate between external and internal faults with NTW based methods especially in the case of faults at or near converter stations. This is because of very small difference in the magnitude of voltages and currents during post fault conditions. Therefore, there is always a requirement of an additional technique like Fourier transform [123], wavelet transform [55-58], linear discriminant analysis [124], Naïve Bayes techniques [125], etc. to distinguish between internal and external faults. However, when an internal fault occurs at some specific distance from VSC station (sensing point), it can readily be differentiated from external fault based on the variations of dc fault voltages and currents. 


\section{Existing Fault Classification and Location Methods}

There are various methods for estimation of faults in MT-HVdc transmission system besides the methods of traveling and non-traveling waves. Impedance method is found applicable for permanent faults and is very practical approach to locate and classify faults in long distance HVdc transmission lines. However, an accuracy is compromised with the increase in the length of transmission lines. Therefore, voltage and current measurements-based methods are developed to address issues of accuracy and speed. Further, signal processing and time frequency analysis are incorporated to enhance performance of voltage and current measurement-based methods. There is a significant improvement in the speed and accuracy of detection with the embedding of knowledge-based methods. However, there are some limitations like inaccuracy in case of incomplete information of faults and time inference in case of bulk power systems. Table 3 gives detailed information about fault classification and location methods, and their limitations.

Table 3. Fault location methods and their limitations.

\begin{tabular}{|c|c|c|}
\hline Serial Number & Fault Location Methods & Limitations \\
\hline 1 & Impedance Based Method & $\begin{array}{l}\text { Only Applicable for Permanent Faults } \\
\text { Error in fault estimation is about } 10 \text { percent } \\
\text { of line length }\end{array}$ \\
\hline 2 & Travelling Wave Method & $\begin{array}{l}\text { Not Good for Faults Near Terminals } \\
\text { Not Good for Faults Having Waveform Very } \\
\text { Close to Zero Crossings }\end{array}$ \\
\hline 3 & Arrival Time Detection Method & $\begin{array}{l}\text { Detection of Wave-head is Difficult } \\
\text { Velocity of Propagation Dependent }\end{array}$ \\
\hline 4 & $\begin{array}{l}\text { Frequency Based Detection } \\
\text { Method }\end{array}$ & $\begin{array}{l}\text { Band-pass Filters are required for extraction } \\
\text { of high frequency components }\end{array}$ \\
\hline 5 & Transient Current Detection & $\begin{array}{l}\text { Surge Capacitors are required for } \\
\text { generation of transient currents }\end{array}$ \\
\hline 6 & $\begin{array}{l}\text { Digital Signal Processing Based } \\
\text { Method }\end{array}$ & High Sampling Rate is Required \\
\hline 7 & $\begin{array}{l}\text { Pure Time and Frequency Based } \\
\text { Methods }\end{array}$ & $\begin{array}{l}\text { Fault signal requires both high time and } \\
\text { frequency resolution } \\
\text { Not suited for travelling or non-stationary } \\
\text { waves }\end{array}$ \\
\hline 8 & $\begin{array}{l}\text { Discrete Wavelet Transform Based } \\
\text { Method }\end{array}$ & $\begin{array}{l}\text { Less Computational Time (Feature) } \\
\text { Low Time Resolution for Fault Signal }\end{array}$ \\
\hline 9 & $\begin{array}{l}\text { Continuous Wavelet Transform } \\
\text { Based Method }\end{array}$ & $\begin{array}{l}\text { Full shifting of analyzing wavelet over the } \\
\text { full domain of input signal (Feature) } \\
\text { Better Accuracy as Compared to DWT }\end{array}$ \\
\hline 10 & $\begin{array}{l}\text { Knowledge Based Methods } \\
\text { Neural Networks } \\
\text { Fuzzy Logic } \\
\text { Bayesian Networks }\end{array}$ & $\begin{array}{l}\text { Failure in case of incomplete information of } \\
\text { fault } \\
\text { Time Inference in case of Big System Fault } \\
\text { Analysis }\end{array}$ \\
\hline
\end{tabular}

\section{Practical Realization of Traveling Wave (TW) Based Commercial Relays}

Traveling waves of current are being used to identify the reflections from the fault location, other end of TL or any discontinuity within TL [126-129]. TWs of the neighboring stations can be eradicated with the help of reference data train of TWs generated from the external faults, line energization and auto reclosing and, switching of capacitor banks. This information is employed with TW generated during fault to find out propagation time and to estimate fault location on TL. The distance between sensing terminal and the fault point is calculated with the help of propagation time and velocity of TWs. Arrival time is determined by using differentiator smoother [127,128]. In differential smoother, leading 
edge is tracked by excluding signal distortion and allowing interpolation between samples. When incident TWs are passed through a junction point (tap) of TL, these TWs are reflected and transmitted in accordance with the characteristic impedance of TL segments. In a single end measurement-based method, time difference between first TW and successive reflected TWs are utilized for estimation of fault location. Sorting out of TWs is required when sensing terminals (VSCs) are closer compared to the distance between fault and sensing terminal of TL [127,128]. Single end fault locator (SEFL) based on TWs is developed by Schweitzer et al. for HVdc system in 1984 [128]. SEFL separates the incident and reflected TWs for dc fault estimation.

Practically, TWs based method of fault location is successfully implemented on Brasada-Harney transmission system, and Bonneville Power Administration's field [127], USA with least error. Attenuation and dispersion are the two phenomena associated with TWs generated in TLs and are caused by energy losses and variations in the inductances and capacitances of TL. It results in decaying of TWs magnitude which in turn, challenges the accuracy of fault location. Therefore, long data window and differentiator smoother filter are required to minimize the effects of attenuation and dispersion in transmission lines. Thus, TWs based methods of fault location works well for HVdc TLs because of non-existence of attenuation and dispersion phenomenon [129].

\section{Future Trends}

With the increased developments in multi-terminal VSC-HVdc systems, estimation of fault location is becoming more and more complex. It is a need to explore precise fault location algorithms so that performance in the complex dynamic environment could not be compromised. Therefore, with an ongoing, never ceasing motivation, research and development especially in the area of protection of dc grids, spread of dc network is inevitable.

With this intention, intelligent estimation of fault location with the availability or unavailability of supervision is gaining attraction. This step opens the door of applications of machine learning and deep learning in the area of dc grid protection. These learning techniques have the ability to acquire information without being explicitly programmed. Machine learning can have direct impact on improvements of relaying strategies aiding HVdc circuit breakers. Convergence issues and correct estimation of fault location in a multi-terminal environment should be addressed because of extracting features in a multi-dimensional environment.

Support vector machine is a supervised machine learning approach. It is found useful because of reduction in time of computations. Labeled training data of fault location is less required. Further, classification of fault with respect to location and type can also be made possible effectively with this approach.

Neural networks can be considered as an alternate approach for estimation of fault location. In this technique, intelligent way of fault location estimation and classification is performed. Artificial neural networks (ANN) can effectively address the nonlinear nature of dc fault current. The learned features associated with the connections among hidden layers an input and output layers can depict the information about the location of fault in MT-HVdc systems.

Radial basis function networks (RBFN) can build strong fault location classifiers by the activation of binomial regression and soft-max regression functions. These fault location classifiers can then be employed in Pearson Correlation for finding the similarity between these classifiers and untagged data.

\section{Conclusions}

Traveling wave and non-traveling wave-based methods are reviewed critically under different circumstances and scenarios. Fault classification and location in dc grid are scrutinized mathematically and analytically. TW and NTW-based methods for fault classification and location broaden the traditional use of dc grid and open up new applications in interconnection of weak ac grids, incorporation of renewable energy technologies and transfer of bulk power to far flung areas with maximum controllability and handling capacity. 
Accuracy of any fault estimation technique not only depends on the environment of application but also on the computational time and convergence in the complex multi-terminal environment. Time inference increases with complex computation and more features for better estimation. Therefore, estimation of fault is required to be done in an adaptive way so that relaying strategies could originate an abrupt trip signal to counter rapidly growing dc fault. This intention leads to expansion of dc grid networks with effective controllability, flexibility, and efficiency.

Author Contributions: Conceptualization, R.M., A.R. and G.A.; formal analysis, R.M.; investigation, G.A., M.R.H., M.Q., M.A.R. and M.A.K.; validation, A.R. and G.A.; resources, R.M.; writing-original draft preparation, R.M.; writing-review and editing, R.M., A.R., G.A., M.R.H., M.Q., M.A.R. and M.A.K.; supervision, A.R., G.A., I.A.; project administration, A.R.; funding acquisition, G.A., M.R.H., M.Q., M.A.R. and M.A.K.

Funding: The authors extend their appreciation to the Deanship of Scientific Research at King Khalid University for funding this work through Research Group Project under grant number R.G.P. 1/166/40.

Conflicts of Interest: The authors declare no conflict of interest.

\section{References}

1. Oni, O.E.; Davidson, I.E.; Bangula, K.N.M. A review of LCC-HVdc and VSC-HVdc technologies and applications. In Proceedings of the 2016 IEEE 16th International Conference on Environment and Electrical Engineering (EEEIC), Florence, Italy, 7-10 June 2016; pp. 1-9.

2. Leterme, W.; Azad, S.P.; Hertem, D.V. A local backup protection algorithm for HVdc grids. IEEE Trans. Power Deliv. 2016, 31, 1767-1775. [CrossRef]

3. Azad, S.P.; Leterme, W.; van Hertem, D. Fast breaker failure backup protection for HVDC grids. Electr. Power Syst. Res. 2015, 138, 99-105. [CrossRef]

4. López, I.; Andreu, J.; Ceballos, S.; de Alegra, I.M.; Kortabarria, I. Review of wave energy technologies and the necessary power-equipment. Renew. Sustain. Energy Rev. 2013, 27, 413-434. [CrossRef]

5. van Hertem, D.; Ghandhari, M.; Curis, J.B.; Despouys, O.; Andree, M. Protection requirements for a multi-terminal meshed dc grid. In Proceedings of the CIGRE 2011 Bologna Symposium-The Electric Power System of the Future: Integrating Supergrids and Microgrids, Bologna, Italy, 13-15 September 2011; pp. 1-8.

6. Alegría, I.; Martín, J.; Kortabarria, I.; Andreu, J.; Ereño, P. Transmission alternatives for offshore electrical power. Renew. Sustain. Energy Rev. 2009, 13, 1027-1038. [CrossRef]

7. Rouzbehi, K.; Candela, J.I.; Gharehpetian, G.B.; Harnefors, L.; Luna, A.; Rodriguez, P. Multiterminal DC grids: Operating analogies to AC power systems. Renew. Sustain. Energy Rev. 2017, 70, 886-895. [CrossRef]

8. Hammons, T.J.; Woodford, D.; Loughtan, J.; Chamia, M.; Donahoe, J.; Povh, D.; Bisewski, B.; Long, W. Role of HVdc transmission in future energy development. IEEE Power Eng. Rev. 2000, 20, 10-25. [CrossRef]

9. Kim, C.; Sood, V.K.; Jang, G.; Lim, S.; Lee, S. HVdc Transmission: Power Conversion Applications in Power Systems; Wiley-IEEE Press: Singapore, 2009.

10. Tang, L.; Ooi, B.T. Locating and isolating dc faults of multi-terminal dc system. IEEE Trans. Power Deliv. 2007, 22, 1877-1884. [CrossRef]

11. Ackermann, T. Transmission systems for offshore wind farms. IEEE Power Eng. Rev. 2002, 22, $23-27$. [CrossRef]

12. Araujo, E.P.; Bianchi, F.D.; Ferre, A.J.; Bellmunti, O.G. Methodology for droop control dynamic analysis of multi-terminal VSC-HVdc grids for offshore wind farms. IEEE Trans. Power Deliv. 2011, 26, 2476-2485. [CrossRef]

13. Meah, K.; Ula, S. Comparative evaluation of HVdc and HVac transmission systems. In Proceedings of the 2007 IEEE Power Engineering Society General Meeting, Tampa, FL, USA, 24-28 June 2007; pp. 1-5.

14. Jiebei, Z.; Campbell, B. Future multi-terminal HVdc transmission systems using voltage source converters. In Proceedings of the 45th International Universities Power Engineering Conference UPEC2010, Cardiff, UK, 31 August-3 September 2010.

15. Bond, S.L.; Bertho, R., Jr.; Coury, D.; Vieira, J. Design of protection schemes for multi terminal HVdc systems. Renew. Sustain. Engery Rev. 2016, 56, 965-974. [CrossRef]

16. Callavik, M.; Blomberg, A.; Hafner, J.; Jacobson, B. The hybrid HVdc breaker. ABB Grid Syst. Tech. Pap. 2012, $361,143-152$. 
17. Cwikowski, O.; Barnes, M.; Shuttleworth, R.; Chang, B. Analysis and simulation of the proactive hybrid circuit breaker. In Proceedings of the 2015 IEEE 11th International Conference on Power Electronics and Drive Systems, Sydney, Australia, 9-12 June 2015; pp. 4-11.

18. Hafner, J.; Jacobson, B. Proactive hybrid hvdc breakers: A key innovation for reliable HVdc grids. In Proceedings of the CIGRE Bologna Symposium, Bologna, Italy, 13-15 September 2011; pp. 1-8.

19. Davidson, C.; Whitehouse, R.; Barker, C.; Dupraz, J.; Grieshaberi, W. A new ultra-fast HVdc circuit breaker for meshed dc networks. In Proceedings of the 11th International Conference on AC and DC Power Transmission, Birmingham, UK, 10-12 February 2015; pp. 1-7.

20. Tahata, K.; Ka, S.; Tokoyoda, S.; Kamei, K.; Kikuchi, K.; Yoshida, D.; Kono, Y.; Yamamoto, R.; Ito, H. HVdc circuit breakers for HVdc grid applications. In Proceedings of the 11th International Conference on AC and DC Power Transmission, Birmingham, UK, 10-12 February 2015; pp. 1-9.

21. Descloux, J. Protection Contre les Courts-Circuits des Réseaux à Courant Continu de Forte Puissance. Ph.D. Thesis, University de Grenoble, Grenoble, France, 2013.

22. Kerf, K.D.; Srivastava, K.; Reza, M.; Bekaert, D.; Cole, S.; Hertem, D.V.; Belmans, R. Wavelet-based protection strategy for dc faults in multi-terminal vsc hvdc systems. IET Gener. Transm. Distrib. 2011, 5, 496-503. [CrossRef]

23. Sneath, J.; Rajapakse, A. Fault detection and interruption in an earthed HVdc grid using rocov and hybrid DC breakers. IEEE Trans. Power Deliv. 2016, 31, 973-981. [CrossRef]

24. Leterme, W.; Beerten, J.; Hertem, D.V. Non-unit protection of HVdc grids with inductive DC cable termination. IEEE Trans. Power Deliv. 2016, 31, 820-828. [CrossRef]

25. Barker, C.; Whitehouse, R.; Adamczyk, A.; Boden, M. Designing fault tolerant HVdc networks with a limited need for HVdc circuit breaker operation. In Proceedings of the CIGRE Session, Paris, France, 25-29 August 2014.

26. Barker, C.; Whitehouse, R. An alternative approach to HVdc grid protection. In Proceedings of the 10th IET International Conference on AC and DC Power Transmission (ACDC 2012), Birmingham, UK, 4-5 December 2012; pp. 1-6.

27. Schmitt, D.; Wang, Y.; Weyh, T.; Marquardt, R. DC side fault current management in extended multi terminal HVdc-grids. In Proceedings of the International Multi-Conference on Systems, Signals \& Devices, Chemnitz, Germany, 20-23 March 2012; pp. 1-5.

28. Merlin, M.; Green, T.; Mitcheson, P.; Trainer, D.; Critchley, R.; Crookes, W.; Hassan, F. The alternate arm converter: A new hybrid multilevel converter with DC-fault blocking capability. IEEE Trans. Power Deliv. 2014, 29, 310-317. [CrossRef]

29. Hajian, M.; Zhang, L.; Jovcic, D. DC transmission grid with low-speed protection using mechanical DC circuit breakers. IEEE Trans. Power Deliv. 2015, 30, 1383-1391. [CrossRef]

30. Lewitson, L.; Brown, M.; Balakrishnann, R. Practical Power System Protection; Elsevier: Amsterdam, The Netherlands, 2004.

31. Asplund, G.; Linden, K.; Barker, C.; Marzin, A.; Baur, U.; Pahalawaththa, N.; Beerten, J.; Rashwan, M.; Christensen, P.; Rittiger, J.; et al. HVdc Grid Feasibility Study. CIGRE-Electra 2013, 50-59.

32. Anderson, P. Power System Protection; John Wiley \& Sons: Hoboken, NJ, USA, 1998.

33. Nanayakkara, O.M.K.K.; Rajapakse, A.D.; Wachal, R. Location of DC line faults in conventional HVdc systems with segments of cables and overhead lines using terminal measurements. IEEE Trans. Power Deliv. 2012, 27, 279-288. [CrossRef]

34. Dewe, M.B.; Sankar, S.; Arillaga, J. The application of satellite time references to HVdc fault location. IEEE Trans. Power Deliv. 1993, 8, 1295-1302. [CrossRef]

35. He, Z.Y.; Lao, K.; Li, X.P.; Li, S.; Yang, J.W.; Mai, R.K. Natural frequency based line fault location in HVdc lines. IEEE Trans. Power Deliv. 2014, 29, 851-859. [CrossRef]

36. Nanayakkara, O.M.K.K.; Rajapakse, A.D.; Wachal, R. Traveling wave based line fault location in star connected multi terminal HVdc systems. IEEE Trans. Power Deliv. 2012, 27, 2286-2294. [CrossRef]

37. Ando, M.; Schweitzer, E.O.; Baker, R.A. Development and field data evaluation of single end fault locator for two terminal HVDC transmission lines-Part 2: Algorithm and evaluation. IEEE Trans. Power App. Syst. 1985, 104, 3531-3537. [CrossRef]

38. Farshad, M.; Sadeh, J. A novel fault location method for HVdc transmission lines based on similarity measure of voltage signals. IEEE Trans. Power Deliv. 2013, 28, 2483-2490. [CrossRef] 
39. Suonan, J.; Gao, S.; Song, G.; Jiao, Z.; Kang, X. A novel fault location method for HVdc transmission lines. IEEE Trans. Power Deliv. 2010, 25, 1203-1209. [CrossRef]

40. Tziouvaras, D. Protection of High-Voltage AC Cables. In Proceedings of the 59th Annual Conference for Protective Relay Engineers, College Station, TX, USA, 4-6 April 2006 2006; pp. 48-61.

41. Hertem, V.D.; Delimar, M. High voltage direct current (HVDC) electric power transmission systems. In Electricity Transmission, Distribution and Storage Systems, 1st ed.; Melhem, Z., Ed.; Woodhead Publishing: Cambridge, UK, 2013; pp. 143-173.

42. Zheng, X.; Nengling, T.; Guangliang, Y.; Haoyin, D. A Transient Protection Scheme for HVDC Transmission Line. IEEE Trans. Power Deliv. 2012, 27, 718-724. [CrossRef]

43. Jovcic, D.; Ahmed, K. High Voltage Direct Current Transmission: Converters, Systems and DC Grids; Wiley: Hoboken, NJ, USA, 2015.

44. Shakerighadi, B.; Ebrahimzadeh, E.; Blaabjerg, F.; Bak, C.L. Large-Signal Stability Modeling for the Grid-Connected VSC Based on the Lyapunov Method. Energies 2018, 11, 2533. [CrossRef]

45. Li, Y.; Liu, K.; Liao, X.; Zhu, S.; Huai, Q. A Virtual Impedance Control Strategy for Improving the Stability and Dynamic Performance of VSC-HVDC Operation in Bidirectional Power Flow Mode. Appl. Sci. 2019, 9, 3184. [CrossRef]

46. Li, B.; He, J.; Tian, J.; Feng, Y.; Dong, Y. DC fault analysis for modular multilevel converter-based system. J. Mod. Power Syst. Clean Energy 2017, 5, 275-282. [CrossRef]

47. Gao, Y.; Han, Y.; Zhang, J.; Xiao, F.; Zhao, Y.; Li, L. Study on Fault Current Characteristics and Current Limiting Method of Plug-In Devices in VSC-DC Distribution System. Energies 2019, 12, 3159. [CrossRef]

48. Li, B.; Liu, H. Current limiting methods for VSC-based DC distribution systems. Energy Procedia 2017, 147, 2257-2263. [CrossRef]

49. Kwon, Y.; Kang, S.; Lee, D.; Kim, H. Fault location algorithm based on cross correlation method for HVDC cable lines. In Proceedings of the IET 9th International Conference on Developments in Power Systems Protection (DPSP 2008), Glasgow, UK, 17-20 March 2008; pp. 360-364.

50. Crossley, P.A.; McLaren, P.G. Distance Protection Based on Travelling Waves. IEEE Trans. Power Appar. Syst. 1983, PAS-102, 2971-2983. [CrossRef]

51. Zou, Y.; Wang, X.; Zang, H.; Liu, C.; Zhou, Q.; Zhou, W. Travelling wave based fault location with high grounding resistance for HVDC transmission lines. In Proceedings of the IEEE PES APAC Power and Energy Conference, Xi'an, China, 25-28 October 2016; pp. 1651-1655.

52. Bustamante-Mparsakis, X.; Maun, J.; Dzienis, C.; Jurisch, A. Travelling wave fault location based on pattern recognition. In Proceedings of the 2017 IEEE Manchester PowerTech, Manchester, UK, 18-22 June 2017; pp. 1-6.

53. Glik, K.; Kowalik, R.; Rasolomampionona, D.; Anwar, S. Travelling wave fault location in power transmission systems: An overview. J. Electr. Syst. 2011, 7, 287-296.

54. Kimbark, E.W. Transient over voltages caused by monopolar ground fault on bipolar dc line: Theory and simulation. IEEE Trans. Power Appar. Syst. 1970, 89, 581-592.

55. Hingorani, N.G. Transient overvoltages on bipolar HVdc transmission lines. IEEE Trans. Power Appar. Syst. 1970, 89, 592-610. [CrossRef]

56. Dommel, H.W.; Michels, J.M. High speed relaying using traveling wave transient analysis. In Proceedings of the IEEE Winter Power Meeting, New York, NY, USA, 29 January-3 February1978; pp. 214-219.

57. Mansour, M.M.; Swift, G.W. Design and testing of a multi microprocessor traveling wave relay. IEEE Trans. Power Deliv. 1986, 1, 74-82. [CrossRef]

58. Arkan, M.; Akmaz, D.; Mamiş, M.S.; Tagluk, M.E. Design and development of travelling-wave-frequency-based transmission line fault locator using TMS320 DSP. IET Sci. Meas. Technol. $2019,13,518-522$.

59. Johns, A.T.; Martin, M.A.; Barker, A.; Walker, E.P.; Crossley, P.A. A new approach to EHV direction comparison protection using digital signal processing technologies. IEEE Trans. Power Syst. 1986, PER-6, 28.

60. Jie, L.; Elangovan, S.; Devotta, J.B.X. Adaptive travelling wave protection algorithm using two correlation functions. IEEE Trans. Power Deliv. 1999, 14, 126-131.

61. Chen, P.; Xu, B.; Li, J. A traveling waves based fault locating system for HVdc transmission lines. In Proceedings of the 2006 International Conference on Power System Technology, Chongqing, China, 22-26 October 2006; pp. 1-4. 
62. Radford, T.W. HVdc line fault locator upgrade. In Proceedings of the HVdc Operating Conference, Winnipeg, MB, Canada, 15-17 September 1987; pp. 189-200.

63. Magnago, F.H.; Abur, A. Fault location using wavelets. IEEE Trans. Power Deliv. 1998, 13, 1475-1480. [CrossRef]

64. Saha, M.; Izykowski, J.; Rosolowski, E. Fault Location on Power Networks; Springer: Berlin/Heidelberg, Germany, 2009.

65. Keswani, R.A. Identification of fault in HVdc converters using wavelet based multi-resolution analysis. In Proceedings of the 2008 First International Conference on Emerging Trends in Engineering and Technology, Nagpur, India, 16-18 July 2008; pp. 954-959.

66. Murthy, P.; Amarnath, J.; Kamakshiah, S.; Singh, B. Wavelet transform approach for detection and location of faults in HVdc systems. In Proceedings of the 2008 IEEE Region 10 and the Third International Conference on Industrial and Information Systems, Kharagpur, India, 8-10 December 2008; pp. 1-6.

67. Vetterli, M.; Herley, C. Wavelets and filter banks: Theory and design. IEEE Trans. Signal Process. 1992, 40, 2207-2232. [CrossRef]

68. Nanayakkara, K.; Rajapakse, A.; Wachal, R. Fault location in extra-long HVdc transmission line using discrete wavelet transform. In Proceedings of the International Conference on Power Systems Transients, Delft, The Netherlands, 14-17 June 2011; pp. 14-17.

69. Borghetti, A.; Corsi, S.; Nucci, C.; Paolone, M.; Paretto, L.; Tinarelli, R. On the use of continuous wavelet transform for fault location in distribution power systems. Int. J. Electr. Power Energy Syst. 2006, 28, 608-617. [CrossRef]

70. Stockwell, R.G.; Mansinha, L.; Lowe, R.P. Localization of the complex spectrum: The s transform. IEEE Trans. Signal Process. 1996, 44, 998-1001. [CrossRef]

71. Gale, P.F.; Crossley, P.A.; Bingyin, X.; Yaozhong, G.; Cory, B.J.; Barker, J.R.G. Fault location based on travelling waves. In Proceedings of the 1993 Fifth International Conference on Developments in Power System Protection, York, UK, 30 March-2 April 1993; pp. 54-59.

72. Hara, S.; Hirose, M.; Hatano, M.; Kinoshita, S.; Ito, H.; Ibuki, K. Fault protection of metallic return circuit of Kii channel HVdc system. In Proceedings of the 7th International Conference on AC-DC Power Transmission, London, UK, 28-30 November 2011; pp. 132-137.

73. Kamiji, M.; Fujii, K.; Ogawa, S.; Fukuda, E. The feature of the Anan-Kihoku direct transmission line-overhead line. In Proceedings of the IEEE/PES Transmission and Distribution Conference and Exhibition, Asia-Pacific, 6-10 October 2002; pp. 1910-1915.

74. Sasaki, S. Suppression of abnormal over voltages on a metallic return HVdc overhead line/cable transmission system. IEEE Trans. Power Appl. Syst. 1925, PAS-97, 1925-1934. [CrossRef]

75. Westerweller, T.; Prince, J.J.; Siemens, A.G.; Erlangen, G. Basslink HVdc interconnector system design considerations. In Proceedings of the 8th IEE International Conference on AC and DC Power Transmission, London, UK, 28-31 March 2006; pp. 121-124.

76. Nanayakkara, K.; Rajapakse, A.D.; Wachal, R. Fault location in extra HVdc transmission line using continuous wavelet transform. In Proceedings of the International Conference on Power Systems Transients, Delft, The Netherlands, 14-17 June 2011.

77. Evrenosoglu, C.Y.; Abur, A. Traveling wave based fault location for teed circuits. IEEE Trans. Power Deliv. 2005, 20, 1115-1121. [CrossRef]

78. Gale, P.F.; Taylor, P.V.; Naidoo, P.; Hitchin, C.; Clowes, D. Traveling wave fault locator experience on Eskom's transmission network. In Proceedings of the 7th International Conference on Developments in Power Systems Protection, Amsterdam, The Netherlands, 9-12 April 2001; pp. 327-330.

79. Kumar, K.P. Fault diagnosis for an HVdc system: A feasibility study of an expert system application. Electr. Power Syst. Res. 1988, 14, 83-89.

80. Shultz, R.D.; Gonzales, R.F. Operating characteristics of an HVdc multi terminal transmission line under single pole faulted conditions and high resistance earth return. Electr. Power Syst. Res. 1986, 10, 103-111. [CrossRef]

81. Swift, G.W. The spectra of fault induced transients. IEEE Trans. Power Appar. Syst. 1979, 98, 940-947. [CrossRef]

82. Styvaktakis, E.; Bollen, M.H.J.; Gu, H.Y. A fault location technique using high frequency fault clearing transients. IEEE Power Eng. Rev. 1999, 19, 58-60. [CrossRef] 
83. Li, Y.L.; Zhang, Y.; Ma, Z.Y. Fault location method based on the periodicity of the transient voltage traveling wave. In Proceedings of the 2004 IEEE Region 10 Conference TENCON, Chiang Mai, Thailand, 21-24 November 2004; pp. 389-392.

84. Dommel, H.W. Electromagnetic Transient Program Manual (EMTP Theory Book); Bonneville Power Administration: Portland, OR, USA, 1986.

85. Ping, C.; Bingyin, X.; Jing, L.; Yaozhong, G. Modern traveling wave based fault location techniques for HVdc transmission lines. J. Tianjin Univ. 2008, 14, 139-143.

86. Swetha, A.; Murthy, P.K.; Sujatha, N.; Kiran, Y. A novel technique for the location of fault on a HVdc transmission line. J. Eng. Appl. Sci. 2011, 6, 62-67.

87. Ikhide, M.; Sarath, B.; Tennakoon, H.H.; Alison, L.; Griffiths, S.S.; Adamczyk, A.J. A transient and non-unit-based protection technique for DC grids based on the rate-of-change (R-o-C) of the fault induced travelling wave components. Sustain. Energy Grids Netw. 2019, 100195. [CrossRef]

88. Hatch. The Lower Churchill Project DC1010-Voltage and Conductor Optimization Newfoundland and Labrador Hydro Lower Churchill Project; Exhibit CE-01 Rev. 1 (Public); Board of Commissioners of Public Utilities: Newfoundland, Canada, 2008.

89. Szechtman, M.; Margaard, T.; Bowles, J.P.; Thio, C.V.; Woodford, D.; Wess, T.; Joetten, R.; Liss, G.; Rashwan, M.; Krishnayya, P.C.; et al. The Cigre HVdc benchmark model-A new proposal with revised parameters. Electra 1994, 157, 61-65.

90. Faruque, M.O.; Zhang, Y.; Dinavahi, V. Detailed modeling of Cigre HVdc benchmark using pscad/emtdc and psb/Simulink. IEEE Trans. Power Deliv. 2006, 21, 378-387. [CrossRef]

91. Reeve, J.; Kapoor, S.C. Digital simulation of traveling waves in HVdc transmission lines. IEEE Trans. Power Appar. Syst. 1972, 91, 2342-2355. [CrossRef]

92. Suonan, J.; Song, G.; Xu, Q. Time domain fault location for parallel transmission line using unsynchronized currents. Int. J. Electr. Power Energy Syst. 2006, 28, 253-260.

93. Dardengo, V.P.; Cavalcante, P.A.H.; de Almeida, M.C. Noise reduction for faults in HVDe lines using mathematical morphology. In Proceedings of the 2017 IEEE PES Innovative Smart Grid Technologies Conference-Latin America, Quito, Ecuador, 20-22 September 2017; pp. 1-6.

94. Lu, Z.; Turner, D.R.; Wu, Q.H.; Fitch, J.; Mann, S. Morphological transform for detection of power quality disturbances. In Proceedings of the 2004 International Conference on Power System Technology, Singapore, 21-24 November 2004; pp. 1644-1649.

95. Jing, M.; Zengping, W.; Yan, X.; Lei, M. Single-ended transient positional protection of transmission lines using mathematical morphology. In Proceedings of the 2005 International Power Engineering Conference, Singapore, 29 November-2 December 2005; pp. 1-603.

96. Gautam, S.; Brahma, S.M. Overview of mathematical morphology in power systems-A tutorial approach. In Proceedings of the 2009 IEEE Power \& Energy Society General Meeting, Calgary, AB, Canada, 26-30 July 2009; pp. 1-7.

97. Jamali, S.; Mirhosseini, S.S. Protection of transmission lines in multi-terminal HVDC grids using travelling waves morphological gradient. Int. J. Electr. Power Energy Syst. 2019, 108, 125-134. [CrossRef]

98. Wu, Q.H.; Lu, Z.; Ji, T. Protective Relaying of Power Systems Using Mathematical Morphology; Springer: London, UK, 2009.

99. Wu, Q.H.; Zhang, J.F.; Zhang, D.J. Ultra-high-speed directional protection of transmission lines using mathematical morphology. IEEE Trans. Power Deliv. 2003, 18, 1127-1133. [CrossRef]

100. Van Der Sluis, L. Transients in Power Systems; John Wiley \& Sons Ltd.: Hoboken, NJ, USA, 2001.

101. Ji, Z.; Zeng, Q.; Liao, J.; Wu, Q.H. A novel mathematical morphology filter for the accurate fault location in power transmission lines. In Proceedings of the TENCON 2009-2009 IEEE Region 10 Conference, Singapore, 23-26 November 2009; pp. 1-6.

102. Zou, L.; Liu, P.; Zhao, Q. Applications of multiresolution morphological analysis in ultra-high speed protection of transmission line. IEE Proc.-Gener. Transm. Distrib. 2006, 153, 515-523. [CrossRef]

103. Li, G.; Zhou, M.; Luo, Y.; Ni, Y. Power quality disturbance detection based on mathematical morphology and fractal technique. In Proceedings of the 2005 IEEE/PES Transmission \& Distribution Conference \& Exposition: Asia and Pacific, Dalin, China, 14-18 August 2005; pp. 1-6.

104. Zhang, Y.; Tai, N.; Xu, B. Fault analysis and travelling wave protection scheme for bipolar HVdc lines. IEEE Trans. Power Deliv. 2012, 27, 1583-1591. [CrossRef] 
105. Takeda, H.; Ayakawa, H.; Tsumenaga, M. New protection method for HVdc lines including cables. IEEE Trans. Power Deliv. 1995, 10, 2035-2039. [CrossRef]

106. Rajesh, K.; Yadaiah, N. Fault identification using wavelet transform. In Proceedings of the 2005 IEEE/PES Transmission \& Distribution Conference \& Exposition: Asia and Pacific, Dalin, China, 14-18 August 2005; pp. 1-6.

107. Long, C.S.; Chun, S.H.; Zhi, W.Y.; Fang, Z. Distance protection scheme with traveling wave for UHVdc transmission line based on wavelet transform. In Proceedings of the 2008 Third International Conference on Electric Utility Deregulation and Restructuring and Power Technologies, Nanjing, China, 6-9 April 2008; pp. 2162-2164.

108. Song, G.; Suonan, J.; Xu, Q. Parallel transmission line for fault location algorithm based on differential component set. IEEE Trans. Power Deliv. 2005, 20, 2396-2406. [CrossRef]

109. Hohn, F.; Jahn, I. HVDC Protection. In Proceedings of the 1st Nordic Workshop on Power Systems Protection and Control, Trondheim, Norway, 25 May 2016.

110. Naidoo, D.; Ijumba, N.M. HVDC Line Protection for the Proposed HVDC Systems. In Proceedings of the 2004 International Conference on Power System Technology, Singapore, 21-24 November 2004; pp. 21-24.

111. Agarwal, S.; Swetapadma, A.; Panigrahi, C.; Dasgupta, A. Fault analysis method of integrated high voltage direct current transmission lines for onshore wind farm. J. Mod. Power Syst. Clean Energy 2019, 7, 621-632. [CrossRef]

112. Bresesti, P.; Kling, W.L.; Hendriks, R.L.; Vailati, R. HVDC Connection of Offshore Wind Farms to the Transmission System. IEEE Trans. Energy Convers. 2007, 22, 37-43. [CrossRef]

113. Chang, B.; Cwikowski, O.; Barnes, M.; Shuttleworth, R.; Beddard, A.; Coventry, P. Review of different fault detection methods and their impact on pre-emptive VSC-HVDC dc protection performance. High Voltage 2017, 2, 211-219. [CrossRef]

114. Zhang, X.; Tai, N.; Wang, Y.; Liu, J. EMTR-based fault location for DC line in VSC-MTDC system using high-frequency currents. IET Gener. Transm. Distrib. 2017, 11, 2499-2507. [CrossRef]

115. Razzaghi, R.; Lugrin, G.; Manesh, H.; Romero, C.; Paolone, M.; Rachidi, F. An efficient method based on the electromagnetic time reversal to locate faults in power networks. IEEE Trans. Power Deliv. 2013, 28, 1663-1673. [CrossRef]

116. Manesh, H.M.; Lugrin, G.; Razzaghi, R.; Romero, C.; Paolone, M.; Rachidi, F. A new method to locate faults in power networks based on electromagnetic time reversal. In Proceedings of the IEEE 2012 IEEE 13th International Workshop on Signal Processing Advances in Wireless Communications, Cesme, Turkey, 17-20 June 2012; pp. 469-474.

117. Wang, Z.; Razzaghi, R.; Paolone, M.; Rachidi, F. Electromagnetic Time Reversal Applied to Fault Location: On the Properties of Back-Injected Signals. In Proceedings of the 2018 Power Systems Computation Conference (PSCC), Dublin, Ireland, 11-15 June 2018; pp. 1-7.

118. Wang, Z.; He, S.; Li, Q.; Liu, B.; Razzaghi, R.; Paolone, M.; Xie, Y.; Rubinstein, M.; Rachidi, F. A full-scale experimental validation of electromagnetic time reversal applied to locate disturbances in overhead power distribution lines. IEEE Trans. Electromagn. Compat. 2018, 60, 60-1562. [CrossRef]

119. Razzaghi, R.; Lugrin, G.; Paolone, M.; Rachidi, F. On the use of electromagnetic time reversal to locate faults in series-compensated transmission lines. In Proceedings of the 2013 IEEE PowerTech Grenoble, Grenoble, France, 16-20 July 2013; pp. 1-5.

120. Razzaghi, R.; Paolone, M.; Rachidi, F.; Descloux, J.; Raison, B.; Retiére, N. Fault location in multi-terminal hvdc networks based on electromagnetic time reversal with limited time reversal window. In Proceedings of the 2014 Power Systems Computation Conference (PSCC), Wroclaw, Poland, 18-22 August 2014; pp. 1-7.

121. Razzaghi, R.; Lugrin, G.; Rachidi, F.; Paolone, M. Assessment of the influence of losses on the performance of the electromagnetic time reversal fault location method. IEEE Trans. Power Deliv. 2017, 32, 2303-2312. [CrossRef]

122. Li, X.; Lin, S.; Jiang, S. Identification method for internal and external faults based on amplitude feature of backward traveling wave for HVDC transmission line. In Proceedings of the 2015 5th International Conference on Electric Utility Deregulation and Restructuring and Power Technologies (DRPT), Changsha, China, 26-29 November 2015; pp. 1166-1169.

123. Muzzammel, R. Traveling Waves-Based Method for Fault Estimation in HVDC Transmission System. Energies 2019, 12, 3614. [CrossRef] 
124. Abedrabbo, M.; Hertem, D.V. A Primary and Backup Protection Algorithm based on Voltage and Current Measurements for HVDC Grids. In Proceedings of the 2016 International High Voltage Direct Current Conference, Shanghai, China, 25-26 October 2016; pp. 854-860.

125. Raza, A.; Akhtar, A.; Jamil, M.; Abbas, G.; Gilani, S.O.; Yuchao, L.; Khan, M.N.; Izhar, T.; Dianguo, X.; Williams, B.W. A Protection Scheme for Multi-Terminal VSC-HVDC Transmission Systems. IEEE Access 2018, 6, 3159-3166. [CrossRef]

126. Schweitzer, E.O.; Guzmán, A.; Mynam, M.V.; Skendzic, V.; Kasztenny, B.; Gallacher, C.; Marx, S. Accurate single-end fault location and line-length estimation using traveling waves. In Proceedings of the 13th International Conference on Developments in Power System Protection, Edinburgh, UK, 7-10 March 2016.

127. Schweitzer, O.; Guzmán, A.; Mynam, M.V.; Skendzic, V.; Kasztenny, B.; Marx, S. Locating faults by the traveling waves they launch. In Proceedings of the 2014 67th Annual Conference for Protective Relay Engineers, College Station, TX, USA, 31 March-3 April 2014; pp. 95-110.

128. Guzmán, A.; Kasztenny, B.; Tong, Y.; Mynam, M.V. Accurate and economical traveling-wave fault locating without communications. In Proceedings of the 2018 71st Annual Conference for Protective Relay Engineers, College Station, TX, USA, 26-29 March 2018; pp. 1-18.

129. Pathirana, A.N. Travelling Wave Based DC Line Fault Location in VSC HVDC Systems; The University of Manitoba: Winnipeg, MB, Canada, 2012.

(C) 2019 by the authors. Licensee MDPI, Basel, Switzerland. This article is an open access article distributed under the terms and conditions of the Creative Commons Attribution (CC BY) license (http://creativecommons.org/licenses/by/4.0/). 